\title{
A Large Design Space Multidisciplinary Optimization of a Mixed Flow Micro Gas Turbine Compressor Stage
}

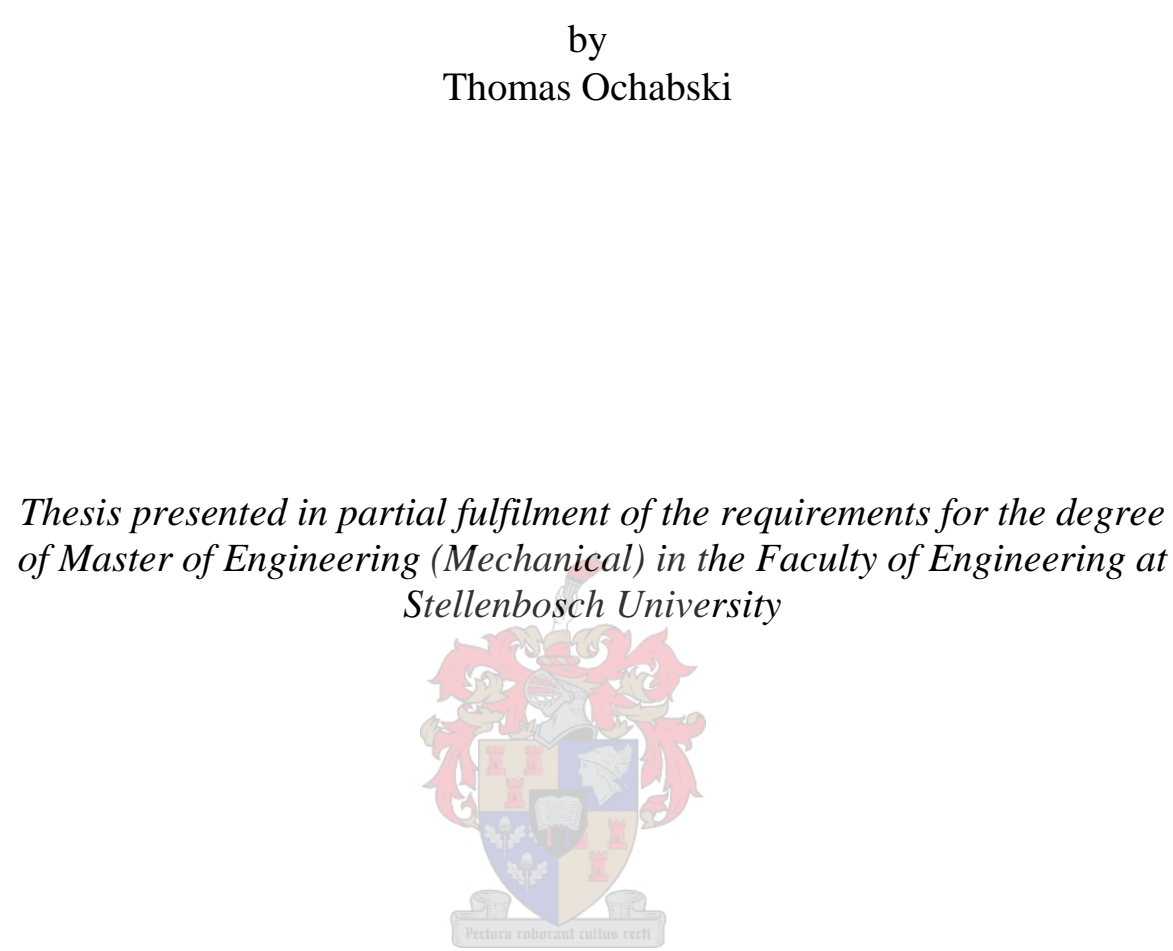

Thesis presented in partial fulfilment of the requirements for the degree Stellenbosch University

Supervisor: Prof. S. J. van der Spuy Co-supervisor: Dr. T. Hildebrandt

December 2019 


\section{Declaration}

By submitting this thesis electronically, I declare that the entirety of the work contained therein is my own, original work, that I am the sole author thereof (save to the extent explicitly otherwise stated), that reproduction and publication thereof by Stellenbosch University will not infringe any third party rights and that I have not previously in its entirety or in part submitted it for obtaining any qualification.

Date: Dẹecembẹper 2019

Copyright (C) 2019 Stellenbosch University All rights reserved. 


\title{
Abstract
}

\section{A Large Design Space Multidisciplinary Optimization of a Mixed Flow Micro Gas Turbine Compressor Stage}

\author{
T. Ochabski \\ Department of Mechanical and Mechatronic Engineering, \\ University of Stellenbosch, \\ Private Bag X1, 7602 Matieland, South Africa. \\ Thesis: MEng (Mech) \\ December 2019
}

This thesis presents a novel method of parametrization and optimization for a large design space exploration of a micro gas turbine compressor stage. 48 free parameters were used to control the meridional channel, blade camber, and structural geometric features. The optimization focused on determining the optimal impeller meridional discharge (mixed flow) angle, $\alpha_{z 2}$, for a predetermined set of constraints. The influence of key geometric features on design performance was assessed using a Pearson correlation coefficient $\left(r_{p}\right)$ map. Stage total-to-static pressure ratio, $P R_{(01-4), D P}$, and efficiency, $\eta_{(01-4), D P}$, were strongly influenced $\left(\left|r_{p}\right|>0,4\right)$ by diffuser outlet passage height and diffuser vane wrap angle. This was due to their control of flow separation magnitude at the diffuser hub in the radial-to-axial bend. A multidisciplinary workflow was scripted to incorporate the CalculiX CrunchiX structural analysis into the NUMECA FINE ${ }^{\mathrm{TM}}$ /Design3D aerodynamic optimization package. Structural feasibility constraints were placed on maximum von Mises stress, blade tip displacement, and resonance frequencies of the impeller. A three-dimensional Pareto front was constructed to assist in selection of the final design. The final design achieved a $P R_{(01-4), D P}$ of 4,15 and $\eta_{(01-4), D P}$ of $86,24 \%$, at a design mass flow rate of $1,089 \mathrm{~kg} / \mathrm{s}$. Choke and stall margins of $7,4 \%$ and $11,8 \%$ were achieved at the design speed of 73000 RPM. 


\section{Uittreksel}

\section{'n Groot Ontwerpsgebied Multidissiplinêre Optimering van 'n Gemengde-Vloei Mikrogasturbine Kompressor}

("A Large Design Space Multidisciplinary Optimization of a Mixed Flow Micro

Gas Turbine Compressor Stage")

T. Ochabski

Departement Meganiese en Megatroniese Ingenieurswese, Universiteit van Stellenbosch, Privaatsak X1, 7602 Matieland, Suid Afrika.

Tesis: MIng (Meg)

Desember 2019

Hierdie tesis beskryf ' $\mathrm{n}$ nuwe metode van parametrisering en optimering vir groot ontwerpsgebiedontginning van 'n mikrogasturbine kompressor. 48 vrye parameters word vir die meridionale kanaal, lemkromming, en strukturele geometriese eienskappe gebruik. Klem word geplaas op die optimale meridionale rotorhoek, $\alpha_{z 2}$, onderhevig aan 'n stel vooropgestelde beperkings. Die invloed van belangrike geometriese kenmerke word beskryf met 'n Pearson korrelasiekoëffisiënt $\left(r_{p}\right)$ kaart. Kompressor totaal-tot-statiese drukverhouding, $P R_{(01-4), D P}$, en benuttingsgraad, $\eta_{(01-4), D P}$, word deur diffusoruitlaathoogte en diffusorvouhoek beïnvloed met $\left|r_{p}\right|>0,4$. Hierdie invloed was die gevolg van die hoogte en vouhoek se effek op diffusor wegbreking in die radiaaltot-aksiale draai. 'n Multidissiplinêre Python kode is geskryf wat die CalculiX CrunchiX strukturele analise kode in die NUMECA FINE ${ }^{\text {TM }} /$ Design3D aërodinamiese analise kode inkorporeer. Strukturele uitvoerbaarheidsbeperkings is op die von Mises spanning, lem verplasing, en vibrasie toegepas. 'n drie-dimensionele Pareto grens word gebou om die finale ontwerp te kies. Die finale ontwerp het 'n $P R_{(01-4), D P}$ en $\eta_{(01-4), D P}$ van 4,15 en $86,24 \%$, onderskeidelik, met 'n massavloeitempo van 1,089 kg/s. Die ontwerp het 'n smoor en staak marge van 7,4\% en 11,8\%, onderskeidelik, teen 'n spoed van 73000 RPM. 


\section{Acknowledgements}

I would like to thank Prof. van der Spuy for his input to the project through study guidance, financial assistance, and organisation of my research in Germany.

I extend a sincere thank you to all members of the NUMECA Ingenieurbüro for my great time with them and their continuing support for all my questions. Specifically, I give thanks to Dr. Thomas Hildebrandt for giving me the opportunity to spend time with your team and Peter Thiel for his software support for my many I.T. queries.

Furthermore, a big thank you to Sven Albert for his mentorship during my time in Germany and his continuing support and interest in the thesis until submission. I very much appreciated all our friendly discussions and constructive work ethic you showed me.

I would like to thank my parents for their support and giving me the opportunity to pursue my career.

Thank you to the CSIR for their assistance through the DST bursary, and Mr. Radeshen Moodley for his guidance for the project requirements.

Finally, thank you to Thomas, Zander, and all others that proof-read and gave input to this thesis. 


\section{Dedications}

To my family and friends... 


\section{Contents}

Declaration $\quad$ i

Abstract $\quad$ ii

Uittreksel iii

Acknowledgements iv

Dedications $\quad$ v

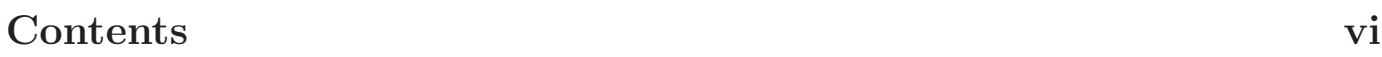

List of Figures $\quad$ ix

List of Tables

Nomenclature $\quad$ xii

1 Introduction 1

1.1 Background ........................ . . . 1

1.2 Motivation and context . . . . . . . . . . . . . . . 1

1.3 Research objectives . . . . . . . . . . . . . . . . . . . . . 3

1.4 Research Method . . . . . . . . . . . . . . . . . . 3

2 Literature study $\quad 5$

2.1 MGT component and flow definitions . . . . . . . . . . 5

2.2 Compressor stage design considerations . . . . . . . . . . 8

2.2 .1 Operating range . . . . . . . . . . . . . . 8

2.2.2 Aerodynamic stage performance . . . . . . . . . . 10

2.2 .3 Geometric constraints . . . . . . . . . . . . . 11

2.2.4 Structural feasibility . . . . . . . . . . . . . . . 11

2.3 Compressor design theory . . . . . . . . . . . . . . . . 12

2.4 Diffuser types . . . . . . . . . . . . . . . . . . . 15

2.4.1 Conventional diffusers . . . . . . . . . . . . . . 15

2.4 .2 Compact diffuser . . . . . . . . . . . . . . 16 
2.5 Previous mixed flow and MGT compressor research . . . . . 16

3 Baseline Design $\quad 19$

3.1 Design requirements . . . . . . . . . . . . . . . . . . 19

3.2 Baseline design process . . . . . . . . . . . . . . . . . . 20

3.3 Preliminary-to-baseline design changes . . . . . . . . . . . 22

4 Optimization Setup $\quad 23$

4.1 Workflow overview . . . . . . . . . . . . . . . 23

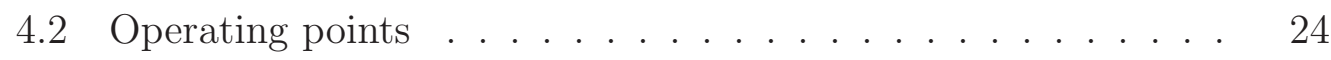

4.3 Parametric model . . . . . . . . . . . . . . . . . . . 25

4.3.1 Impeller meridional model . . . . . . . . . . . . . 25

4.3.2 Diffuser meridional model . . . . . . . . . . . . . . . 26

4.3.3 Meridional parameter coupling . . . . . . . . . . . 28

4.3.4 Impeller blade model . . . . . . . . . . . . . . . . . 30

4.3.5 Diffuser blade model . . . . . . . . . . . . . . . . . 31

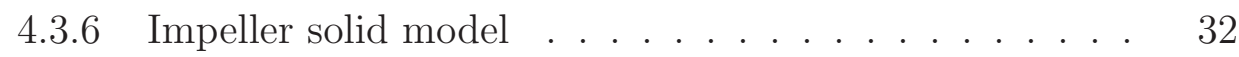

4.4 Database generation . . . . . . . . . . . . . . . . . . . 33

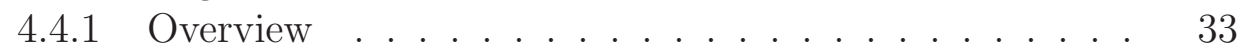

4.4 .2 Parameter scattering . . . . . . . . . . . . . . 33

4.4 .3 Design space . . . . . . . . . . . . . . . . . . . . . . . . . . . . . . . . 33

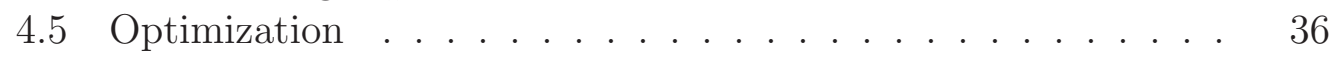

4.5.1 Optimization methodology . . . . . . . . . 36

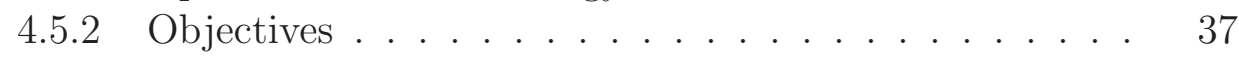

4.5 .3 Constraints . . . . . . . . . . . . . . . 38

5 Aerodynamic Numerical Setup $\quad 40$

5.1 Computation overview . . . . . . . . . . . . . . . . 40

5.2 Meshing setup . . . . . . . . . . . . . . . . . 40

5.2.1 Meshing template and flow domain . . . . . . . 40

5.2 .2 Validity criteria . . . . . . . . . . . . . . 44

5.3 Solver setup . . . . . . . . . . . . . . . . . . . . . . 45

5.3.1 Models and assumptions . . . . . . . . . . . . . . . 45

5.3 .2 Boundary conditions ................... 46

5.3 .3 Convergence criteria . . . . . . . . . . . . . . . . 47

5.3.4 Post-processing . . . . . . . . . . . . . . 48

6 Structural Numerical Setup $\quad 50$

6.1 Computation overview . . . . . . . . . . . . . . . 50

6.2 Meshing setup . . . . . . . . . . . . . . . . 50

6.3 Solver setup . . . . . . . . . . . . . . . . 51

6.3.1 Models and assumptions . . . . . . . . . . . . . 51

6.3.2 Boundary conditions ................. . . 51

6.3.3 Post-processing . . . . . . . . . . . . . . . 52 
7 Results $\quad 54$

7.1 Optimization strategy assessment . . . . . . . . . . . 54

7.1.1 Parameter scattering method comparison . . . . . . . 54

7.1.2 Design success filtering . . . . . . . . . . . . 55

7.2 Design performance improvement . . . . . . . . . . . 56

7.3 Aerodynamic geometric feature influence . . . . . . . . . . 57

7.3.1 Geometric feature multi-parameter dependencies . . . . 57

7.3.2 Parameter influence. . . . . . . . . . . . . . . 58

7.4 Structural geometric feature influence . . . . . . . . . . . 68

7.5 Pareto front . . . . . . . . . . . . . . . 70

7.6 Final selected design . . . . . . . . . . . . . . . . . . . . 73

7.6.1 Aerodynamic performance . . . . . . . . . . . 73

7.6 .2 Structural feasibility . . . . . . . . . . . . . . . 75

7.6 .3 Closing remarks . . . . . . . . . . . . . . 77

8 Conclusions and Recommendations $\quad 78$

8.1 Research objectives outcomes . . . . . . . . . . . . . . 78

8.2 Recommendations . . . . . . . . . . . . . . . . . . 81

8.3 Suggestions for future research . . . . . . . . . . . . . 81

$\begin{array}{lc}\text { References } & 83\end{array}$

$\begin{array}{lr}\text { A Mesh and evaluation plane validity study } & 88\end{array}$

$\begin{array}{ll}\mathrm{B} \mathrm{y}^{+} \text {plots } & 90\end{array}$

$\begin{array}{ll}\text { C Software specific settings } & 91\end{array}$

$\begin{array}{ll}\text { D Validation case } & 95\end{array}$

$\begin{array}{ll}\text { E Database generation and design samples } & 97\end{array}$

$\begin{array}{ll}\text { F Final design } & 100\end{array}$ 


\section{List of Figures}

2.1 Typical MGT assembly overview (adapted from ESTEQ (2016)) . 5

2.2 Impeller front and meridional velocity triangles (adapted from Diener et al. (2016)) . . . . . . . . . . . . . . 6

2.3 Impeller meridional view defining geometry vocabulary . . . . . . 7

2.4 Mixed flow wedge diffuser (left), and crossover diffuser (right) . . 7

2.5 Diffuser velocity triangles . . . . . . . . . . . . 8

2.6 Typical compressor performance curves (Sayers, 1990) . . . . . . 9

3.1 Preliminary and baseline geometry comparison . . . . . . . . . . 22

3.2 Preliminary and baseline meridional channel comparison . . . . . 22

4.1 Workflow process overview . . . . . . . . . . . . 24

4.2 Illustration of selected operating points for optimization process . 25

4.3 Impeller meridional control point description . . . . . . . . . . . . 26

4.4 Diffuser meridional outer control point description . . . . . . . . . 27

4.5 Diffuser meridional inner control point description . . . . . . . . . 28

4.6 Sample designs with varying of only the $\alpha_{z 2}$ parameter . . . . . . 29

4.7 Camber control point description . . . . . . . . . . . . . 30

4.8 Blade thickness control point description . . . . . . . . . . . . 31

4.9 Impeller solid body control points . . . . . . . . . . . . . . . . . 32

4.10 Modelling logic process . . . . . . . . . . . . . . . . 37

5.1 Meridional view of mesh . . . . . . . . . . . . . . . 41

5.2 B2B mesh of both blade rows at $50 \%$ span . . . . . . . . . 42

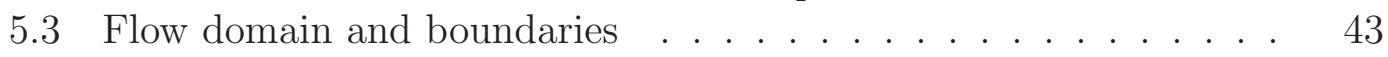

5.4 Convergence check using total pressure ratio . . . . . . . . . . . 47

5.5 Evaluation plane location . . . . . . . . . . . . . . . . 48

6.1 CSM boundary conditions (left) and applied temperature distribution (right) . . . . . . . . . . . . . . . . . . 52

6.2 Impeller displacement . . . . . . . . . . . . . . . . . . 53

7.1 Parameter scattering comparison of three database populating methods used for DB1 . . . . . . . . . . . . . . . . 55

7.2 Design improvement (performance curves) . . . . . . . . . 56 
7.3 Impeller length influence on camber angle . . . . . . . . . . . . . 58

7.4 Aerodynamic Pearson correlation coefficient map . . . . . . . . . 59

7.5 Convergence success rate with respect to inducer radius . . . . . . 60

7.6 Impeller relative Mach number at $95 \%$ span . . . . . . . . . . . . 60

7.7 Best design meridional (left) and 50\% span B2B (right) comparison 62

7.8 Vaneless gap diffusion increase . . . . . . . . . . . . . 63

7.9 Static pressure distribution in the diffuser of OPTI1 . . . . . . . 63

7.10 Diffuser choke absolute Mach number at 50\% span . . . . . . . . 64

7.11 Diffuser outlet passage height regression . . . . . . . . . . 65

7.12 Diffuser wrap regression . . . . . . . . . . . . . 65

7.13 Diffuser hub separation of OPTI2 . . . . . . . . . . . 66

7.14 Diffuser discharge absolute Mach number comparison . . . . . . . 67

7.15 Diffuser blade loading at $50 \%$ span; near onset of stall $(m=0,985$ $\mathrm{kg} / \mathrm{s}) \ldots \ldots \ldots \ldots \ldots \ldots . \ldots \ldots \ldots$

7.16 Structural Pearson correlation coefficient map . . . . . . . . . . . 69

7.17 Impeller undercut and resulting overhang . . . . . . . . . . . . . 69

7.18 Pareto front 3-D dome . . . . . . . . . . . . . . . 71

7.19 Pareto surface projection onto $m_{\text {choke }}$ vs $\Delta P R_{(01-05) \text {,stall }}$ plane . . 71

7.20 Performance curves of selected designs . . . . . . . . . . . 72

7.21 Pareto surface projection onto $m_{\text {choke }}$ vs $\eta_{(01-4), D P}$ plane $\ldots . . .73$

7.22 Final design compressor map . . . . . . . . . . . . . . . 74

7.23 Von Mises stress results for the final selected design . . . . . . . 75

7.24 Final design Campbell diagram . . . . . . . . . . . . . 76

7.25 Main blade $5^{\text {th }}$ vibration mode shape . . . . . . . . . . 77

A.1 Mesh surface projection . . . . . . . . . . . . . . . . . . 88

A.2 Mesh independence study . . . . . . . . . . . . . . . . . . 89

A.3 Evaluation plane location study . . . . . . . . . . . . . . . 89

B.1 $\mathrm{y}^{+}$of hub and blades (top), and shroud (bottom) . . . . . 90

C.1 Grid point topology of each blade type . . . . . . . . . . . . . 93

C.2 Hub bulb grid point topology . . . . . . . . . . . . . . 93

D.1 Validation performance curves . . . . . . . . . . . . . . 96

E.1 Blade profiles (section 1) of random database designs . . . . . . . 97

E.2 Sample designs with varying only axial length parameters . . . . . 98

E.3 Sample designs with varying only impeller endwall curvature parameters (left) and varying only passage height parameters (right) 98

E.4 Diffuser wrap possible range . . . . . . . . . . . . . . . . . . . . . . . 98

E.5 Optimized design convergence . . . . . . . . . . . . . . . . . 99

F.1 Final design geometry . . . . . . . . . . . . . . . 100 


\section{List of Tables}

4.1 Free parameter list . . . . . . . . . . . . . . . . . 34

4.2 Selected parameter bound evolution between optimizations . . . . 35

4.3 Optimization constraints . . . . . . . . . . . . . 38

5.1 Mesh quality criteria . . . . . . . . . . . . . . . 44

5.2 Outlet boundary conditions . . . . . . . . . . . . . . . 46

6.1 7075-T651 Aluminium material properties with values obtained from ASM Inc. (2019) . . . . . . . . . . . . . . . . . 51

7.1 Blade leading and trailing edge angles . . . . . . . . . 61

A.1 Mesh quality . . . . . . . . . . . . . . . 88

C.1 Parametric modeller software settings . . . . . . . . . . . . . . 91

C.2 Meshing software settings . . . . . . . . . . . . . . . . 92

C.3 Solver software settings . . . . . . . . . . . . . . . . . . 94

E.1 Database design validity count . . . . . . . . . . . . . 99

F.1 Final design important meridional geometry parameters . . . . . 101

F.2 Final design important blade geometry parameters . . . . . . . . 101

F.3 Final design aerodynamic performance parameters . . . . . . . . . 101 


\section{Nomenclature}

\section{Variables}

A Cross-sectional area normal to mean flow ... $\left[\mathrm{m}^{2}\right]$

a Sonic velocity . . . . . . . . . $[\mathrm{m} / \mathrm{s}]$

$b \quad$ Hub-to-shroud flow passage height $\ldots \ldots \ldots[\mathrm{m}]$

C Absolute flow velocity . . . . . . $[\mathrm{m} / \mathrm{s}]$

$\vec{C} \quad$ Absolute flow velocity vector ....... $\ldots \ldots[\mathrm{m} / \mathrm{s}]$

$C_{f} \quad$ Coefficient of friction $\ldots \ldots \ldots \ldots \ldots \ldots$

$C_{p} \quad$ Diffuser static pressure recovery coefficient ... $[-]$

$d S \quad$ Differential surface area $\ldots \ldots \ldots\left[\mathrm{m}^{2}\right]$

$h \quad$ Specific enthalpy .............. $[\mathrm{J} / \mathrm{kg}]$

$i \quad$ Incidence angle . . . . . . . . . . $\left[{ }^{\circ}\right]$

$k \quad$ Vaneless gap radius ratio ........... $[-]$

L Blade loading coefficient ........... $[-]$

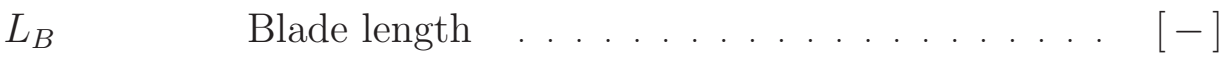

$M_{a} \quad$ Absolute Mach number ........... $[-]$

$M_{r} \quad$ Relative Mach number ........... $[-]$

$m \quad$ Mass flow rate . . . . . . . . . $[\mathrm{kg} / \mathrm{s}]$

$\Delta m \quad$ Nondimensional operating range . . . . . . . $[-]$

$\Delta m_{\text {choke }} \quad$ Nondimensional choke margin . . . . . . . . $[-]$

$N \quad$ Rotational speed . . . . . . . . . . [RPM]

$P_{\text {shaft }} \quad$ Compressor shaft power input ....... [W]

$P R_{(01-4)} \quad$ Pressure ratio (total-to-static, state 1 to 4$) \ldots[-]$

$P R^{\prime} \quad$ Normalized fluctuation of pressure ratio .... $[-]$

$\overline{P R} \quad$ Averaged pressure ratio $\ldots \ldots \ldots . \ldots \ldots \ldots$

$\Delta P R_{\text {stall }} \quad$ Near stall pressure ratio gradient $\ldots \ldots \ldots[\mathrm{s} / \mathrm{kg}]$

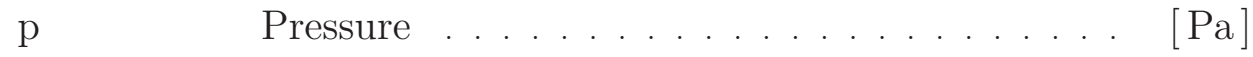

$\overline{\Delta p} \quad$ Mean suction-to-pressure side pressure difference $[\mathrm{Pa}]$

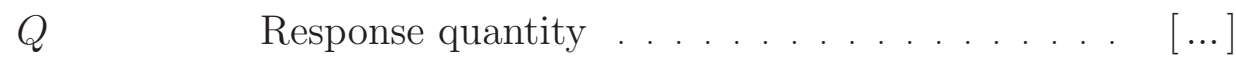

$R \quad$ Universal gas constant .......... $[\mathrm{J} / \mathrm{kgK}]$ 


\begin{tabular}{|c|c|c|}
\hline$R e$ & Reynolds number & {$[-]$} \\
\hline$r$ & Radius & {$[\mathrm{m}]$} \\
\hline$r_{p}$ & Pearson correlation coefficient . . . & {$[-]$} \\
\hline$T$ & Temperature & {$\left[{ }^{\circ} \mathrm{C}\right]$} \\
\hline$t$ & Blade thickness & {$[\mathrm{m}]$} \\
\hline$U$ & Impeller velocity & {$[\mathrm{m} / \mathrm{s}]$} \\
\hline$W$ & Relative flow velocity & {$[\mathrm{m} / \mathrm{s}]$} \\
\hline$y_{1}^{+}$ & Dimensionless wall distance $\ldots$. & {$[-]$} \\
\hline$Z$ & Number of blades ... & {$[-]$} \\
\hline$\alpha$ & Absolute flow angle & {$\left[{ }^{0}\right]$} \\
\hline$\beta$ & Blade angle & {$\left[{ }^{\circ}\right]$} \\
\hline$\delta_{z-t i p}$ & Blade tip displacement (z-direction) & {$[\mathrm{m}]$} \\
\hline$\gamma$ & Specific heat ratio . . . & {$[-]$} \\
\hline$\eta_{(01-4)}$ & Efficiency (total-to-static, state 1 to 4 ) & {$[-]$} \\
\hline$\rho$ & Density & {$\left[\mathrm{kg} / \mathrm{m}^{3}\right]$} \\
\hline$\sigma_{V M}$ & Von Mises stress & {$[\mathrm{MPa}]$} \\
\hline$\mu$ & Dynamic viscosity & {$\left[\mathrm{m}^{2} / \mathrm{s}\right]$} \\
\hline$\mu_{\tau}$ & Friction velocity & {$[\mathrm{m} / \mathrm{s}]$} \\
\hline$\omega$ & Rotational velocity . . & {$[\mathrm{rad} / \mathrm{s}]$} \\
\hline
\end{tabular}

\section{Subscripts}

$\begin{array}{ll}\text { choke } & \text { Choke point } \\ D P & \text { Design point } \\ \mathrm{h} & \text { Hub } \\ \text { HEP } & \text { Highest efficiency point } \\ \mathrm{m} & \text { Mean flow path } \\ \mathrm{r} & \text { Radial flow component; flow angle relative to } r \text {-direction } \\ \text { ref } & \text { Reference value for determining machine Reynolds number } \\ \mathrm{s} & \text { Shroud; isentropic relative state } \\ \text { stall } & \text { Stall point } \\ z & \text { Axial flow component; flow angle relative to } z \text {-direction } \\ 0 & \text { Ambient state conditions } \\ 00 & \text { Total ambient thermodynamic state } \\ 1 & \text { Impeller inlet state conditions } \\ 2 & \text { Impeller exit state conditions } \\ 3 & \text { Diffuser inlet state conditions }\end{array}$


$4 \quad$ Diffuser exit state conditions

$5 \quad$ Domain exit state conditions

$\theta \quad$ Tangential flow component; flow angle relative to tangent

$\begin{array}{ll}\text { Abbreviations } & \\ \text { ANOVA } & \text { Analysis of variance (statistical method) } \\ \text { B2B } & \text { Blade-to-blade } \\ \text { CFD } & \text { Computational fluid dynamics } \\ \text { CSIR } & \text { Council for Scientific and Industrial Research } \\ \text { CSM } & \text { Computational solid mechanics } \\ \text { CVT } & \text { Centroidal Voronoi Tessellations } \\ \text { GA } & \text { Genetic algorithm } \\ \text { LCVT } & \text { Latinized Centroidal Voronoi Tessellations } \\ \text { LE } & \text { Leading edge } \\ \text { LHS } & \text { Latin Hypercube Sampling } \\ \text { LOO } & \text { Leave-one-out } \\ \text { MGT } & \text { Micro gas turbine } \\ \text { MLC } & \text { Mean-line code } \\ \text { RBFN } & \text { Radial basis function network } \\ \text { SM } & \text { Surrogate model } \\ \text { TE } & \text { Trailing edge } \\ \text { UAV } & \text { Unmanned aerial vehicle } \\ \text { VM } & \text { Von Mises } \\ \text { 1-D } & \text { One-dimensional } \\ 3-D & \text { Three-dimensional }\end{array}$




\section{Chapter 1}

\section{Introduction}

\subsection{Background}

The unmanned aerial vehicle (UAV) industry strives towards the development of propulsion systems that maximise engine thrust and efficiency but minimise weight or size and manufacturing cost. UAVs are powered by electric motors, internal combustion piston engines or gas turbine engines. The latter are commonly referred to as micro gas turbine (MGT) engines due to their smaller size, compared to the larger gas turbine engines commonly used in the air transport industry.

All MGTs are composed of three primary stages; a compressor, combustor and turbine stage. The compressor stage of a MGT consists of two major components: a rotating impeller that imparts mainly kinetic energy to the moving fluid, and a stationary diffuser that converts the kinetic energy to pressure energy in preparation for combustion. The compressor stage is also required to remove flow swirl using either a row of de-swirling vanes, or a swept diffusion passage. The impeller can be classified as either, radial, or mixed flow (combination of radial and axial) depending on the direction the fluid leaves the impeller blades relative to the axis of rotation. This paper assesses the influence that key design parameters have on the overall stage performance of a mixed flow compressor.

\subsection{Motivation and context}

This thesis contributes to the existing body of knowledge surrounding MGT development. This is done by designing an optimized mixed flow impeller and diffuser for a MGT with a required thrust output of 650 N. Findings related to parameter influence on design point efficiency and operating mass flow rate range will aid future designers at selecting compressor geometry for mixed flow type MGT engines. Of key interest are findings related to the use of a crossover 
(continuous vane) mixed flow diffuser, since information pertaining to such a diffuser is currently relatively scarce.

A full workflow for a multidisciplinary, multipoint and simultaneous multi-row optimization of a MGT compressor stage with large geometric freedom (48 free parameters) is given. The workflow commences by specifying a preliminary design obtained by an analytical mean-line method, and ends with an aerodynamically optimized, structurally feasible, compressor stage.

This thesis develops a MGT compressor stage design capable of satisfying a set of design requirements supplied by the Council for Scientific and Industrial Research (CSIR) and adds to the existing body of MGT work performed by Stellenbosch University in conjunction with the CSIR. A summary of such previous research is given below:

\section{Centrifugal compressor development}

De Wet (2011) wrote a mean-line code (MLC) to predict the compressor performance of a diesel locomotive turbocharger. The MLC is based on the turbomachinery design theory presented by Aungier (2000).

Van der Merwe (2012) adapted the code developed by de Wet (2011) for the design of a suitable radial MGT impeller based on predetermined dimensional constraints of a BMT-120 engine with a $200 \mathrm{~N}$ thrust requirement. The code was validated against existing performance data and computational fluid $d y$ namics (CFD) results.

Krige (2013) developed a MLC for use in radial vaned diffuser design. The MLC was then used in conjunction with CFD analysis to optimize a diffuser design suitable for use with the impeller previously developed by van der Merwe (2012).

De Villiers (2014) used the work of van der Merwe (2012) and Krige (2013) to concurrently optimize a complete radial compressor stage (impeller and diffuser).

Burger (2016) modified the MLC to investigate the performance of a crossover diffuser with a swept vaned passage from the impeller outlet up to the combustor inlet. This negated the need for a separate $90^{\circ}$ bend and axial de-swirlers as required in purely radial diffusers.

\section{Mixed flow compressor development}

Diener et al. (2016) initiated research at Stellenbosch University focused on mixed flow MGT compressors. Diener performed a CFD optimization of a 
mixed flow impeller for an increased thrust output requirement of $600 \mathrm{~N}$.

Kock (2017) further modified the MLC for the design of a mixed flow crossover diffuser suited to the impeller developed by Diener et al. (2016). Kock determined that the crossover diffuser outperforms a vaneless diffuser fitted with de-swirling vanes. Kock subsequently performed a CFD optimization of only the diffuser, achieving a compressor total-to-total pressure ratio $\left(P R_{(01-04)}\right)$ of 4.44 and total-to-total efficiency $\left(\eta_{(01-04)}\right)$ of $80 \%$.

Bindeman (2019) adapted the MLC for use with mixed flow impellers. This was done by implementing a new slip model and a new method of calculating the impeller throat area to better match with CFD results of the impeller designed by Diener et al. (2016).

Swanepoel (2018) experimentally tested the crossover compressor developed by Kock (2017) at a reduced speed of 50000 RPM (design speed of 95000 RPM) due to testing facility limitations. Swanepoel found that impeller tip clearance had a bigger effect on stage performance when used with a crossover diffuser compared to a vaneless diffuser.

\subsection{Research objectives}

The objectives stipulated for this research were as follows:

- Perform thorough literature study related to compact compressor design.

- Set up a workflow that is capable of exploring a large geometric diversity of the compressor.

- Optimize a compressor obtained during the preliminary design phase, to meet the requirements of the CSIR, with focus placed on determining the optimal mixed flow angle for the given requirements.

- Identify the influence of various geometry features on stage performance.

The choice to optimize the mixed flow angle was made due a shortcoming identified from previous literature. All available literature would either assume a mixed flow angle from the design onset, or optimise only the impeller with limited geometric diversity. A multi-row optimization of high geometric diversity was therefore implemented to bridge this identified shortcoming in literature.

\subsection{Research Method}

The procedure followed in order to achieve the desired objectives is detailed below. 
Firstly, a thorough literature review of existing research towards mixed flow compressor development was conducted. This was performed with the aim of continuing the work of Diener et al. (2016) and Kock (2017) to eventually optimize Diener's impeller outlet angle of $74,5^{\circ}$ for use in conjunction with a vaned diffuser.

A baseline design geometry was obtained that could satisfy the design requirements specified by the CSIR. The design was obtained using the COMPAL ${ }^{\circledR}$ and AxCent ${ }^{\circledR}$ preliminary design tools.

A parametric model was subsequently constructed using AutoBlade ${ }^{\mathrm{TM}}$ and fitted to the baseline geometry. Blade and endwall curve control points were coupled with user defined parameters to broadly manipulate specific geometric features while promoting the number of feasible geometries that could be obtained during the optimization process.

The aerodynamic and structural meshers and solvers were configured for implementation in the optimization process. The impeller developed by Diener et al. (2016) was used as a validation case to prove the aerodynamic numerical setup.

A fully automated workflow was scripted in Python for implementation into the FINE $^{\mathrm{TM}} /$ Design3D turbomachinery design package. This was done as a nonstandard workflow comprising of a simultaneous multidisciplinary optimization of two blade rows in the compressor stage.

Two large database and optimization runs were performed using the design of experiments method. The initial optimization focused on meridional channel geometry, while the second optimization focused on blade geometry and structural feasibility.

Finally, links between geometric parameters and stage performance were identified. A final performance curve comparison was made between the baseline and final selected designs. The final design was chosen from a Pareto front which compared stage total-to-static efficiency with operating mass flow range. 


\section{Chapter 2}

\section{Literature study}

\subsection{MGT component and flow definitions}

\section{Overview}

A cutaway view of a typical MGT component assembly is shown in Figure 2.1. The design shown implements a radial impeller with accompanying radial wedge type diffuser including a $90^{\circ}$ bend and axial de-swirler, prior to flow entering the combustion chamber. Fuel is introduced to the air flow inside a flame holder (located inside the combustion chamber) which maintains sufficient flow velocity, temperature and flow mixing to sustain the continual combustion when in operation. The hot combustion gasses impart work onto the turbine stage as they expand and exit the MGT. The turbine drives the shaft which powers the impeller. The remaining flow energy provides thrust as it accelerates through the nozzle. (Oppong et al., 2015)

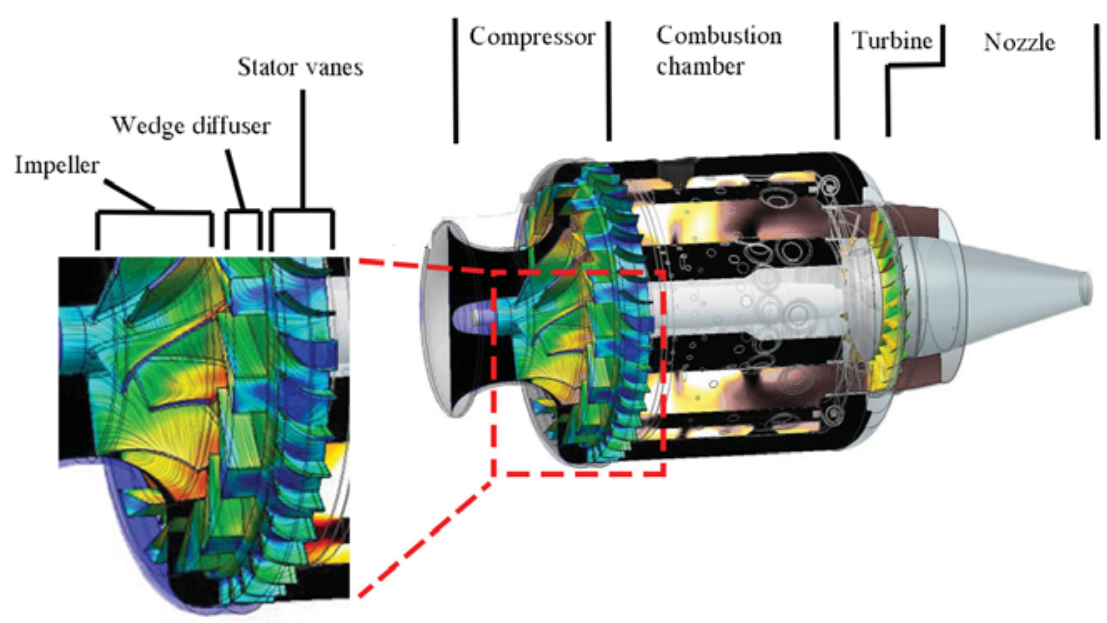

Figure 2.1: Typical MGT assembly overview (adapted from ESTEQ (2016)) 


\section{Impeller definitions}

The purpose of an impeller is to impart kinetic and pressure energy to the air entering a MGT. Figure 2.2 shows the velocity triangles at the impeller inlet and exit. Air enters the impeller predominantly axially (positive $z$-direction) with absolute velocity $C_{1}$, where subscript ' 1 ' indicates impeller inlet state conditions and $C$ refers to absolute fluid velocity. $U$ and $W$ are defined as the absolute impeller, and relative fluid-impeller, velocities, respectively. Flow angles are defined by $\alpha$ and blade angles by $\beta$.

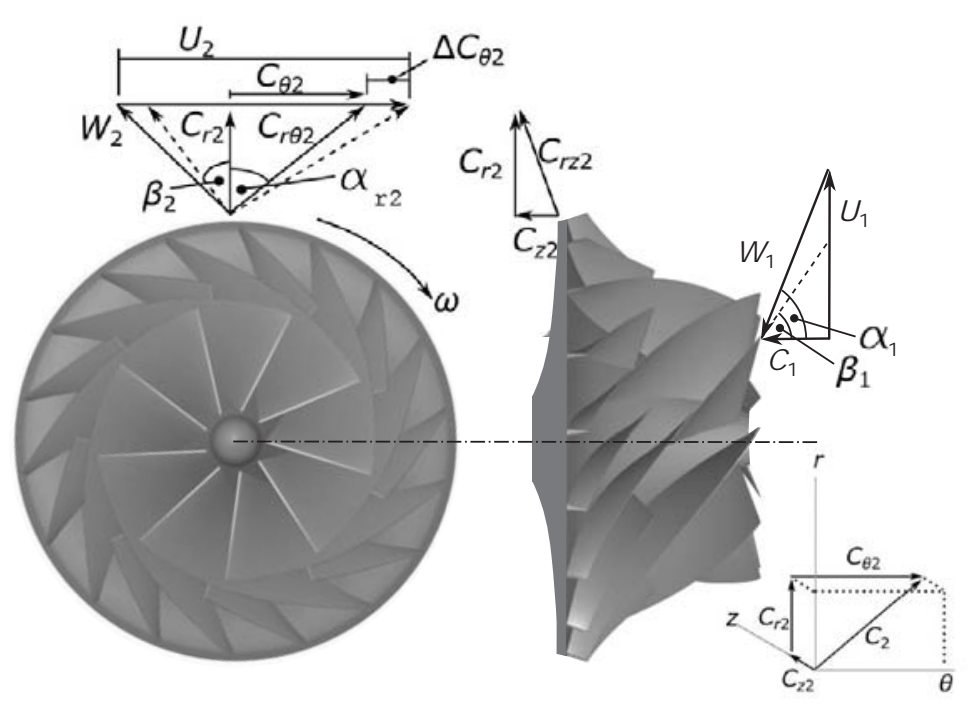

Figure 2.2: Impeller front and meridional velocity triangles (adapted from Diener et al. (2016))

Impeller exit flow (subscript 2) has additional absolute velocity components in the radial and rotational directions (subscripts $r, \theta$ ). Flow at the exit is not aligned with the exit blade angle due to slip which results in a reduction of tangential velocity by $\Delta C_{\theta 2}$. Rotational velocity $(\omega)$ is defined in the positive $\theta$-direction. The resulting velocity triangles with and without slip are indicated by the solid and dashed lines, respectively.

Figure 2.3 shows a meridional view of a mixed flow impeller with accompanying geometric vocabulary. Hub and shroud outlet radii are defined as $r_{2 h}$ and $r_{2 s}$, respectively, with measurement reference being from the $z$-axis of rotation. Hub-to-shroud passage height is defined as $b_{2}$. The impeller meridional discharge angle, $\alpha_{z 2}$, characterizes the compressor as mixed flow when $0<\alpha_{z 2}<90$. 


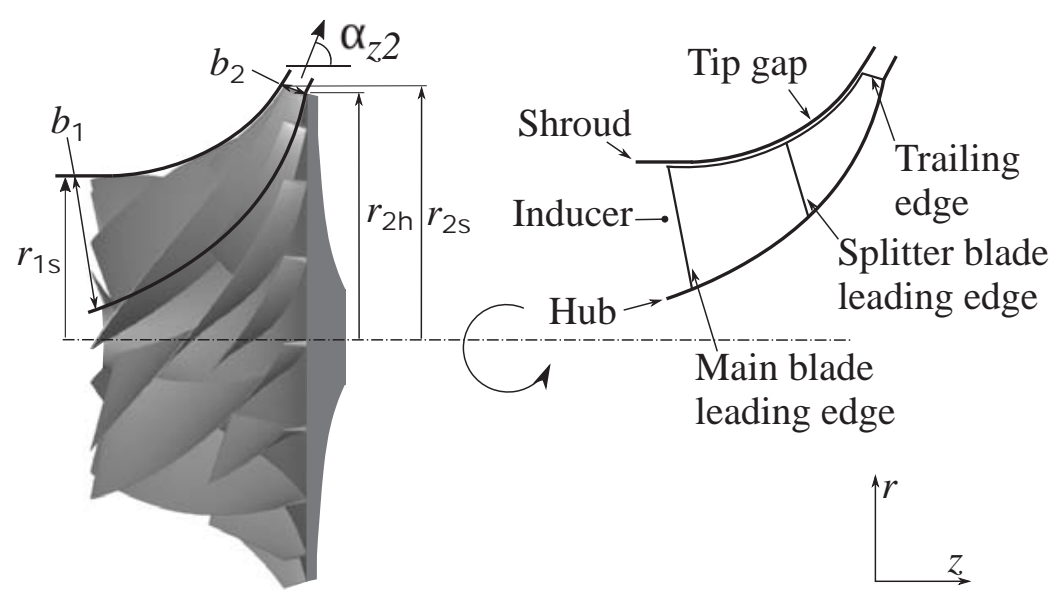

Figure 2.3: Impeller meridional view defining geometry vocabulary

\section{Diffuser definitions}

The meridional view of a crossover diffuser is shown in Figure 2.4, including state numbering conventions used in this thesis. A vaned crossover diffuser can replace a conventional wedge diffuser with accompanying vaneless radialto-axial bend and subsequent de-swirling vanes, with a single row of curved or swept blades (Burger, 2016).
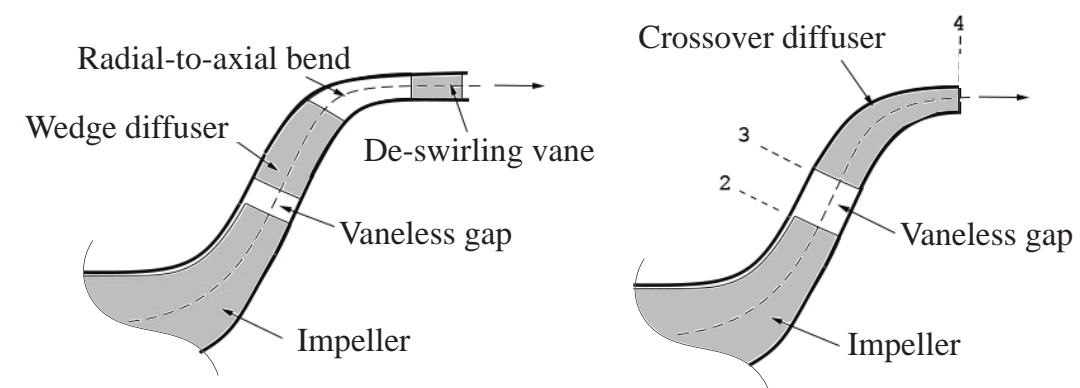

Figure 2.4: Mixed flow wedge diffuser (left), and crossover diffuser (right)

Figure 2.5 gives the diffuser flow angle and magnitude numbering definitions used in this thesis. Diffuser passage radius and width definitions are also given. The diffuser leading edge absolute flow, $C_{3}$, has velocity components in all three coordinate directions $(r, z, \theta)$ due to the mixed flow meridional angle introducing a $z$-component, while swirl is imparted by the rotating impeller. Diffuser incidence is calculated as the difference between the absolute flow angle and blade angle, $i_{\text {diffuser }}=\alpha_{r 3}-\beta_{3}$. The mean absolute flow magnitude decreases from impeller discharge, $\left|C_{2}\right|$, to diffuser leading edge, $\left|C_{3}\right|$, due to diffusion in the vaneless gap (Ziegler et al., 2003). 


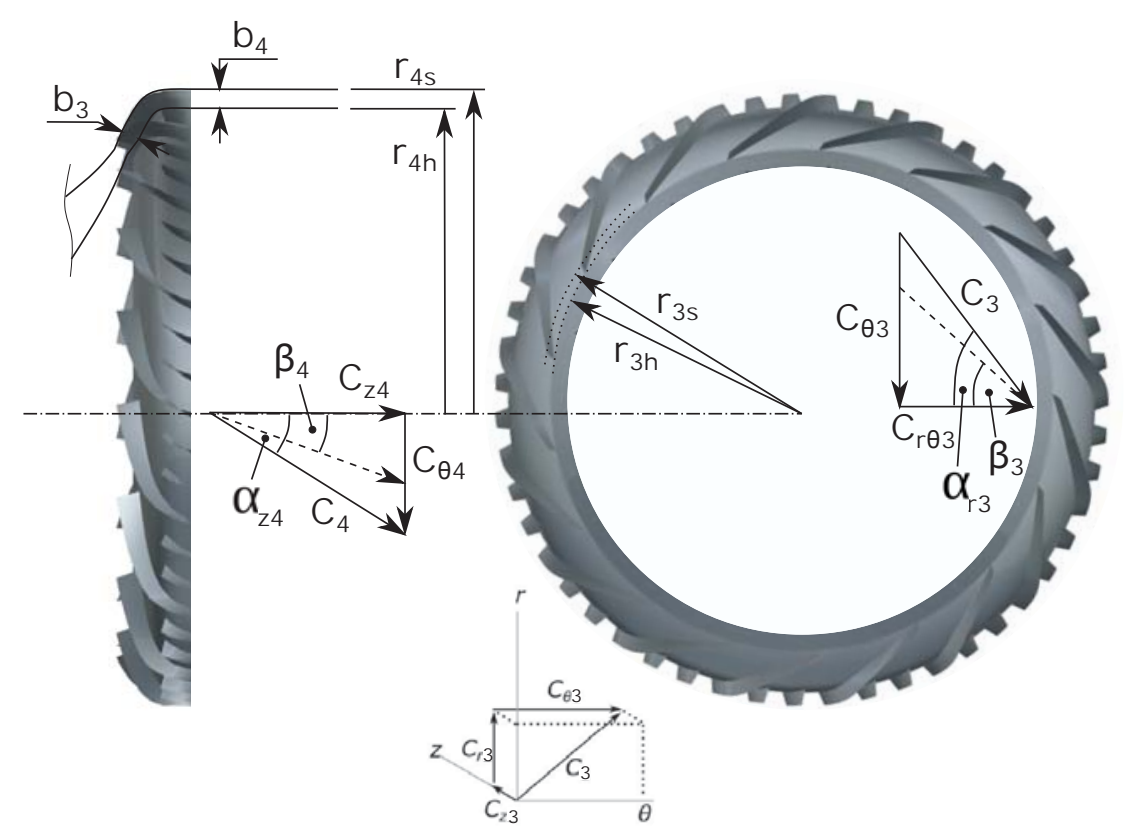

Figure 2.5: Diffuser velocity triangles

Diffuser discharge is assumed to have negligible radial component and a rotational swirl angle, $\alpha_{z 4}$. Diffuser mean discharge flow is assumed to not be aligned with the trailing edge blade angle, $\beta_{4}$. This is due to high flow turning (observed by Han et al. (2018)) and possible blade separation (observed by Kock (2017)) towards the diffuser exit, resulting in the flow not being well mixed-out at the diffuser trailing edge.

\subsection{Compressor stage design considerations}

A compressor stage is required to satisfy a set of constraints with respect to flow discharge as well as structural and geometric feasibility while maximising some aerodynamic performance indicator (usually stage total-to-static efficiency). All such design considerations are discussed below.

\subsubsection{Operating range}

Figure 2.6 shows a typical compressor map with pressure ratio performance curves at 7 different speeds (nondimensionalized by design speed) across the mass flow rate range that is constrained by the surge line and choke limit. A nondimensional operating range parameter, $\Delta m$, is defined as the difference between the highest and lowest attainable mass rate at a constant speed and 
nondimensionalized by the highest efficiency mass flow rate, $m_{H E P}$,

$$
\Delta m=\frac{m_{\text {stall }}-m_{\text {choke }}}{m_{H E P}} .
$$

Typically a high $\Delta m$ is favourable to allow for greater throttling range of the engine without incurring either stall or choke conditions (defined below).

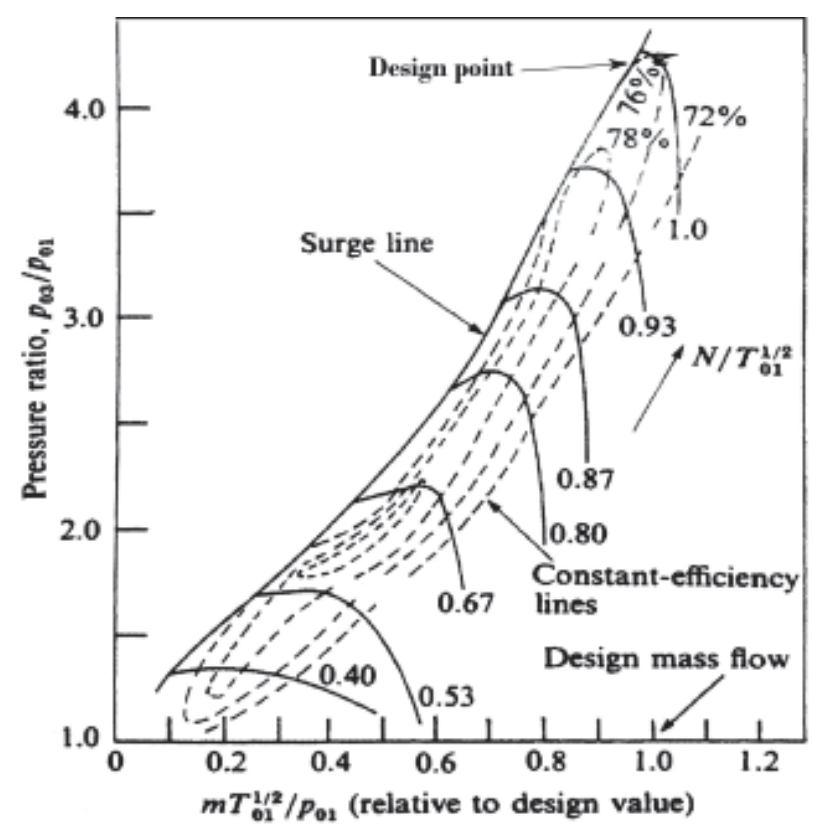

Figure 2.6: Typical compressor performance curves (Sayers, 1990)

\section{Compressor choke}

Fluid physics determine that volume flow rate cannot increase further once sonic conditions, $C^{2}=a^{2}=\gamma R T$, occur at the throat of a constrained flow (Aungier, 2000). A further increase in mass flow rate can therefore only be achieved though an increase in inlet density. The choke mass flow rate, $m_{\text {choke }}$ for a compressor inducer is given by Dixon (1998) as

$$
m_{\text {choke }}=A_{0} \rho_{00} a_{00}\left(\frac{2}{\gamma+1}\right)^{\gamma+1 / 2(\gamma-1)}
$$

where $A$ and $a$ denote the passage throat area and sonic velocity, respectively. Similarly, the diffuser inlet choke flow rate can be determined using the diffuser throat area and air density.

Such a sonic constraint limits the possible mass flow rate through an MGT, thus narrowing the operational mass flow rate envelope. If sonic conditions 
do arise, a sudden compression of the flow occurs across a shock wave (Dixon, 1998). The shock is also associated with energy dissipation from the flow, with shock magnitude increasing with higher Mach numbers. Typically, compressors operate at a design point on the performance curve which is located with a sufficient choke margin

$$
\Delta m_{\text {choke }}=\frac{m_{\text {choke }}-m_{D P}}{m_{D P}}
$$

to allow for an increase in flow rate through throttling.

\section{Compressor stall}

Stall (or surge) is encountered beyond the lowest stable mass flow rate point on a constant speed curve. Once encountered, a complete flow reversal occurs through the compressor resulting in a complete loss of compressor speed and flame-out of the subsequent combustor. Similarly to the choke margin, a well designed compressor should operate with a sufficient surge margin

$$
\Delta m_{\text {stall }}=\frac{m_{D P}-m_{\text {stall }}}{m_{D P}}
$$

to prevent component damage and avoid unwanted loss of control of turbine performance (Dixon, 1998).

Rotating stall is a localised flow phenomenon of a few blades; and unlike surge, which results in a severe and sudden loss of power, rotating stall causes a slight decrease in overall performance and is not pulsating in nature. Rotating stall is caused by the impeller wake inducing temporary stall of the diffuser vanes due to fluctuations in flow magnitude or direction. Rotating stall therefore proceeds cyclically and can lead to structural damage resulting from fatigue of the blades that are being repeatedly stalled and un-stalled. Since this flow phenomenon is time dependent, only an unsteady CFD computation is able to indicate the presence of rotating stall.

\subsubsection{Aerodynamic stage performance}

The two primary compressor stage performance indicators are pressure ratio and efficiency, and are assessed at either a set operating point, or a range of mass flow rates. The stage total-to-total pressure ratio (isentropic),

$$
P R_{(01-04)}=\frac{p_{04}}{p_{01}}
$$


must be met to supply the combustion chamber with sufficiently dense air, as required by the fuel-air ratio to allow for efficient combustion. Stage total-tototal efficiency (isentropic) is now defined as the ratio of isentropic to actual energy increase of the fluid as

$$
\eta_{(01-04)}=\frac{\Delta h_{(01-04)} \text { isentropic }}{\Delta h_{(01-04)}}=\frac{\frac{p_{04}}{p_{01}} \frac{\gamma-1}{\gamma}-1}{\frac{T_{04}}{T_{01}}-1}
$$

where a higher efficiency is desirable to reduce exhaust gas energy required to drive the compressor, which increases exhaust energy available for thrust produced by the MGT engine. The blade-to-blade stage discharge flow angle (swirl), $\alpha_{z 4}$, is also typically specified as a constraint by the combustor designer to maximise air-fuel mixing and flame distribution inside the combustor.

\subsubsection{Geometric constraints}

Compressor design is limited by the physical space limitations of fitting a MGT into an aircraft. These sizing constraints are set out by the fuselage designers of the aircraft and typically include the frontal area (compressor maximum radius) and axial length. Compressor frontal area is usually large for radial and mixed flow turbines when compared to axial flow compressors. This can result in considerable aerodynamic pressure drag if fitted to the exterior of an UAV. Consequently, mixed flow MGTs are usually housed inside a UAV (Goldstein, 1948). Compressor maximum radial constraint is therefore the driving factor for the use of compact compressor stages in small UAV aircraft.

\subsubsection{Structural feasibility}

The impeller of a high rotation speed compressor stage experiences large centrifugal loading. This results in structural feasibility constraints with respect to maximum von Mises stress, body and tip deformation, and resonance frequencies. A peak and bulk (majority of body) von Mises stress should be lower than the material yield stress (with accompanying safety factor placed on bulk stress), to avoid permanent deformation or failure of the impeller. Impeller displacement should be considered to avoid blade-shroud interference as this will rapidly damage the blade tips, or cause complete failure of the impeller. Similarly, resonance speeds should be located away from typical operating speeds to avoid fatigue and possible failure of the impeller. 


\subsection{Compressor design theory}

\section{Blade sweep}

Impeller main blade sweep, or leading edge meridional lean, is a method of scaling the blade chord length difference between blade tip and hub side. Blade sweep can be used to influence the efficiency of an impeller by shifting the leading edge loading in a spanwise direction which subsequently influences the effects of shock induced separation at the shroud in transonic compressors (He and Zheng, 2017). He and Zheng also found that the optimal sweep angle for transonic impellers typically lies around $10^{\circ}$ of forward sweep if structurally feasible. Blade forward sweep, however, increases stress in the leading edge fillet due to the additional overhang mass supported by the main blade leading edge. Diffuser sweep can also be used to scale blade chord, but to a smaller magnitude due to the greatly reduce passage heights in the diffuser $\left(b_{4}, b_{3}\right)$ when compared to the impeller inlet height $\left(b_{1}\right)$.

\section{Impeller slip}

Impeller slip reduces the impeller tangential discharge velocity by $\Delta C_{\theta 2}$ which reduces the work input to the fluid due to a lower absolute discharge velocity. Slip results due to a relative eddy that forms in the discharge passage resulting from the pressure difference between the high pressure area across the leading face of one blade and the low pressure area across the trailing face of an adjacent blade (Stodola, 1927). Impeller slip prediction is important to achieve a good preliminary design, but was not well understood for mixed flow impellers until the research of Qiu et al. (2011). Qiu et al. introduced a well validated unified slip model that consists of: a radial term (based on the model of Stodola (1927)) including Coriolis forces, a turning term based on streamline curvature as continued from research by Carter and Hughes (1946), and finally a passage variation term. Qiu et al. determined that a lower $\alpha_{z 2}$ results in less slip due to the decrease in Coriolis forces (proportional to sine of $\alpha_{z 2}$ ) and subsequent decrease in trailing edge blade loading.

\section{Blade loading}

Blade loading, $L$, is the vane suction-to-pressure side pressure difference, $\overline{\Delta p}$, nondimensionalized by blade row inlet-to-outlet pressure difference (Aungier, 2000). For the diffuser this is given as

$$
L_{\text {diffuser }}=\frac{\overline{\Delta p}}{p_{3}-p_{4}} .
$$

Impeller tip loading influences the losses associated with impeller tip leakage flow. Denton (1993) approximates that tip leakage flow can account for up 
to $30 \%$ of losses incurred in the impeller of an axial compressor stage and although the effect is reduced in purely radial turbomachinery, the imperative still remains to reduce tip leakage. Tiralap et al. (2017) suggests that increasing blade loading towards the trailing edge (aft-loading) of the impeller blade is a good method of reducing tip leakage due to the delay in tip leakage flow. In a diffuser, diffusion of flow can be achieved by an increase in passage cross sectional area or fluid turning. In vaned diffusers, de-swirling (a form of flow turning) increases blade loading and subsequently increases the risk of separation for highly loaded blades.

\section{Impeller meridional discharge angle}

As previously stated, impellers can be categorised as radial, mixed flow or axial depending on the impeller outlet angle, $\alpha_{z 2}$. Radial impeller compressor stages $\left(\alpha_{z 2} \approx 90^{\circ}\right)$ typically exhibit pressure ratios ranging from 4:1 to 7:1 with a single impeller. Axial compressor stages $\left(\alpha_{z 2} \approx 0^{\circ}\right)$ require multiple blade rows and cascades to achieve an equivalent pressure ratio. This is due to the absence of Coriolis effects in axial compressors contributing to a low pressure rise per each axial stage. As such, axial compressors are typically longer, but have a smaller frontal area $\left(r_{4 s}\right)$, than a comparable radial compressor (Sayers, 1990). Furthermore, radial compressors perform well in a larger range of flow rates than axial compressors; however, axial compressors usually achieve a 3$4 \%$ better design point efficiency (Dixon, 1998). A compressor stage with a mixed flow impeller typically exhibits a cross-over between radial and axial compressor performance.

\section{Vaneless gap}

For any vaned or passage diffuser, a vaneless diffusion gap must be placed between the impeller trailing edge and the diffuser leading edge. This diffuses the flow in transonic compressors, which reduces the shock at the diffuser leading edge. The vaneless gap also allows mixing-out of the impeller wake which reduces incidence oscillations at the diffuser leading edge (Aungier, 2000). The vaneless gap radius ratio, $k$, is the ratio of mean diffuser leading edge radius to mean impeller trailing edge radius,

$$
k=\frac{r_{3 m}}{r_{2 m}}
$$

where subscript ' $m$ ' denotes mean radius. Aungier (2000) suggests a gap ratio of 1,06 $<k<1,12$ but good results for a vaned diffusers with $k=1,15$ were obtained by Marconcini et al. (2010). Bennett et al. (2000) states that higher values for $k$ result in larger boundary layer formation across the vaneless gap, which subsequently contributes to blockage at the diffuser leading edge. 


\section{Diffuser discharge flow}

Flow entering the combustion chamber is required to meet a specified static pressure ratio, $P R_{(01-4), D P}$, and swirl angle, $\alpha_{z 4}$. Additionally, a flow with low distortion of pressure and velocity in the tangential direction is desired to simplify the combustor design process (Burger, 2016). Krige (2013) and de Villiers (2014) noted significant flow irregularities in their respective radial compressors due to recirculation in the $90^{\circ}$ vaneless bend.

Burger (2016) states that a crossover diffuser is likely to achieve performance benefits over conventional type diffusers when the constraint on discharge swirl is relaxed to above $25^{\circ}$ due to the absence of de-swirling vanes.

\section{Static pressure recovery coefficient}

The diffusion performance of a diffuser is determined with a static pressure recovery coefficient, $C_{p}$, which gives the static pressure rise through the diffuser as a percentage relative to diffuser inlet kinetic energy as follows:

$$
C_{p}=\frac{p_{4}-p_{3}}{p_{03}-p_{3}}
$$

Japikse and Baines (1998) state a typical $C_{p}$ range from 0,5 to 0,7 for unlimited radial constraint diffusers due to a longer radial passage length available to fully diffuse the flow prior to a volute or collector. Japikse and Baines (1998) further state that for a radially constrained compressor stage, a typical $C_{p}$ of between 0,2 and 0,5 can be expected due to its inability to sufficiently diffuse flow in a short passage without incurring separation losses.

\section{Diffuser blade number}

Blade number selection is typically performed early in the design process and later adapted based on flow and performance observations. Aungier (2000) states that blade number can affect both operating range by controlling secondary flows, and efficiency by controlling blade surface viscous losses. Aungier (2000) suggests that the radial diffuser vane number can be determined using

$$
Z_{\text {diffuser }}=\frac{2 \pi\left(r_{4} \cos \beta_{4}-r_{3} \cos \beta_{3}\right)}{t_{4} b_{4}+b_{3}\left(\tan \theta_{c} L_{B}-t_{3}\right)}
$$

where $t$ and $L_{B}$ are the vane thickness and chord length, respectively. The passage divergence angle, $\theta_{c}$, typically has a value near $5,5^{\circ}$ (Aungier, 2000). 


\section{Endwall curvature}

Japikse and Baines (1998) describe compressors as prone to separation at any surface with a high curvature. This is due to the added turning of a flow which is already unstable due to a positive pressure gradient in the mean flow direction. Japikse and Baines thus suggest to reduce endwall curvature where possible in regions of high diffusion.

\subsection{Diffuser types}

\subsubsection{Conventional diffusers}

\section{Vaneless diffuser}

Vaneless diffusers are comprised of a passage with increasing cross-sectional area to diffuse flow and obtain a static pressure increase. This type of diffuser has the widest operating range of all diffuser types due to no occurrence of vane separation or blockage (Aungier, 2000). However, vaneless diffusers are not applicable for MGT implementation due to low diffusion rates leading to large relative size requirement in comparison to any vaned or wedge type diffuser (Dixon, 1998).

\section{Channel diffuser}

Channel diffusers are the most common and well studied diffusers for MGT application (Japikse, 1996). Channel diffusers have a discrete number of flow passages separated by a wedge island with straight sidewalls, such as those investigated by Ziegler et al. (2003) and Krige (2013). If the wedge sidewall is curved, the flow passages are referred to as 'pipes', as investigated by Bennett et al. (2000). Diffusion rate is controlled by varying channel divergence angle and wedge sidewall angle (Aungier, 2000). Krige (2013) investigated various wedge type configurations for MTG application and states that the diffuser leading edge should be sloped and blade angles varied from hub to shroud to match impeller discharge flow angle at design point.

\section{Vaned diffuser}

Vaned diffusers use aerodynamic blades to achieve a higher efficiency at design point, but rapidly lose performance in off-design operation when compared with vaneless equivalent diffusers (Aungier, 2000). Vaned diffusers, unless of low solidity, are also susceptible to choking in the throat (typically inlet) due to blade thickness contributing to passage blockage. The inlet blade angle, $\beta_{3}$ is typically in the range of $68^{\circ}<\beta_{3}<74^{\circ}$, and it strongly influences stall margin and shock losses for transonic flow. (Aungier, 2000). 


\section{Tandem vaned diffuser}

Tandem cascade type diffusers are comprised of two or more blade rows prior to the de-swirling vanes. A tandem vaned diffuser often achieves better operating range performance in comparison to a single blade row diffuser. This is due to the reformation of the boundary layer in each successive blade row which reduces blockage contributed by the boundary layer. This also reduces the likelihood of flow separation towards the trailing edge (Japikse, 1996).

\subsubsection{Compact diffuser}

Compact diffusers are of particular interest to the aerospace industry, where engine frontal area is often constrained and a reduction in either axial or radial engine size provides a reduction in engine mass. Channel diffusers, such as those used by Krige (2013), are typically used for UAV application; however, large losses are incurred in the radial-to-axial vaneless bend in such a radially constrained compressor. Successful implementation of a compact crossover type diffuser by Burger (2016), Kock (2017), and Jie and Guoping (2010) have shown a reduction in losses incurred in the radial-to-axial diffuser bend by use of a continuous vane to assist in flow turning. Jie and Guoping (2010) report a static pressure recovery coefficient, $C_{p}$, of 0,65 and $11 \%$ improvement in engine thrust when compared to a standard channel diffuser. Similarly, Han et al. (2018) used a 'fishtail' type diffuser to achieve an improvement in performance over a channel diffuser, but state that a continuous vaned type diffuser will have a less mixed-out flow distribution at diffuser discharge due to secondary flows contributed by the vane wake.

\subsection{Previous mixed flow and MGT compressor research}

Research towards mixed flow compressors began in the late 1940s with three papers produced by the National Advisory Committee for Aeronautics regarding the development of a turbojet aircraft engine with a design mass flow of $8,89 \mathrm{~kg} / \mathrm{s}$ and $356 \mathrm{~mm}$ maximum stage diameter. The first paper by Goldstein (1948), presented design theory for mixed flow impellers with subsequent experimental results presented by Wilcox (1948). Finally, Wilcox and Robbins (1951) presented brief supersonic design theory for a vaned diffuser with accompanying experimental results for the complete stage. Wilcox and Robbins found that the thickness of the boundary layers and blade wakes contributed significantly to blockage, which prevented the diffuser from reaching design point before choking. Furthermore, it was found that transonic diffuser leading edge shock significantly affected flow angles in the vaneless gap when compared 
to a fully vaneless diffuser and indicated major shortcomings of available transonic diffuser design theory. Wilcox (1948) further determined that a mixed flow impeller will be more compact and simpler than an equivalent axial compressor but will have a reduced operating range.

After the initial mixed flow compressor research, general research focus shifted to axial multistage compressors due to their reduced weight and much larger mass flow operating range (favourable for large aircraft turbojet propulsion) when compared to centrifugal and mixed flow compressors. During the 1980s, the need for smaller turbojet engines increased with the introduction of UAVs and lightweight manned turbojet aircraft.

Kano et al. (1984) developed a mixed flow compressor operating at 7,46 kg/s and a pressure ratio of 2 . Kano et al. found that a compressor with an impeller meridional discharge angle, $\alpha_{z 2}$, of $60^{\circ}$, achieved twice the flow rate of an equivalent purely radial compressor. Furthermore, flow separation was observed at the convex vaneless gap wall prior to the radially vaned diffuser. Sarkar (1992) presented a design method based on 2D cascade theory and compared this against experimental results for a subsonic conical impeller with $\alpha_{z 2}$ $=22,5^{\circ}$. Sarkar achieved a good design point prediction but noted that shortcomings at stall side prediction were likely due to the slip factor formulation, developed by Stodola (1927), being for purely radial impellers.

Since the late 2000s, major advances in CFD modelling, specific to transonic compressor flow, have allowed a much better understanding of shock losses, shock induced separation and transonic boundary layer development (with associated blockage effects). Further developments in manufacturing methods have allowed for more complex centrifugal blade geometries with thinner minimum manufacturable thicknesses. This has increased the viability of transonic mixed flow small turbojet and MGT engines.

Cevik and Uzol (2011) used the design of experiment method to optimize an $86 \mathrm{~mm}$ diameter transonic mixed flow impeller, with $\alpha_{z 2}=50^{\circ}$, and a 4,35 total-to-total pressure ratio at $0,388 \mathrm{~kg} / \mathrm{s}$, requiring a shaft power of $84,1 \mathrm{~kW}$. Cevik and Uzol encountered issues of separation from the impeller shroud downstream of the leading edge shock. Zhu et al. (2013) determined that the interaction between shock and tip leakage vortex results in low momentum (or even separated) flow regions at the impeller shroud. Zhu et al. successfully reduced the magnitude of these low momentum flow regions using a grooved shroud casing, which subsequently improved the stall margin by $2,7 \%$. Rajakumar et al. (2013) verified that the stall margin is strongly influenced by tip leakage effects which cannot be sufficiently reduced with any practical change in tip gap size for a mixed flow impeller. 
Jie and Guoping (2010) identified the diffuser and radial-to-axial bend to be a major performance loss contributor in MGT compressors. This was due to the high separation and low pressure recovery coefficient resulting from the small radial space allowance for the diffuser. Jie and Guoping proposed and successfully tested a novel continuous vane (crossover) diffuser with reduced endwall curvature. This was introduced by a swept diffusion passage, achieving a $40 \%$ increase in static pressure recovery coefficient to a $C_{p}$ of 0,65 . Successive optimizations and flow investigations of crossover diffusers were conducted by Burger (2016) and Kock (2017). A patent was issued for Tarnowski and Bulot (2018) which describes the crossover diffuser as mentioned above. Han et al. (2018) and Han (2018) present and assess the performance of a 'fishtail' diffuser which is a channel diffuser with a swept meridional passage. Han et al. achieved a 2,4\% efficiency increase and 4,7\% surge margin increase compared to the original radial wedge diffuser with the disadvantage of strong wake formations in the stage discharge flow. Furthermore, Han et al. found that the addition of either splitters or de-swirlers did not improve stage performance due to strong vortices in the 'fishtail' channel.

Recently, design strategy has shifted from independent aerodynamic and structural component optimizations, to multidisciplinary optimizations of a full stage or even a full engine. Verstraete et al. (2010) performed a multidisciplinary optimization of a radial compressor and determined that the blade hub thickness and blade leading edge lean have considerable impact on von Mises stress but negligible aerodynamic impact. Verstraete et al. further state that endwall curvature strongly affects both aerodynamic and structural results but requires greater sample numbers due to the increased number of free parameters defining endwall features.

Giri et al. (2016) designed and optimized an MGT compressor with mixed flow impeller and diffuser, and axial de-swilring vanes with a maximum diameter of $255 \mathrm{~mm}$ and $\alpha_{z 2}$ of $55,5^{\circ}$, achieving a pressure ratio of 5,0 and $81 \%$ efficiency. Giri et al. note that high pressure ratio MGT compressors will incur significant losses in turning the supersonic impeller discharge to the axial discharge direction. Sadagopan and Camci $(2019 a, b)$ completed a design methodology and flow analysis for a complete mixed flow compressor stage with $\alpha_{z 2}$ ranging of $47^{\circ}-60^{\circ}$ and target pressure ratio of 6,0 in the $1-10 \mathrm{~kg} / \mathrm{s}$ mass flow range. The stage incorporated a supersonic axial tandem diffuser and achieved an efficiency of $75,7 \%$ with a mass flow of $3 \mathrm{~kg} / \mathrm{s}$.

Full engine optimizations are inherently computationally expensive and are mostly performed beyond academic research. One such optimization of a KJ66 MGT engine was completed by Teixeira et al. (2018) with the aim of reducing fuel burn while maintaining thrust performance. 


\section{Chapter 3}

\section{Baseline Design}

\subsection{Design requirements}

The compressor stage developed during this research project was to be implemented in a UAV MGT engine. The design was to meet the following requirements to satisfy the constraint reasoning discussed in section 2.2:

- Stage total-to-static pressure ratio between 4 and 4,5 at a design point mass flow rate of $1,089 \mathrm{~kg} / \mathrm{s}$

- Choke mass flow rate of at least $1,130 \mathrm{~kg} / \mathrm{s}$

- Stall mass flow rate of at most $1,00 \mathrm{~kg} / \mathrm{s}$

- Blade-to-blade absolute flow angle of $25^{\circ}-35^{\circ}$ entering the combustion chamber

- The stage is to be structurally feasible for manufacture using 7075-T651 aluminium alloy, which implies:

- A maximum localized von Mises stress of at most $380 \mathrm{MPa}$ with the majority of stress below $300 \mathrm{MPa}$

- Acceptable impeller deformation to avoid shroud interference

- No resonance encountered near design speed

- Design point total-to-static stage efficiency of at least $83 \%$, with the objective of maximizing efficiency.

These requirements were to be met at an operating speed of 73000 RPM, with a maximum diameter of $180 \mathrm{~mm}$ for the stage.

To conform to available manufacturing methods, the blades were to be flank milled with a minimum thickness of any blade section of no less than 0,2 mm. Flank milling implies that the blade shape definition is to be comprised of only 
two camber and thickness profiles (in this case at hub and shroud surfaces) with linear interpolation spanning between the two sections. Such a limitation is often implemented to produce a simple blade geometry that is suitable for manufacture by the milling process, while reducing the number of blade parameters and simplifying the early optimization phase.

\subsection{Baseline design process}

A baseline design was first developed that meets the desired operating range in order to be used as a starting point and performance reference for the subsequent optimization process.

\section{Design type choices}

The impeller meridional discharge angle, $\alpha_{z 2}$, was chosen to be located between $50^{\circ}$ and $90^{\circ}$. This range was selected based on the relatively well performing mixed flow compressors developed by Giri et al. (2016), Kock (2017) and Sadagopan and Camci (2019a) for a similar operating mass flow rate. The lower bound for $\alpha_{z 2}$ was chosen based on the research of Sadagopan and Camci $(2019 b)$, which suggests that more axial designs are not likely to attain the desired pressure ratio requirements in a single (compact) stage.

A crossover diffuser was chosen for this design to reduce losses associated with the vaneless bend while maintaining a small frontal area for UAV application. Frontal area was strictly restricted with the maximum diameter constraint supplied by the CSIR, while stage discharge into the downstream combustor was to be axial in the meridional plane. This necessitated a compact diffuser design of high diffusion rate to fit within the geometric constraint. The relaxed stage discharge swirl requirement further benefited the decision of using a crossover diffuser, which was found by Burger (2016) to perform well at higher discharge swirl angles due to the absence of additional de-swirling vanes.

\section{Mean-line design procedure}

An initial estimate of key design parameters was obtained using COMPAL ${ }^{\circledR}$, which is a mean-line state based preliminary design tool that uses semi-empirical turbomachinery relations such as those described by Dallenbach (1961), Whitfield (1990), Dixon (1998), and Aungier (2000). This was necessary to obtain an estimate of design parameters such as impeller leading and trailing edge blade angles, inducer radius, and impeller discharge radius. For example, im- 
peller inlet blade angles would be determined by

$$
\frac{\omega^{2} m}{\pi k \rho_{01} a_{01}^{3}}=\frac{M_{r 1}^{3} \cos \left(\beta_{s 1}\right) \sin ^{2}\left(\beta_{s 1}\right)}{\left(1+\frac{1}{5} M_{r 1}^{2} \cos ^{2}\left(\beta_{s 1}\right)\right)^{4}} .
$$

as described by Dixon (1998) for no prewhirl $\left(C_{\theta 1}=0\right)$ and assuming $\gamma=1,4$ (ratio of specific heats). Dixon states that a well designed inlet will have transonic conditions at operating point but with allowance for a fluctuation in mass flow rate without reaching choke.

Limited crossover diffuser design methodology was available at the time of writing this thesis. This lead the diffuser parameter selection process to be based on assumptions from theory available for radial vaned, vaneless, and channel diffusers. Consequently, COMPAL ${ }^{\circledR}$ also delivered limited capabilities for a thorough preliminary diffuser design process.

For example, to obtain an initial diffuser vane number, an estimate of crossover vane length had to be determined. Chord length for an equivalent radially vaned diffuser as given by

$$
L_{B}=\frac{2\left(r_{4}-r_{3}\right)}{\cos \beta_{3}+\cos \beta_{4}}
$$

was first determined. $\beta_{3}$ was selected based on the previously stated range (subsection 2.4.1), while $\beta_{4}$ was selected to match the required exit swirl. The obtained length was subsequently multiplied by a semi-arbitrary value of 1,5 to obtain an estimate of the curved chord length in a crossover diffuser. This scaled value was subsequently substituted into Equation 2.10, along with a discharge swirl angle of $\alpha_{z 4}=0,25^{\circ}$ and inlet passage height equal to the impeller outlet passage height (obtained from COMPAL ${ }^{\circledR}$ ), such that $b_{3}=$ $b_{2}$. The leading and trailing edge blade thickness was set to the minimum manufacturable thickness of $0,2 \mathrm{~mm}$. It should be noted that the obtained value for $Z_{\text {diffuser }}$ was only a coarse estimate of initial main blade number and was revised later during the optimization process.

After the design requirements and certain geometry parameters were supplied as input by the user, a full geometry parameter list was received as output. This parameter list was imported into AxCent ${ }^{\circledR}$ which builds a full geometry by applying Bézier interpolation for blade shape between the state points determined in COMPAL ${ }^{\circledR}$. Additionally, AxCent ${ }^{\circledR}$ estimates a meridional geometry using internally calculated flow and pressure coefficients that are compared against an existing design database. Within $\mathrm{AxCent}{ }^{\circledR}$, the preliminary design was iteratively adjusted using a combination of both internally available design tools and implementation of design theory presented in Chapter 2. A comparison of the preliminary and final baseline designs are shown in Figure 3.1, with key design changes discussed below. 


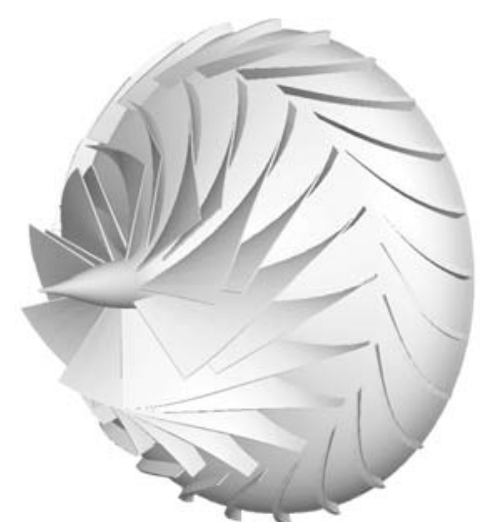

(a) Preliminary (AxCent)

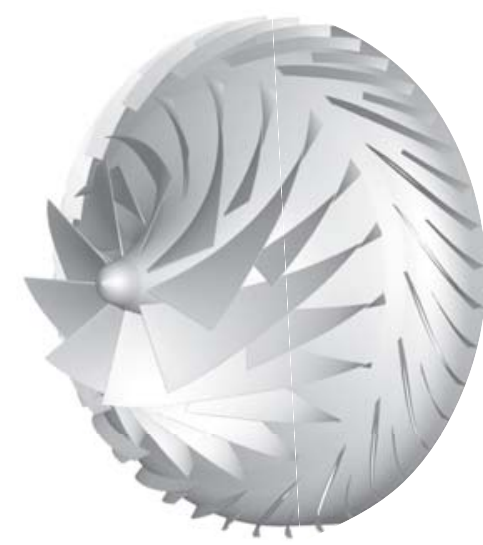

(b) Baseline

Figure 3.1: Preliminary and baseline geometry comparison

\subsection{Preliminary-to-baseline design changes}

A rounded hub inlet bulb was added to the preliminary design as shown in Figure 3.2, to represent practical implementation. The preliminary design achieved a choke margin considerably lower than that which was predicted using flow estimates substituted into Equation 2.2. To increase the choke margin, the impeller splitter leading edge was moved significantly further downstream to reduce blockage contributed by splitter thickness in the region of high blade solidity (due to lean). Furthermore, both the impeller hub and diffuser shroud endwalls were adjusted to increase the respective throat area in both blade rows. The vaneless gap size was also increased to conform with the $k$ value suggested by Aungier (2000) (see section 2.3) and a splitter was added to the diffuser due to very low blade solidity towards the preliminary diffuser trailing edge.

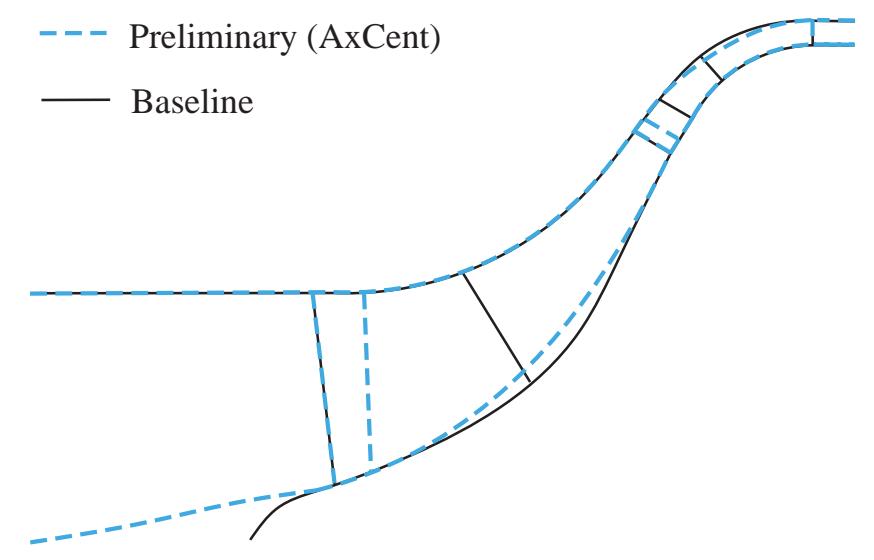

Figure 3.2: Preliminary and baseline meridional channel comparison 


\section{Chapter 4}

\section{Optimization Setup}

\subsection{Workflow overview}

Once a baseline design geometry was selected, the workflow proceeds from preliminary design phase to data-gathering and optimization phase. The baseline geometry was meshed and the flow solver set up for both aerodynamic and structural computations. A parametric model was chosen and fitted to the baseline geometry and coupling between various parameters implemented with corresponding parameter bounds chosen. A database generation was subsequently performed. Results of the database were filtered and imported into an optimization process to meet the design requirements while maximising the objectives.

Figure 4.1 describes the full optimization workflow. The workflow was hosted by the FINE ${ }^{\mathrm{TM}}$ /Design3D optimization algorithm ('Modelling' block in the figure). A Python script (developed by NUMECA Ingenieurbüro) was adapted for sequencing each step of structural analysis, as well as modelling and meshing of the aerodynamic analysis. The Python script was implemented to perform a simultaneous multi-row optimization. Furthermore, the script was needed to perform the structural analysis using the CalculiX open source solver, which was not part of the standard NUMECA workflow. Each aspect of the optimization process is now discussed. 


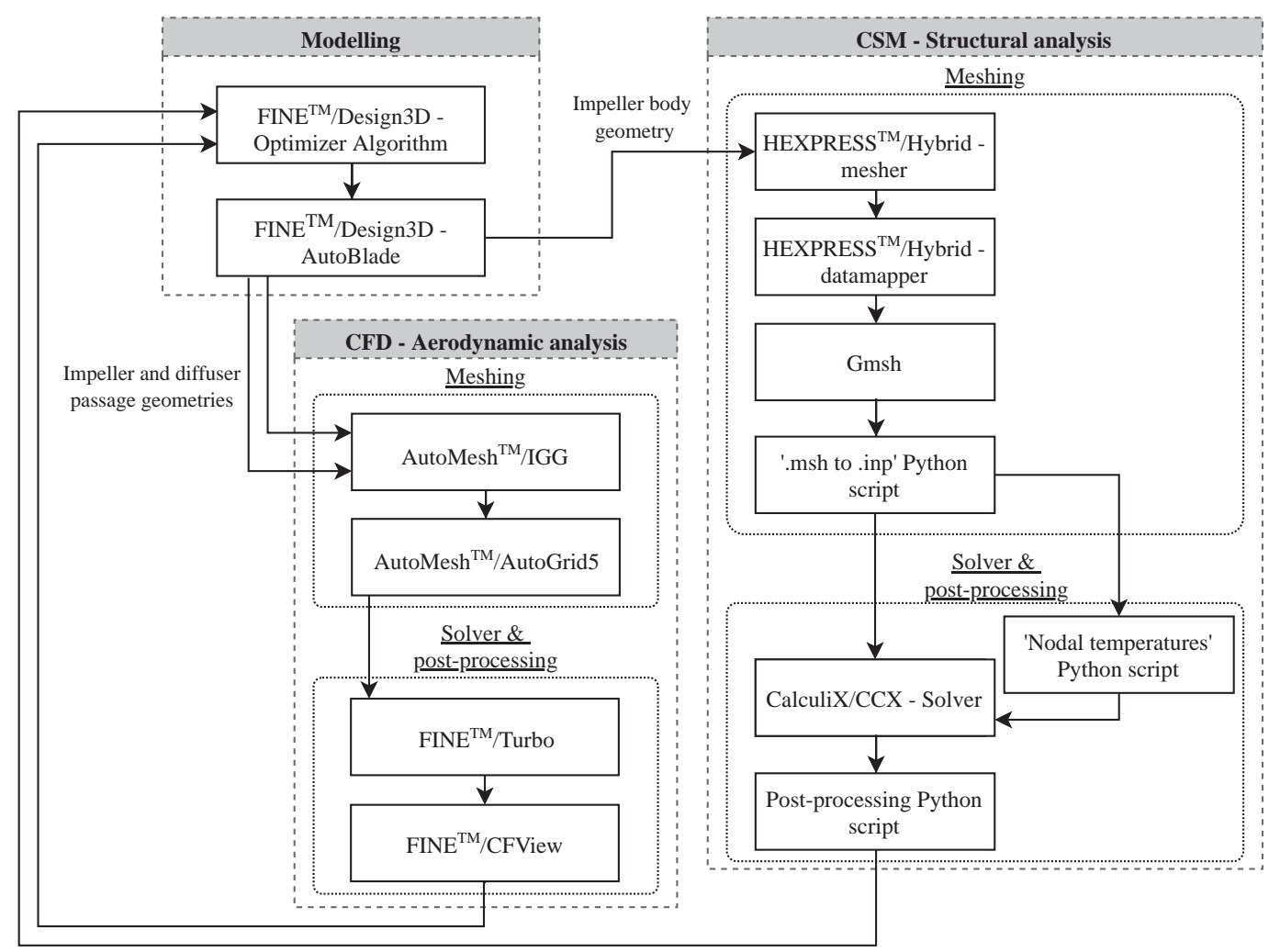

Figure 4.1: Workflow process overview

\subsection{Operating points}

For each design four operating points were computed as shown in Figure 4.2, namely: one choke point (CP), one design point (DP) and two near stall points (SP1 and SP2). The points were selected to obtain a set of responses (results) that can quantify the performance curve range and design point performance as described in section 2.2.

Two near stall point computations were performed to obtain a near stall stability quantification,

$$
\Delta P R_{(01-05), \text { stall }}=\frac{P R_{(01-05), S P 1}-P R_{(01-05), S P 2}}{m_{S P 1}-m_{S P 2}}
$$

where the difference in total pressure ratio is divided by the respective difference in mass flow of each stall point to determine the performance curve pressure gradient near stall. A more negative gradient implies that the points are further from the true stall point and thus are more stable at the computed mass flow rate than a design with a less negative gradient. 


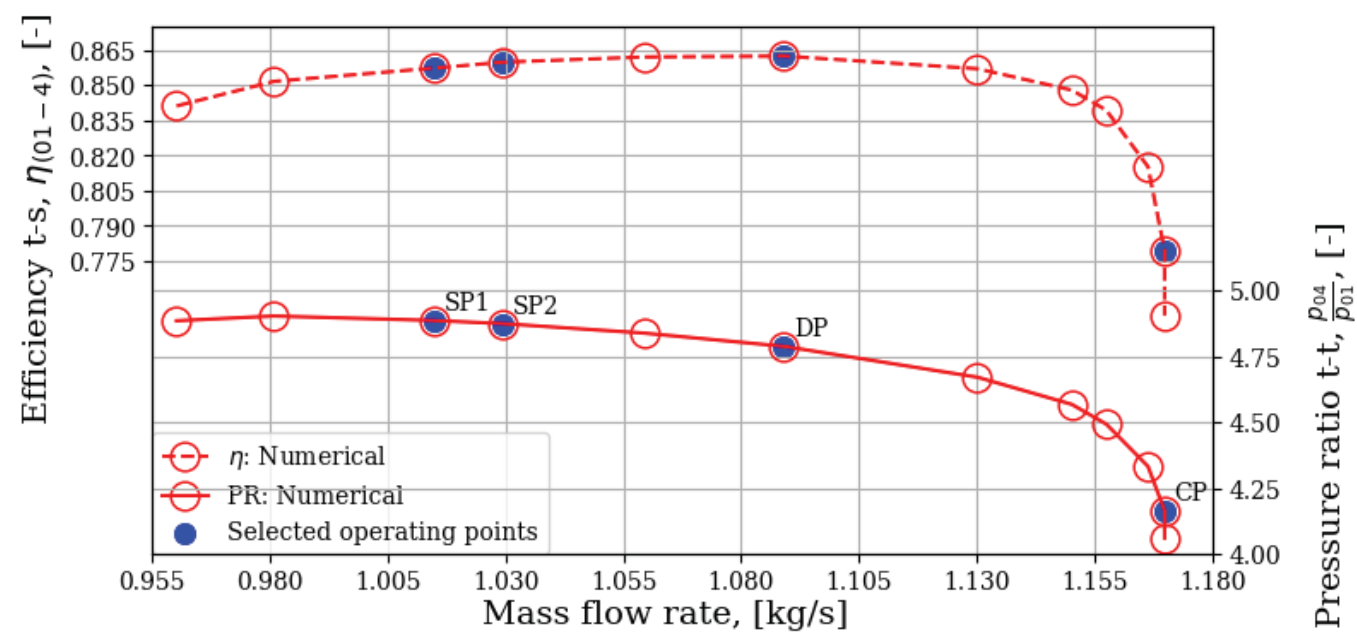

Figure 4.2: Illustration of selected operating points for optimization process

\subsection{Parametric model}

The parametric modeling was performed using AutoBlade ${ }^{\mathrm{TM}}$ which forms part of the NUMECA FINE ${ }^{\mathrm{TM}} /$ Design3D turbomachinery design package. Two separate parametric models were used for the impeller and diffuser blade parameters, however, the meridional passage parameters were common for both parametric models. Each model was configured with appropriate endwall descriptions comprising of Bézier curves and straight lines. Blade camber and thickness descriptions, as well as stacking laws and blade configurations were also configured before fitting the model to the geometry developed in the baseline design process. The choices of impeller and diffuser blade description, as well as meridional description models are discussed below, with a full list of model settings listed in Table C.1.

\subsubsection{Impeller meridional model}

The impeller meridional channel consists of two 5-point Bézier curves describing the hub and shroud curves in the bladed portion of the impeller, with a Bézier-spline describing the inlet bulb (hub side) and line segment describing the inducer (shroud side). The inlet bulb geometry was kept constant with all 4 points fixed in position, while the inducer radius was determined by the free parameter R_IN which defined the radius of the first 3 shroud points as seen in Figure 4.3. The impeller outlet position was controlled by shifting the last hub Bézier point with R_ITE_H (radius impeller-trailing-edge hub) and Z_ITE_H (z-coordinate impeller-trailing-edge hub). The impeller outlet size and orientation was obtained by placing the last shroud Bézier point according to the $\alpha_{z 2}$ (meridional angle) and H_ITE (height impeller-trailing-edge) 
parameters. Endwall curvature near the outlet was controlled by moving the point adjacent to the exit, along a line which defines $\alpha_{z 2}$ and also coincides with the last Bézier point, with the D_ITE_H and D_ITE_S parameters. Point S4 was given freedom of movement within specified bounds, as shown by the red shaded area, while the remaining Bézier points were each constrained to linear movement by releasing only one free coordinate parameter, ' $\mathrm{R}_{-}$' or ' $\mathrm{Z}_{-}$' respectively. Such reductions in freedom of movement were done to minimize the number of free parameters while still having control of a large range of feasible geometries.

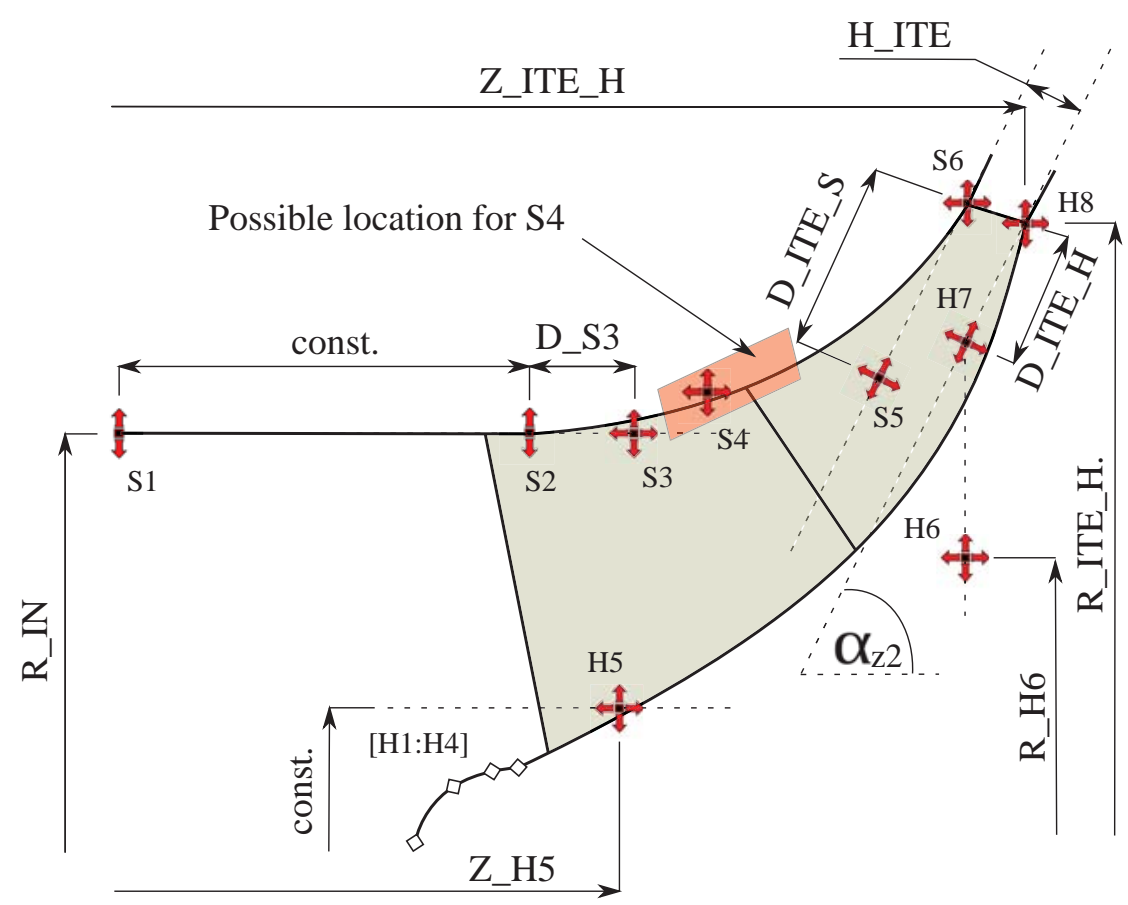

Figure 4.3: Impeller meridional control point description

To ensure manufacturability, no shroud points were allowed to be located at a radius less than R_IN as this would require a shroud casing with lower radius at certain locations than the inducer radius. Such a casing cannot be fitted to the impeller due to interference at the impeller leading edge tip.

\subsubsection{Diffuser meridional model}

The diffuser meridional channel profile was found to have a significant effect on flow separation at the hub due to flow experiencing both diffusion and a relatively sharp change in flow direction from near radial to purely axial in the meridional plane. As such, parameters were introduced to have strong control over diffuser cross-sectional area and endwall curvature. 
Figure 4.4 describes parameters controlling upstream and downstream portions of the diffuser and flow domain. All diffuser Bézier points are located relative to the impeller trailing edge points. The W_GAP parameter controls vaneless diffusion gap width and D_GAP controls vaneless gap added expansion relative to a parallel wall channel at inclination $\alpha_{z 2}$ as shown by the inclined dotted lines. The added expansion was placed at the hub due to expected separation at the shroud of the vaneless gap, as observed by Kock (2017). Diffuser exit channel axial position and height are controlled by W_DTE and H_DTE with downstream flow domain geometry kept constant but shifted relative to the diffuser exit. Reasoning for the domain shape and exit pinch is given in subsection 5.2.1.

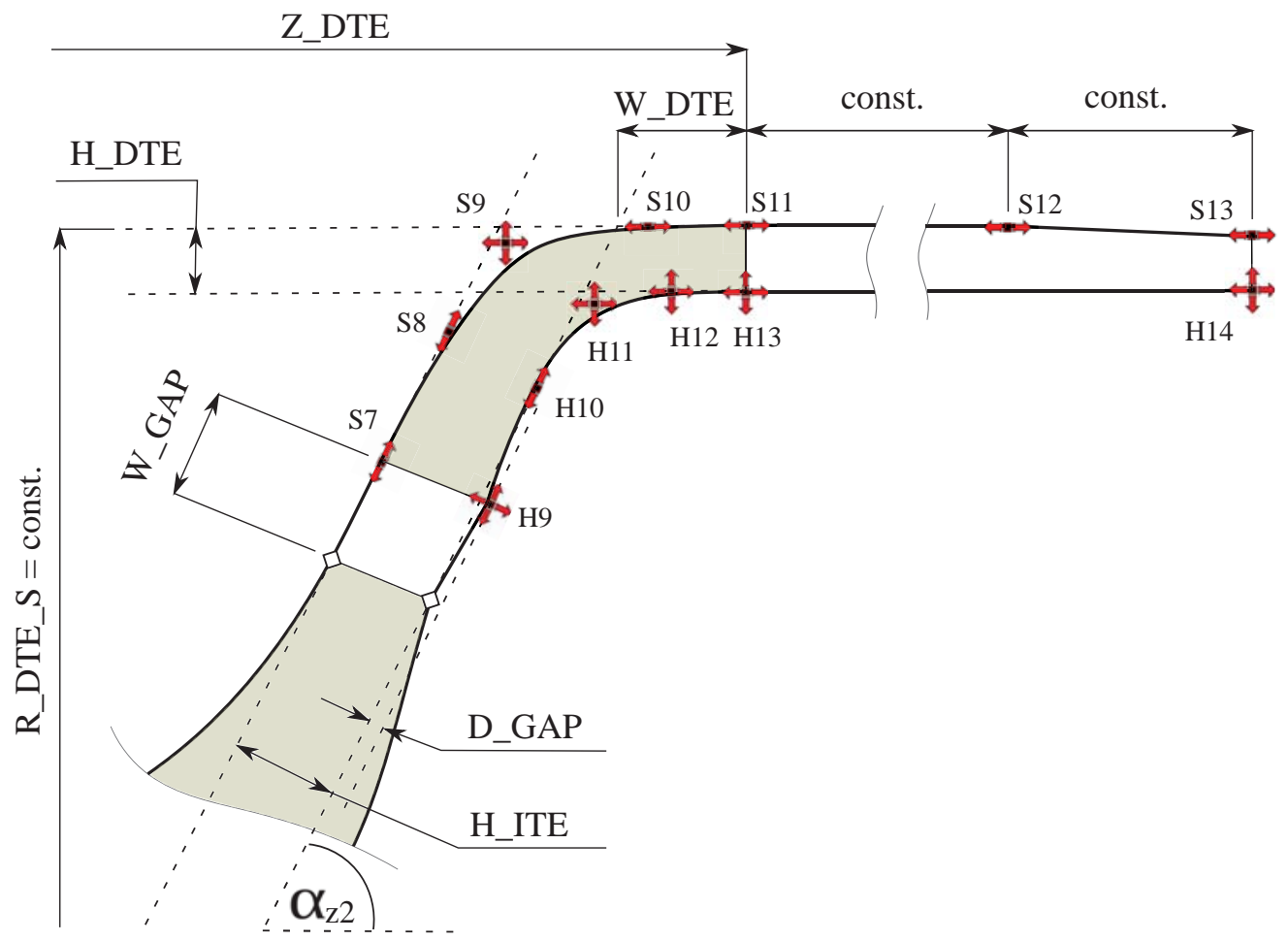

Figure 4.4: Diffuser meridional outer control point description

Figure 4.5 shows parameters controlling the bladed portion of the meridional channel. Two sets of parallel lines passing through the impeller and diffuser trailing edge points restrict Bézier point freedom with all points, excluding S9 and H11, lying on these lines. This was done to ensure endwall slope continuity from impeller to diffuser and the downstream domain, with the exception of the discontinuity associated with the vaneless gap expansion. Exact location of these aforementioned points are controlled by parameters D_DLE_S $\left(/ \_H\right)$ and D_DTE_S (/_H). Points S9 and H11 are both free in the $r$ - $z$-directions but are bound to a region with upper radius and lower $z$-values bound by parallel 
lines to prevent S9 from moving above the diffuser outer radial constraint. The radial constraint also prevents an ' $S$ ' shape in either the hub or shroud curves, while the $z$-value lower bound was introduced to increase the number of feasible geometries.

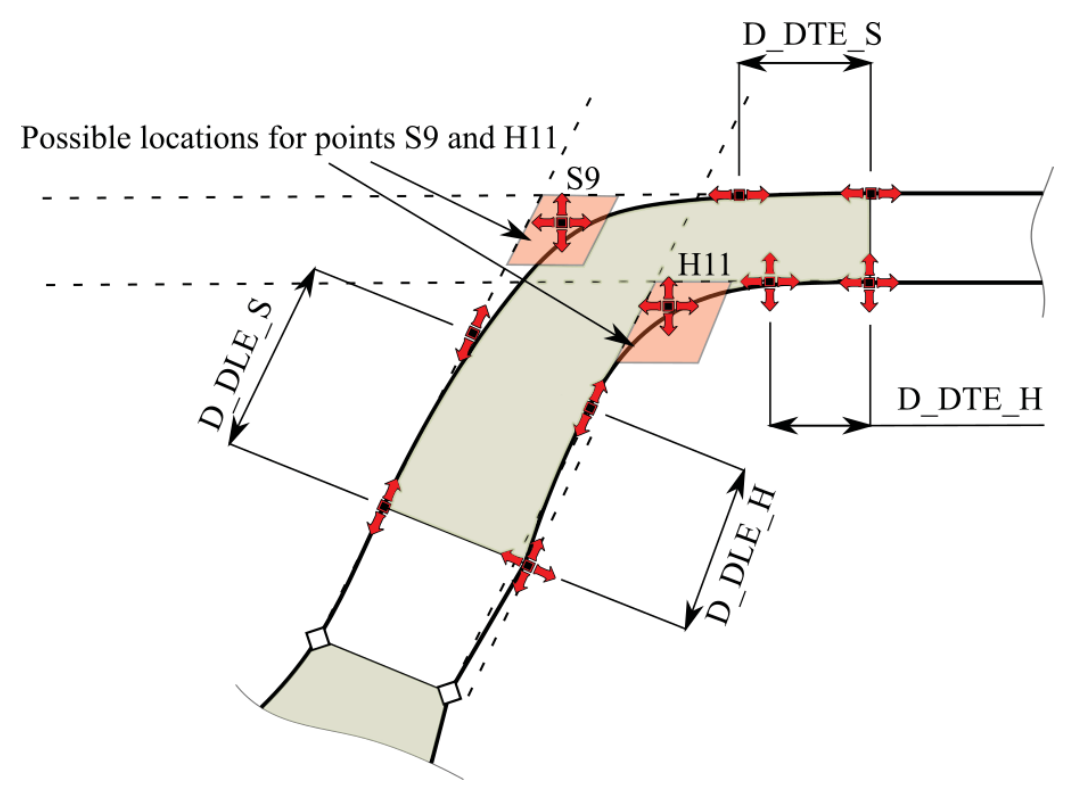

Figure 4.5: Diffuser meridional inner control point description

\subsubsection{Meridional parameter coupling}

Due to the large number of free parameters, a large range of possible geometries were constructed (later discussed in subsection 7.1.1). Predicting all possible parameter combinations and eliminating all unfeasible geometries was not possible, but measures were implemented to reduce the number of unfeasible geometries using parametric feature constraints and introducing interdependencies between parameters.

\section{Impeller shroud curvature}

Impeller shroud separation is heavily influenced by shroud curvature which can be controlled by points S3, S4, and S5. To reduce unfeasible impeller shroud curves (due to inflection or aggressive curvature) obtained with the variation in impeller axial length, the Possible location for $S_{4}$ region was coupled to points S3 and S5. The midpoint of this region was set to coincide with the mean $z$-coordinate of points S3 and S5. 


\section{Diffuser passage height}

Many designs initially exhibited a choke point below the design mass flow rate due to a small diffuser throat cross-sectional area. To reduce the likelihood of this happening, Points S9 and H11 were limited to a minimum proximity of $5 \mathrm{~mm}$ from each other by implementing the min operator in the parameter description function. Additionally, points S9 and S8 were prevented from exceeding the diffuser maximum radius. The diffuser trailing edge shroud radius, R_DTE_S, was set equal to the maximum allowable radius. Similarly, points H10 and H11 were prevented from exceeding the diffuser trailing edge hub radius, as obtained by R_DTE_S - H_DTE.

\section{Meridional angle to axial length coupling}

The impeller meridional angle parameter, $\alpha_{z 2}$, and impeller axial length parameter, Z_ITE_H, were coupled to control impeller geometry by pivoting around a point coinciding between the inducer radius, R_IN, tangent line and the impeller exit hub angle as shown in Figure 4.6. This method of coupling maintained axial and meridional angle freedom but reduced the number of designs with an undesirable ' $S$ ' shape impeller shroud inflection. Such an inflection was encountered in designs with a short axial length and high meridional angle. This coupling method also reduced the number of designs with excessively long blade length and bad blade angles in the elongated impeller inlet section. Such an issue was encountered in designs of long axial length and high meridional angle.

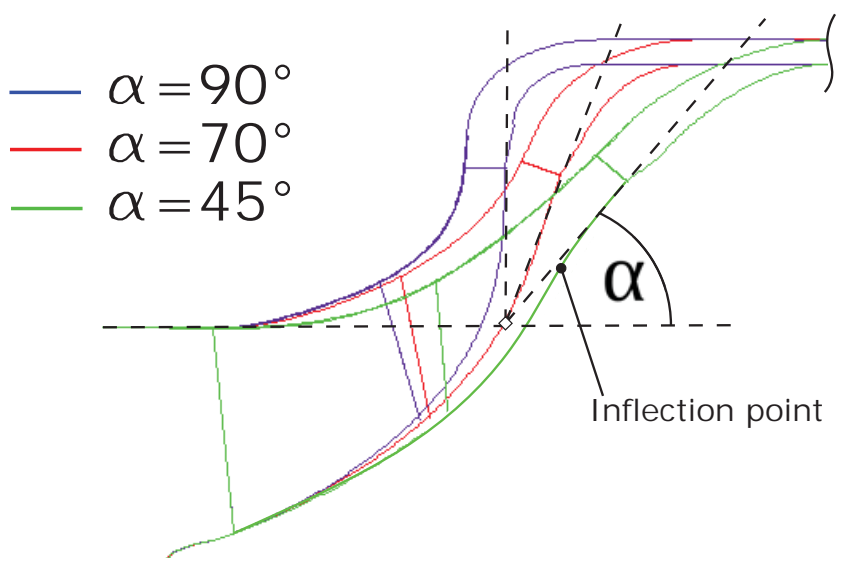

Figure 4.6: Sample designs with varying of only the $\alpha_{z 2}$ parameter 


\subsubsection{Impeller blade model}

The impeller main blade camber model consists of two camber descriptions. The hub side camber description was located at $-0,05$ times passage height (blade section 1) and the shroud side camber description was located at 1,05 times passage height (blade section 2). This was chosen due to the flank milling manufacturing requirement, while blade sections had to intersect the channel endwall for proper geometry generation. The splitter camber profile was defined as a symmetric interpolation of the adjacent main blade camber curves. Main and splitter blade trailing edges were cut to blunt at a constant $D M R$ (constant meridional distance), while the leading edge was of constant radius construction. A trailing edge stacking law was also applied. Leading edge position was obtained by linear interpolation between a point on each section defined at a constant axial position with main blade forward sweep controlled by a difference parameter between both respective constants.

To increase the percentage of feasible blade profiles, all Bézier points on section 1 and section 2 were coupled with user-defined parameters as illustrated in Figure 4.7a. Section 1 blade leading edge was used as a reference for all camber points. In section 1, the first and last Bézier point offset was controlled by parameters $\mathrm{H} 1$ and $\mathrm{H} 4$, where $\mathrm{H} 1$ directly influences blade leading edge angle, while H4 controls blade wrap angle and thus chord length. Due to a large variation in blade lengths causing many unfeasible blade shapes with noncoupled points, parameters H2_DELTA and H3_DELTA were introduced to move the two middle camber points relative to point H4. Furthermore, section 2 was linked to section 1 by parameter H4_DELTA which coupled the final camber points on both blade sections to reduce unfeasible geometries generated while maintaining sufficient geometric control.

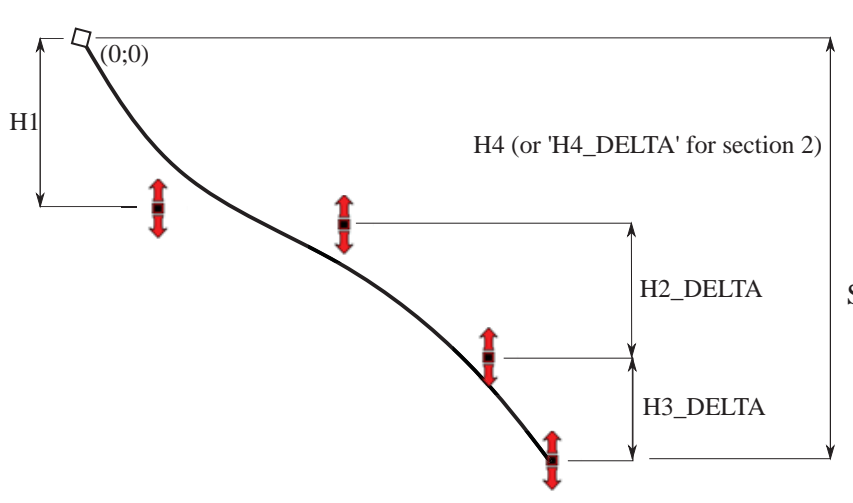

(a) Impeller

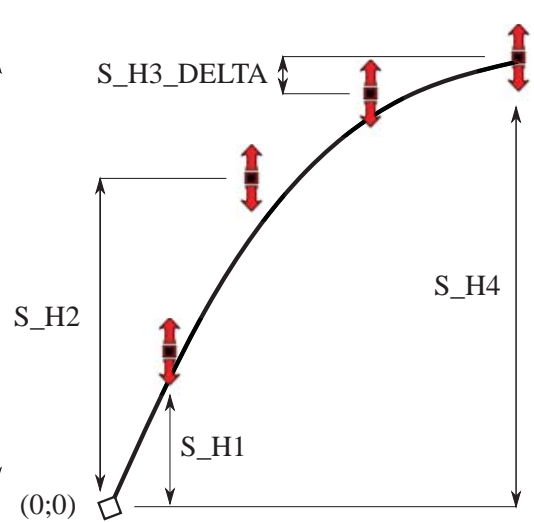

(b) Diffuser

Figure 4.7: Camber control point description 
The thickness distributions of the impeller main and splitter blade were controlled independently with a 5-point Bézier-spline, as shown in Figure 4.8a. The Bézier-spline controls leading edge radius (constant), leading edge half wedge angle LE_HALF_ANGLE, impeller maximum blade thickness point T_IMID, and impeller trailing edge thickness T_ITE. A geometric spacing ratio of 2 was applied to place maximum thickness near $30 \%$ blade length and a trailing edge half-angle of zero was set to achieve an approximate airfoil shape. Parameter bounds were set such that no blade portion contained a thickness less than the minimum manufacturable thickness. Examples of database geometries are shown in Figure E.1.

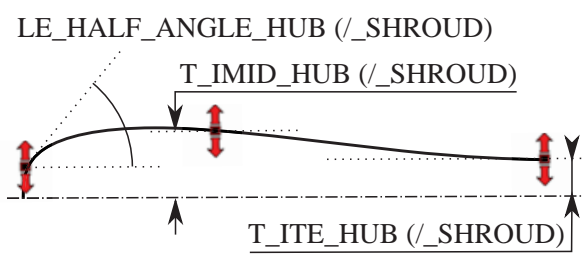

(a) Impeller

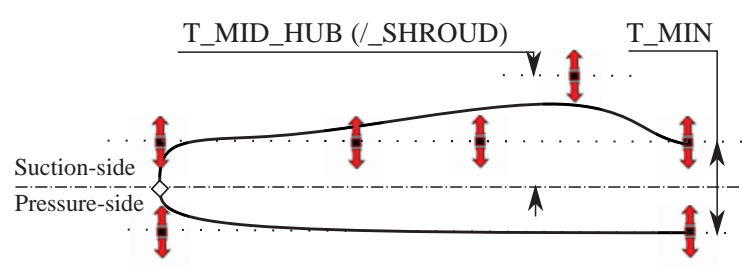

(b) Diffuser

Figure 4.8: Blade thickness control point description

\subsubsection{Diffuser blade model}

The diffuser blade parametric model was constructed similarly to the impeller with a 4-point Bézier controlling the camber profile. Point S_H2 (Figure 4.7b) was uncoupled from the blade wrap parameter, S_H4, since blade camber curvature in the first $50 \%$ of blade length was deemed a sensitive characteristic and was thus controlled independently of the latter $50 \%$ of the camber profile. An example of wrap control using only S_H4 is shown in Figure E.4. The diffuser blade geometry was interpolated between two constant spanwise height sections located at $-0,05$ and 1,05 times passage height. The final diffuser model consisted of 2 splitter blades with all blades having blunt trailing edges at a constant axial position. A leading edge stacking point was employed with a straight leading edge interpolated between the intersections of the hub and shroud with two constant radius lines. The constant radius lines were coupled with the W_GAP parameter to obtain a diffuser leading edge that is parallel with the impeller trailing edge in the meridional plane.

The diffuser thickness control points are given in Figure $4.8 \mathrm{~b}$ with pressure and suction side Bézier points controlled by T_MIN (minimum thickness) and T_MID (maximum thickness). Such a profile was chosen since it was expected to help control suction side separation occurring at the diffuser hub. 


\subsubsection{Impeller solid model}

The impeller solid body was modelled as a periodic section $\left(1 / 9^{\text {th }}\right)$ with geometry defined by 4 lines and a 4-point Bézier curve in the meridional profile, as shown in Figure 4.9. Four parameters were implemented to control the backface and disk face of the body for the purpose of controlling body stress and tip displacement. All free points are located relative to the impeller trailing edge hub point to allow more feasible solid body geometries with impellers of differing axial lengths. Parameter W_OUTER controls the body outer face width, while W_BACK controls the body backface bore shoulder area. Parameters W_BORE and W_CUT control the extruded bore length and disk face undercut angle, respectively. The undercut angle parameter was introduced since it was determined by van der Merwe (2012) to influence tip displacement, while Diener et al. (2016) found that the undercut could be used to control stress in the bore and blade trailing edge.

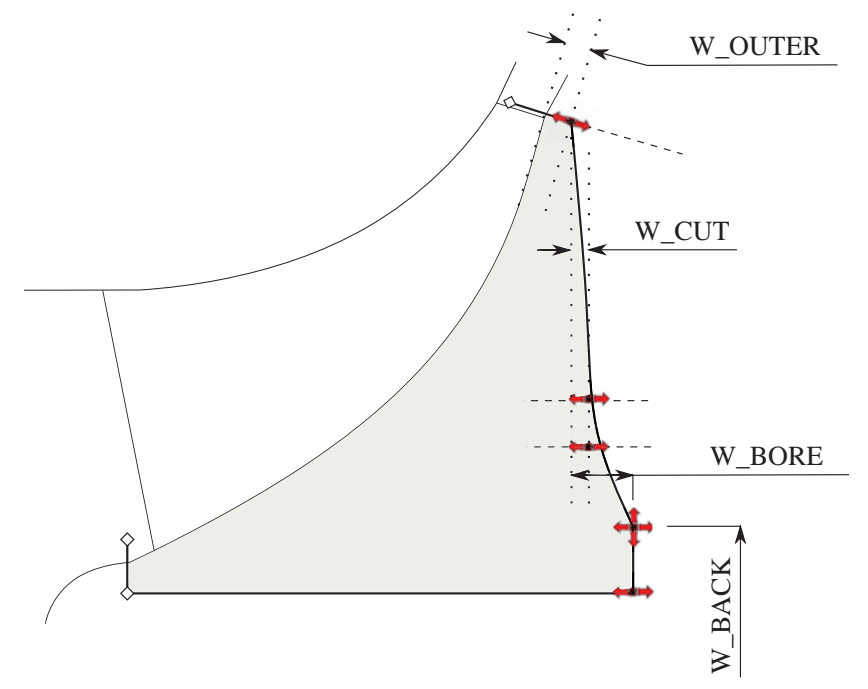

Figure 4.9: Impeller solid body control points

To ensure successful solid body construction in AutoBlade ${ }^{\mathrm{TM}}$, the solid body control endpoints were set to intersect the hub endwall. Additionally, the solid body control points were placed $0,5 \mathrm{~mm}$ downstream of the impeller trailing edge to ensure full intersection between blade root and solid domain for the purpose of successful blade fillet generation. The fillet was modelled as a 'constant radius' type with no fillet at the blunt trailing edge. 


\subsection{Database generation}

\subsubsection{Overview}

The optimization process consists of first populating the possible design space by running a database generation that pseudo-randomly scatters free parameters (independent variables) across the design space with the aim of obtaining trends in responses (dependent variables) and feasibility information of the entire bounded design space using as few database points as possible. Hildebrandt et al. (2009) suggest computing at least three times more successful database designs than the number free parameters for a good design space population.

After each design in the database was simulated, a '* plan' file was appended with the accompanying design number, parameter values, response values, and success flag. The success flag indicates whether the design simulation achieved desired convergence and response values can be assumed valid. The success flag was only set as valid if no failures occurred during computation and all convergence requirements, as specified in subsection 5.3.3, were satisfied.

\subsubsection{Parameter scattering}

Three databases were computed with parameter scattering determined using the Latin Hypercube Sampling (LHS), Centroidal Voronoi Tessellations (CVT) and Latinized Centroidal Voronoi Tessellations (LCVT) methods. LHS is the process of transforming the design space into a set of multidimensional discrete cubes (Hypercubes) and then moving parameters within the cube in such a manner as to ensure the greatest possible geometric diversity (spacing) between each parameter point (Saka et al., 2007). The LHS method is known to result in clustering of parameters, thus reducing the efficiency of design space exploration, while the CVT method produces a more uniform distribution of parameters across a larger area but tends to cluster near coordinate axes. The LCVT method combines both methods by applying a Latinization (geometric scattering within a Latin Hypercube) to an initial CVT parameter set to obtain the most effective design space exploration (NUMECA International, 2019c).

\subsubsection{Design space}

Selecting free parameters and corresponding upper and lower bounds was an iterative process relying on a combination of previous research, compressor design literature and largely personal intuition. A discussion on free parameter selection and choice of corresponding bounds for each optimization is presented below. 


\section{Free parameter selection}

Two databases and subsequent optimization processes were completed. The first optimization, OPTI1, included free parameters controlling mostly endwall and blade meridional features (see Table 4.1). The second optimization, OPTI2, froze most meridional parameters and focused on blade camber profile and thickness distribution. OPTI2 also included impeller body parameters to control bore stress and body deformation.

Table 4.1: Free parameter list

\begin{tabular}{|c|c|c|c|c|c|}
\hline \multicolumn{3}{|c|}{ First Optimization (OPTI1) } & \multicolumn{3}{|c|}{ Second Optimization (OPTI2) } \\
\hline Geometry type & Geometry feature & Free parameters & Geometry type & Geometry feature & $\overline{\text { Free parameters }}$ \\
\hline \multirow{4}{*}{ Channel profile } & Meridional angle & 1 & Channel profile & Vaneless expansion & 1 \\
\hline & $\begin{array}{l}\text { Hub and shroud } \\
\text { curvature }\end{array}$ & 8 & $\begin{array}{l}\text { Blade profile } \\
\text { (meridional) }\end{array}$ & $\begin{array}{l}\text { Diffuser splitter } \\
\text { (position) }\end{array}$ & 1 \\
\hline & Passage heights & 3 & Camber profile & Impeller camber & 7 \\
\hline & Vaneless expansion & 2 & & Diffuser camber & 8 \\
\hline \multirow{8}{*}{$\begin{array}{l}\text { Blade profile } \\
\text { (meridional) }\end{array}$} & Impeller axial length & 1 & Thickness profile & Impeller main blade & 3 \\
\hline & Diffuser axial length & 1 & & Impeller splitter & 1 (+1 from main) \\
\hline & Impeller inducer radius & 1 & & Diffuser splitter blade & 1 \\
\hline & Impeller outlet radius & 1 & Tangential & Impeller/Diffuser lean & 2 \\
\hline & $\begin{array}{l}\text { Impeller splitter } \\
\text { (position and angle) }\end{array}$ & 2 & Solid body & Impeller body & 2 \\
\hline & $\begin{array}{l}\text { Diffuser splitter } \\
\text { (position and angle) }\end{array}$ & 2 & & & \\
\hline & Impeller sweep & 1 & & & \\
\hline & Vaneless gap size & 1 & & & \\
\hline \multirow[t]{2}{*}{ Camber profile } & Impeller camber & 8 & & & \\
\hline & Diffuser camber & 6 & & & \\
\hline \multirow[t]{2}{*}{ Thickness profile } & Impeller & 6 & & & \\
\hline & Diffuser & 2 & & & \\
\hline \multirow[t]{2}{*}{ Tangential } & Impeller lean & 1 & & & \\
\hline & Total: & 48 & & Total: & 25 \\
\hline
\end{tabular}

OPTI1 was computed with the aim of exploring a large design space region and determining the general best region for the current design requirements. This was achieved by freeing many parameters (mostly meridional) that were deemed to have a strong response influence. This included R_IN, R_ITE_H, $\alpha_{z 2}$ and blade edge angles of both blade rows.

OPTI2 was computed with the aim of further optimising the design achieved in OPTI1 and introducing requirements of structural feasibility. The most influential parameters of OPTI1 were identified with the analysis of variance (ANOVA) method and subsequently frozen at the optimal value. This was done to allow the weaker parameters' influence to become more evident and improve the ANOVA for these weak parameters for OPTI2. 


\section{Free parameter bounds}

Once a free parameter list was selected, the upper and lower bounds for each parameter had to be selected to fully define the possible design space. The bound selection and evolution process is described as follows.

Firstly, parameters present in well-defined design methodology literature are assessed. For example, inducer shroud radius, R_IN, is understood to strongly influence the inducer choke mass flow as indicated by Equation 3.1, therefore a desired range of choke mass flow in the inducer can be substituted and corresponding R_IN bounds obtained. Table 4.2 lists the bounds chosen for OPTI1 and the optimized (and frozen) value for OPTI2. Similarly, typical ranges for vaneless gap radius ratio and diffuser leading edge angle were obtained from literature (see section 2.3) to determine W_GAP and S_H1 bounds respectively.

Table 4.2: Selected parameter bound evolution between optimizations

\begin{tabular}{lllllc}
\hline \multirow{2}{*}{ Geometry feature } & \multirow{2}{*}{ Parameter } & OPTI1 & \multicolumn{3}{c}{ OPTI2 } \\
& & LB & UB & LB & UB \\
\hline Meridional angle & $\alpha_{z 2}$ & $50^{\circ}$ & \multicolumn{2}{c}{$85^{\circ}$} & \multicolumn{2}{c}{$71,2^{\circ}$} \\
Inducer shroud radius & R_IN & $41,5 \mathrm{~mm}$ & $44,5 \mathrm{~mm}$ & \multicolumn{2}{c}{$44,45 \mathrm{~mm}$} \\
Impeller wrap (hub) & H3_DELTA & $-1,35$ & $-1,00$ & $-1,25$ & $-1,21$ \\
Vaneless added expansion & D_GAP & $-0,40 \mathrm{~mm}$ & $1,00 \mathrm{~mm}$ & $0,15 \mathrm{~mm}$ & $0,35 \mathrm{~mm}$ \\
Vaneless gap width & W_GAP & $5,50 \mathrm{~mm}$ & $8,00 \mathrm{~mm}$ & \multicolumn{2}{c}{$6,20 \mathrm{~mm}$} \\
Diffuser LE angle (shroud) & S_H1 & $64^{\circ}$ & $76^{\circ}$ & $70^{\circ}$ & $74^{\circ}$ \\
Backface undercut & W_CUT & \multicolumn{2}{c}{$0 \mathrm{~mm}$} & $-2,00 \mathrm{~mm}$ & $2,00 \mathrm{~mm}$ \\
\hline
\end{tabular}

Secondly, parameters with limited information in design literature were assessed by use of the preliminary design software in order to obtain coarse feasible bounds. This method was implemented for the meridional angle and impeller wrap parameter, H3_DELTA. These parameter bounds were often too large, producing many unfeasible designs. By plotting design success flag vs parameter value after OPTI1, the evolved bounds were obtained (see subsection 7.3.2 for success rate graphs). For example, the range of H3_DELTA was reduced from $30 \%$ to $3,3 \%$. Similarly, meridional passage curvature parameters were assessed with this method (for possible geometries see Figure E.2 and Figure E.3).

Finally, parameters with no quantifiable (only observation based suggestions) design literature were assessed. For example, the effects of impeller undercut were mentioned by van der Merwe (2012) and used only to guide the semiintuitive selection of undercut distance. Undercut was only introduced into OPTI2 since structural results were not considered in OPTI1. 


\subsection{Optimization}

\subsubsection{Optimization methodology}

The optimization process initiates by training a surrogate model (SM) on the '*.plan' file generated during the database process. A SM is a mathematical estimation of response values, given a set of parameters as input (Bagheri et al., 2017). The SM uses available responses and accompanying parameters to perform multidimensional curve fitting and subsequently build a mathematical model of the 'black-box' type problem faced when optimizing a design purely using CFD. The problem is defined as 'black-box' type since there exists only a parameter list as input and a response list as output values for the CFD chain, without any exact knowledge of how any input parameter controls any response. For this investigation, the Radial Basis Function Network (RBFN), the Tuned-RBFN, and the Kriging models were compared with a Leave-One-Out (LOO) analysis with the best being chosen for the optimization process. The LOO analysis removes one sample from the training data and uses remaining data to train the SM, before comparing the difference of the omitted sample's response values to the predicted response values obtained from the SM. This process is repeated for each data point (each design), before returning a correlation coefficient of the predicted and actual response values. A strong correlation indicates a good prediction of responses by the SM. The LOO analysis was performed using the internal MINAMO tool contained in FINE $^{\mathrm{TM}} /$ Design3D.

A Genetic Algorithm (GA) optimizer was subsequently applied to the trained SM to determine the current predicted best design based on the objective function described in subsection 4.5.2. A GA implements the concept of natural selection, as found in nature, by selecting a set of parameters and then repeatedly modifying a set of parameters by either random selection, or specified mutation, depending on the weighting of probability constants supplied to the GA by the user (Deb, 1999). The GA proceeds with the aim of reducing the objective function value at each subsequent parameter 'generation' until a specified number of generations is reached. Once this pseudo-optimized design was achieved, the parameters were sent to Autoblade ${ }^{\mathrm{TM}}$ for geometry generation and subsequent continuation of the workflow.

The optimization process (shown in Figure 4.10) continues with each subsequent design appended to the '*.plan' file and SM being updated. The SM used in MINAMO also determines the feasible design space using the success flag from the '*.plan' file and heavily penalises the objective function of any design located within a unfeasible region (NUMECA International, 2019c). 


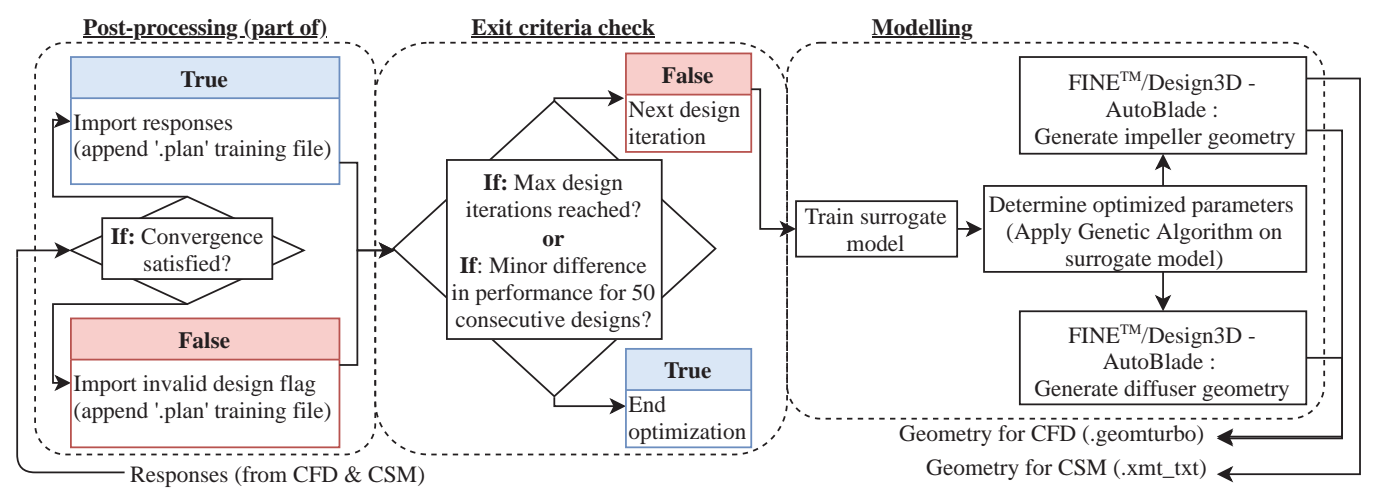

Figure 4.10: Modelling logic process

\subsubsection{Objectives}

For OPTI1, an initial attempt was made to perform a multi-objective optimization on the 48 free parameter database (DB1) using the Pareto front method. The Pareto front method disregards any weighting applied to each objective and aims to achieve a set of designs located along a 'front' of best performance relative to each objective and any combination of the specified objectives. A Pareto method was successfully implemented by Li et al. (2017) to optimize an impeller with focus on stall performance. In this thesis $\eta_{(01-4), D P}, m_{\text {choke }}$ and $\triangle P R_{(01-05), \text { stall }}$ were chosen as objectives. The optimization attempt was found to generate a large number of designs with significantly different operating curve ranges and positions due to the $m_{\text {choke }}$ and $\Delta P R_{(01-05) \text { stall }}$ objectives. The large variety of operating curves made design point efficiency comparison unreliable. The optimization algorithm could not converge to a region of best overall designs, but rather obtained many unconverged designs. The choice was thus made to rather implement a single objective optimization with the aim of maximising $\eta_{(01-4), D P}$ while operating range responses were rather set as constraints.

For OPTI2, the Pareto optimization method was successfully applied by optimizing the three objectives of maximizing $\eta_{(01-4), D P}, m_{\text {choke }}$ and $\Delta P R_{(01-05), \text { stall }}$. A reliable Pareto front comparison was possible since a smaller range in operating curve position for all assessed designs was achieved with the narrower design space range. 


\subsubsection{Constraints}

\section{Constraint implementation}

The MINAMO optimization algorithm prioritizes all constraint violations over objective optimization by first searching for designs that least violate the constraints and only proceeding to maximize (or minimize) objectives once all constraints are expected to be satisfied. The constraint penalty, $P$ defined as

$$
P=W\left(\frac{Q_{i m p}-Q}{Q_{i m p}}\right)^{k}
$$

where $W$, and $k$ are weighting and scaling constants, respectively. $Q$ and $Q_{i m p}$ are the response quantity and imposed target value, respectively. $Q_{i m p}$ is also used to nondimensionalize the penalty term. $W$ and $k$ were both set to 1, since the MINAMO Pareto method disregards weighting provided that all constraints are satisfied.

\section{Design and choke point constraints}

The constraints required to satisfy the design requirements specified in section 3.1 are listed in Table 4.3. At design point, stage total-to-static pressure ratio and diffuser blade-to-blade discharge angle are constrained. Choke mass flow was the only response constrained from the choke point computation.

Table 4.3: Optimization constraints

\begin{tabular}{llll}
\hline Response & OPTI & Type & Q imp \\
\hline$P R_{(01-4), D P}$ & both & $<$ & 4,5 \\
$P R_{(01-4), D P}$ & both & $>$ & 4,15 \\
$\alpha_{z 4}$ & both & $<$ & $35^{\circ}$ \\
$\alpha_{z 4}$ & both & $>$ & $25^{\circ}$ \\
$\sigma_{V M, \text { max }}$ & 2 & $<$ & $380 \mathrm{MPa}$ \\
$\delta_{z-\text { tip, } \text { max }}$ & 2 & $<$ & $0,12 \mathrm{~mm}$ \\
$m_{\text {choke }}$ & both & $>$ & 1,13 \\
$\Delta P R_{(01-05), \text { stall } P W}$ & both & $>$ & 0,015 \\
\hline
\end{tabular}

\section{Stall point constraint}

A stall mass flow design requirement cannot be explicitly implemented since most designs are likely to not converge if a mass flow boundary condition at stall were to be applied. This is due to the inherent physical flow instability 
encountered near stall. Stall performance was determined as described in section 4.2 by Equation 4.1; however, the $\Delta P R_{(01-05), \text { stall, } P W}$ value supplied to the SM was manipulated as a piecewise function based on stall point (SP1) pressure ratio convergence fluctuation, $P R_{(01-05) \text { stall }}^{\prime}$. The piecewise function was constructed to help the $\mathrm{SM}$ with $\Delta P R_{(01-05), \text { stall }}$ prediction as follows:

$$
\begin{gathered}
\Delta P R_{(01-05), \text { stall, } P W}=f\left(P R_{(01-05), \text { stall }}^{\prime}\right) \\
f\left(P R_{(01-05), \text { stall }}^{\prime}\right)=\left\{\begin{array}{lr}
\overline{\Delta P R_{(01-05), \text { stall }}} & P R_{(01-05), \text { stall }}^{\prime}<0,005 \\
-P R_{(01-05), \text { stall }}^{\prime} & 0,005<P R_{(01-05), \text { stall }}^{\prime}<0,015 \\
\text { 'unconverged' } & P R_{(01-05), \text { stall }}^{\prime}>0,015
\end{array}\right.
\end{gathered}
$$

where if $P R_{(01-05) \text { stall }}^{\prime}>0,015$, the design is considered unconverged and responses are not used for SM training. However, if $0,005<P R_{(01-05) \text {,stall }}^{\prime}<$ 0,015 , the design is considered pseudo-converged and responses are used for SM training but do not satisfy the $\triangle P R_{(01-05), \text { stall, } P W}$ constraint and the design is interpreted as converged but unsatisfactory. Only a design with $P R_{(01-05) \text { stall }}^{\prime}<0,015$ is considered both converged and satisfactory with respect to the stall pressure ratio gradient constraint.

For the converged but unsatisfactory case described above, $\triangle P R_{(01-05), \text { stall, } P W}$ is semi-arbitrarily set equal to $-P R_{(01-05) \text { stall }}^{\prime}$. The resulting value is therefore always interpreted by the optimizer as unsatisfactory with increasing constraint violation magnitude as $-P R_{(01-05), \text { stall }}^{\prime}$ (fluctuation) increases.

\section{Structural constraints}

Computational solid mechanics (CSM) results were not considered for OPTI1 since the initial meshing strategy delivered non-physical stress concentrations due to low fillet mesh refinement near the main blade leading edge. The CSM meshing strategy was subsequently improved and CSM responses included as constraints for OPTI2.

Maximum von Mises stress $\left(\sigma_{V M, \max }\right)$ was required to be below the minimum yield stress of $380 \mathrm{MPa}$ for 7075-T651 aluminium. This value was deemed acceptable without any safety factor provided that this is only a localized peak stress and the majority of the impeller's stress is below $300 \mathrm{MPa}$. This was confirmed by the CSIR and by experimental results of van der Merwe (2012).

Impeller maximum allowable tip displacement $\left(\delta_{z-t i p, \text { max }}\right)$ was set to a value of $0,12 \mathrm{~mm}$ to ensure no blade-shroud interference with a tip clearance of $0,2 \mathrm{~mm}$. 


\section{Chapter 5}

\section{Aerodynamic Numerical Setup}

\subsection{Computation overview}

All aspects of the aerodynamic design process were performed using the NUMECA FINE ${ }^{\mathrm{TM}} /$ Design3D software chain in conjunction with an externally scripted Python workflow. The script allowed automated parametric modeling and meshing of both impeller and diffuser blade rows. A geometry generated by the parametric modeler, as described in section 4.3, was imported into AutoGrid $5^{\mathrm{TM}}$ for meshing according to predetermined meshing template. The mesh would subsequently be imported into the FINE ${ }^{\mathrm{TM}} /$ Turbo solver template with post-processing performed using $\mathrm{CFView}^{\mathrm{TM}}$. The template for each step is described below.

\subsection{Meshing setup}

\subsubsection{Meshing template and flow domain}

A mesh template was established that contains all mesh settings and was applied to each successive geometry (provided the geometry contained a matching topology to that specified in the template) to generate the mesh cells and domain bounds. Impeller and diffuser rows were meshed separately with a non-matching mesh on the upstream and downstream sides of the impellerdiffuser interface as shown in Figure 5.1. All meshing software specific settings are given in Table C.2 with reasoning for certain settings given below. 


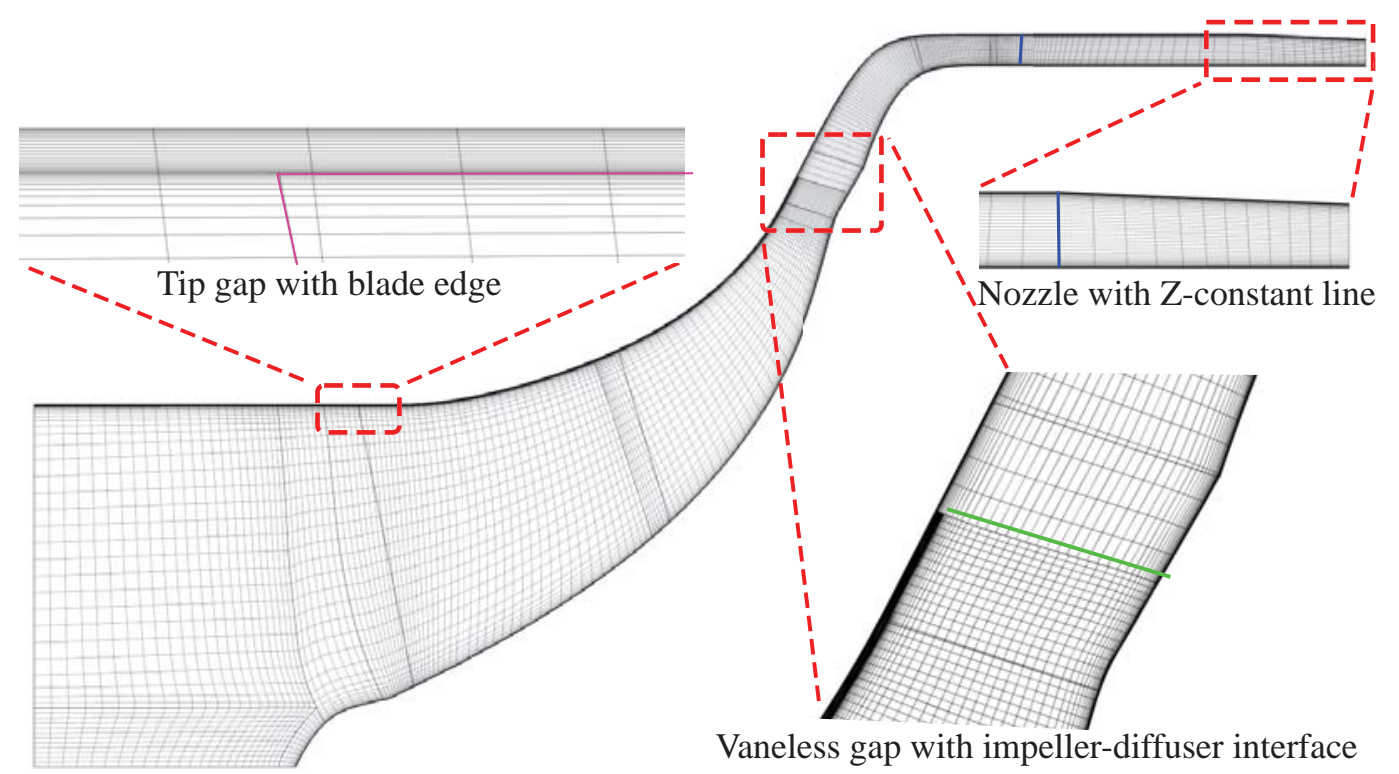

Figure 5.1: Meridional view of mesh

\section{First cell height}

The first cell height requirement is dictated by the Spalart-Allmaras (SA) turbulence model (section 5.3), which requires a corresponding first cell centroid $\mathrm{y}^{+}$of $y_{1}^{+}<10$ (Wilcox, 1998). The first cell height was calculated using

$$
y_{1}^{+}=\frac{\rho \mu_{\tau} y_{w a l l}}{\mu}
$$

where friction velocity is expressed as

$$
\mu_{\tau}=\sqrt{0,5\left(V_{r e f}^{2}\right) C_{f}}
$$

The coefficient of friction is obtained by assuming a ' $1 / 7^{\text {th }}$ ' velocity profile and substituting the Reynolds number based on an estimated inlet velocity and inlet radius of $C_{r e f}=300 \mathrm{~m} / \mathrm{s}$ and $b_{\text {ref }}=0,04 \mathrm{~m}$ with an air kinematic viscosity of $\nu=1,57 \times 10^{-5} \mathrm{~m}^{2} / \mathrm{s}$

$$
\begin{aligned}
C_{f} & =\frac{0,027}{R e_{r e f}^{1 / 7}} \\
R e_{r e f} & =\frac{C_{r e f} b_{r e f}}{\nu} .
\end{aligned}
$$

The diffuser first cell height was set equal to that of the impeller. $\mathrm{y}^{+}$Plots for the final design and mesh (Figure B.1) show that the $\mathrm{y}^{+}$requirement is satisfied for valid turbulence modelling with only a few cells exceeding a $\mathrm{y}^{+}$of 10 and no cells exceeding a $\mathrm{y}^{+}$of 15 . 


\section{Blade to blade topology}

Both blade rows were meshed with blunt trailing edges and rounded leading edges with grid point topology given in Figure C.1. The first cell height at the trailing edge was set 3 times greater than the general first cell height since this greatly improved mesh skewness and expansion ratio near the trailing edge (see Figure 5.2). This improved mesh quality outweighed the necessity to properly resolve the trailing edge flow, which was expected to always be fully separated on the blunt surface. A large number of cells were placed near the impeller-diffuser interface due to large static pressure and density gradients expected in this region, originating at the impeller trailing edge and diffuser leading edge. The near blade ' $\mathrm{O}$ ' mesh was set to a higher conservative value of 25 layers due to the necessity to resolve possible flow separation in both rows.

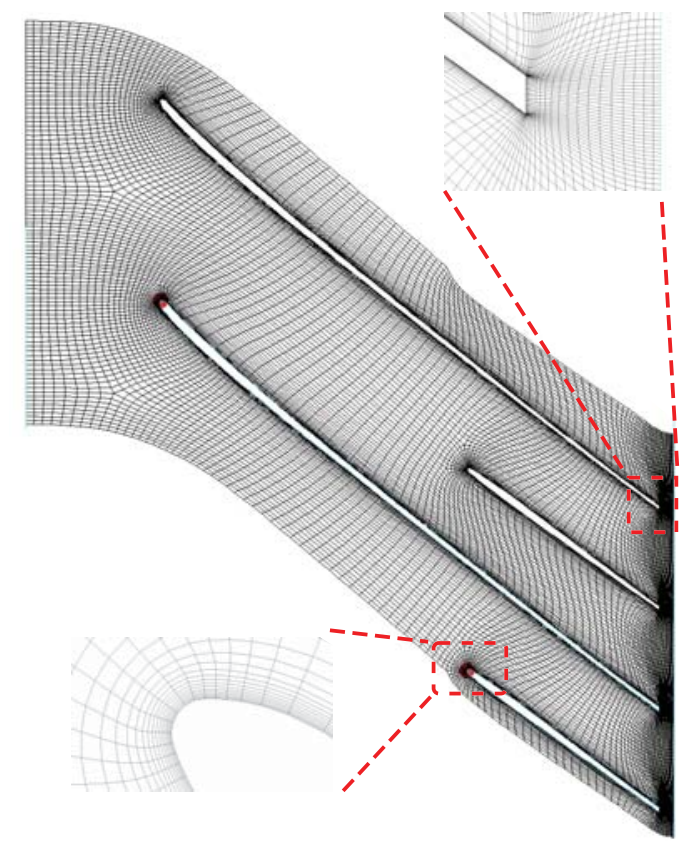

(a) Impeller

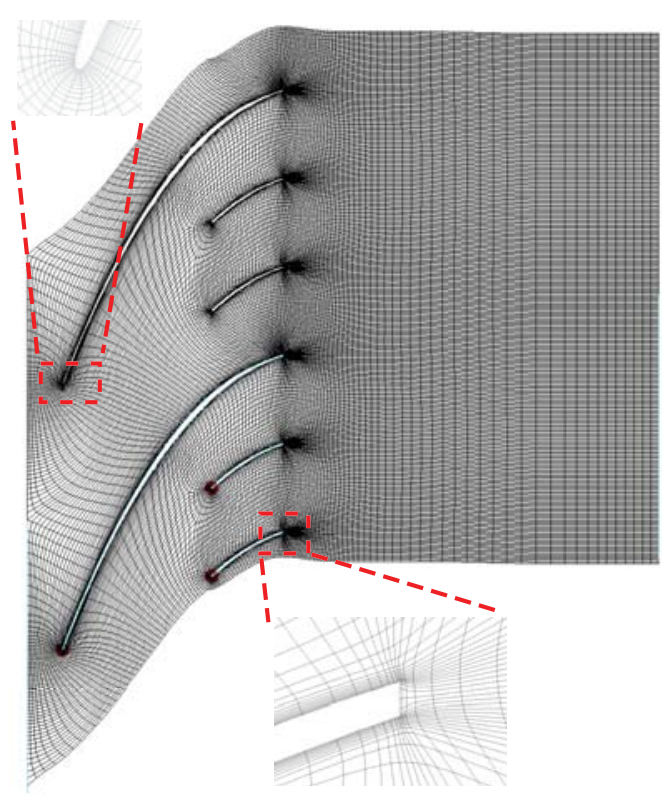

(b) Diffuser

Figure 5.2: B2B mesh of both blade rows at $50 \%$ span

\section{Upstream domain}

The domain upstream of the impeller leading edge was extended roughly 0,5 times impeller chord length (see Figure 5.3). The domain included a rounded hub bulb geometry formed with a Bézier-spline linking a point at zero radius upstream of the blade, with the intersection of leading edge and hub. The bulb grid point topology is given in Figure C.2. 


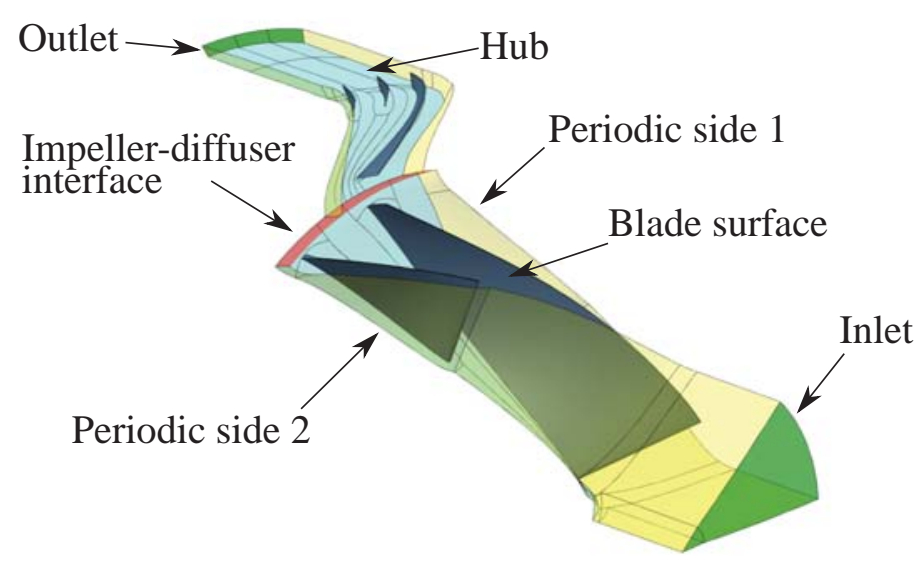

Figure 5.3: Flow domain and boundaries

\section{Bladed domain}

The domain surrounding all blades was meshed with ' $\mathrm{H} \& \mathrm{I}$ ' topology and 'O' topology in the boundary layer cells. The impeller blade was meshed with a constant $0,2 \mathrm{~mm}$ tip gap containing 21 cells in the radial direction, while the diffuser contained no gaps. No blade fillets were included in the CFD domain due to their negligible influence on stage performance when compared to the major free parameter influence expected (van der Merwe, 2012). The impeller-diffuser interface was situated in the middle of the vaneless gap in the meridional profile with no additional $Z$-constant lines placed in the vaneless gap to allow a smoother transition (less angular skewness) from the near blade mesh to the impeller-diffuser interface. The Z-constant line is defined in the meridional profile and creates a plane at constant meridional location. Cell faces are then forced to be located against this created plane. A 3-D mesh projection onto both the blade and hub surfaces is shown in Figure A.1.

\section{Downstream domain}

The domain downstream of the diffuser trailing edge was extended roughly 1,5 times the diffuser chord in the positive $z$-direction. A pinch (nozzle) was applied towards the domain exit to reduce cross-sectional area by $15,4 \%$ and increase flow velocity. This resulted in a negative pressure gradient with no risk of endwall flow separation and subsequent backflow into the domain. A Z-constant line was placed at the start of the nozzle to capture the abrupt endwall angle change and to force cells to align perpendicularly to the flow near the domain exit. Another Z-constant line was placed between the diffuser trailing edge and the expected evaluation plane position to reduce cell nonorthogonality with respect to the evaluation plane. This was done to reduce the interpolation error during post-processing of area weighted values at the evaluation plane. 


\subsubsection{Validity criteria}

Two mesh independence studies were performed for the optimization process. An initial study was performed to establish a mesh template that would be used for the optimization process. Due to the large variation in geometry from the baseline to the final design, a second mesh study with mesh improvement was performed using the final geometry. The second mesh study was performed to ensure validity of final performance curves results, thus all meshing related settings and mesh study results pertain to the final mesh template.

Three meshes were compared at the 4 operating points computed during the optimization phase. The three meshes consisted of 1,8- 2,2- and 4,4-million cells, with constant near blade cell count and uniform topology setup. The 4,4and 2,2-million cell meshes produced a good result correlation with a maximum $\eta_{(01-4)}$ difference of $0,05 \%$ obtained at the stall point (see Figure A.2). A comparison of the 1,8- and 2,2-million cell meshes produced a considerable difference in $\eta_{(01-4)}$ of $0,7 \%$ at the stall point. The 2,2 million cell mesh was thus accepted as valid, while maintaining a small cell count for less computational effort.

Final mesh quality values and suggested thresholds by (NUMECA International, 2019a) are shown in Table 5.1. The relatively low percentage of cells violating the suggested limits was deemed acceptable for valid results. The few 'bad' cells did not cause convergence issues, thus the mesh was chosen for all computations. Additional information for cell count and quality for the inlet bulb, impeller and diffuser mesh blocks are given in Table A.1.

Table 5.1: Mesh quality criteria

\begin{tabular}{llll}
\hline Quality indicator & Suggested limit & Worst value & \% cell violation \\
\hline Angular skewness & $>20^{\circ}$ & $27^{\circ}$ & 0 \\
Aspect ratio & $<10000$ & 570,3 & 0 \\
Expansion ratio & $<2,5$ & 3,28 & 0,090 \\
Spanwise angular deviation & $<45^{\circ}$ & $94,96^{\circ}$ & 0,047 \\
\hline
\end{tabular}




\subsection{Solver setup}

\subsubsection{Models and assumptions}

All solver software specific settings are listed in Table C.3 with reasoning for certain settings given below. For all computations, the Spalart-Allmaras turbulence model was used due to it's successful implementation and validation in the previous research of He and Zheng (2017), Diener et al. (2016) and Burger (2016). The standard SA turbulence model was chosen, without extended wall functions, due to it's ability to better solve cases with flow separation which was predicted to occur in the diffuser of certain designs (NUMECA International, 2019b). This model is also computationally significantly faster to converge in comparison to the $k-\omega$ SST turbulence model which is often applied to turbomachinery cases (Wilcox, 1998).

Air was modeled as a perfect gas with constant specific heats, while viscosity was modeled as a function of temperature using Sutherland's law. The perfect air assumption was shown by Diener et al. (2016) and Krige (2013) to be reasonable for compressors with similar impeller discharge temperatures (near $500 \mathrm{~K}$ ). Air was treated as a compressible fluid due to the large pressure ratios and shock waves expected in a transonic compressor.

The impeller-diffuser interface was treated as a Non-reflecting 1-D boundary with no localized characteristic correction (LOCCOR) for density, velocity components or pressure across the upstream and downstream surfaces (LOCCOR parameter set to 0 ). This was done to better resolve the shock originating at either the diffuser leading edge or the impeller trailing edge, and passing through the impeller-diffuser interface (S Albert 2018, personal communication, 27 September).

Spatial and temporal discretization was set to central (cell quantity derivative determined using adjacent cell values) and local time stepping (time step is determined on a per cell basis depending on cell size), as recommended by NUMECA International (2019b). Convergence time was significantly improved by enabling the $C P U$-booster which allows Courant-Friedrichs-Lewy (CFL) values of up to 1000. A nearest-to-stall point stable computation was computed with a CFL of 1000 and compared with a computation with a CFL of 3 as suggested by Diener et al. (2016), who encoutered convergence issues related to the CPU-booster. Convergence time was significantly faster with a CFL of 1000 , and the stall point mass flow varied negligibly $(<0,001 \%)$. The upper CFL limit of 1000 did therefore not produce non-physical stall results and was deemed acceptable for use in the optimization. 


\subsubsection{Boundary conditions}

Inlet flow conditions were set to an absolute temperature and pressure of $293 \mathrm{~K}$ and $100 \mathrm{kPa}$, respectively. A velocity direction was imposed as purely axial $\left(C_{1}=C_{z 1}\right)$ and turbulent viscosity set to $0.0001 \mathrm{~m}^{2} / \mathrm{s}$. Solid walls consisted of the blade and shroud surfaces as well as hub surface starting from the inlet bulb and terminating at the domain exit. All walls were modeled as adiabatic with a non-slip wall condition with negligible surface roughness. A rotational velocity was applied to the impeller blades, and the impeller hub up to the impellerdiffuser mesh interface. This resulted in a minor non-physical representation of the rotating hub surface since the impeller-diffuser mesh interface position did not coincide with the impeller rotating hub edge position (2 $\mathrm{mm}$ difference). An Area defined rotation could not be applied to the impeller hub due to a variable trailing edge radius and axial position. A comparison was made between results obtain using the Area defined and Constant rotation speed settings with at most a $0,01 \mathrm{kPa}$ difference in $P R_{(01-04)}$ (obtained at stall point). The Constant rotation speed for the entire impeller hub was deemed acceptable for valid results. All domain side patches were set as periodic connections due to the symmetric blade repetition in both blade rows.

Outlet boundary conditions were varied to achieve the desired operating points as summarised in Table 5.2. For both the stall points and design point, a mean mass flow across the outlet face was imposed using the Pressure adaptation method. An initial pressure was applied to the first iteration (as an estimate), initially obtained using COMPAL ${ }^{\circledR}$ in the baseline design process. The initial pressure was later adjusted to help convergence stability by reducing the initial pressure of both stall points by $10 \mathrm{kPa}(2,5 \%)$. By reducing the initial outlet pressure, the early iterations would proceed from a more stable operating point (closer to the design point) towards the stall side.

Table 5.2: Outlet boundary conditions

\begin{tabular}{llll}
\hline Operating point & Outlet condition & $\begin{array}{l}\text { Initial pressure: } \\
\text { outlet (static) }\end{array}$ & $\begin{array}{l}\text { Initial pressure: } \\
\text { interface (static) }\end{array}$ \\
\hline Stall point 1 & $1,015 \mathrm{~kg} / \mathrm{s}$ & $405 \mathrm{kPa}$ & $305 \mathrm{kPa}$ \\
Stall point 2 & $1,030 \mathrm{~kg} / \mathrm{s}$ & $400 \mathrm{kPa}$ & $303 \mathrm{kPa}$ \\
Design point & $1,089 \mathrm{~kg} / \mathrm{s}$ & $390 \mathrm{kPa}$ & $300 \mathrm{kPa}$ \\
Choke point & $260 \mathrm{kPa}($ static) & - & $280 \mathrm{kPa}$ \\
\hline
\end{tabular}

The choke point was reached using an averaged static pressure imposed on the outlet face. A pressure of roughly $65 \%$ of the design point outlet static pressure was imposed to ensure choked flow. For all operating points, an initial impeller-diffuser interface pressure was applied. 


\subsubsection{Convergence criteria}

Convergence for all desired operating points had to be satisfied for each design to qualify the response set as valid. Convergence quantification issues were incurred at both stall points and design point. Stall point convergence was affected by oscillation of responses due to the physically unstable operating condition. The design point for certain designs attained a non-physical 'near convergence' when choke mass flow rate was located below, or within $1 \%$, of design mass flow rate. The choke point was a stable operating point due to the relatively low sensitivity to changes in outlet pressure.

The stall point outlet total pressure was monitored across a set number of iterations before the predetermined maximum iteration count was reached, as shown in Figure 5.4. Monitoring was performed between iteration number 450 to 550. A nondimensional fluctuation response, $P R_{(01-05), \text { stall }}^{\prime}$ was subsequently calculated as follows:

$$
P R_{(01-05), \text { stall }}^{\prime}=\frac{P R_{(01-05), \text { stall-max }}-P R_{(01-05), \text { stall }- \text { min }}}{P R_{(01-05), \text { stall-mean }}}
$$

with $P R_{(01-05) \text { stall }}^{\prime}<0,005$ deemed sufficient to satisfy convergence. Choke point convergence was also assessed using Equation 5.5 but stable convergence was always observed.

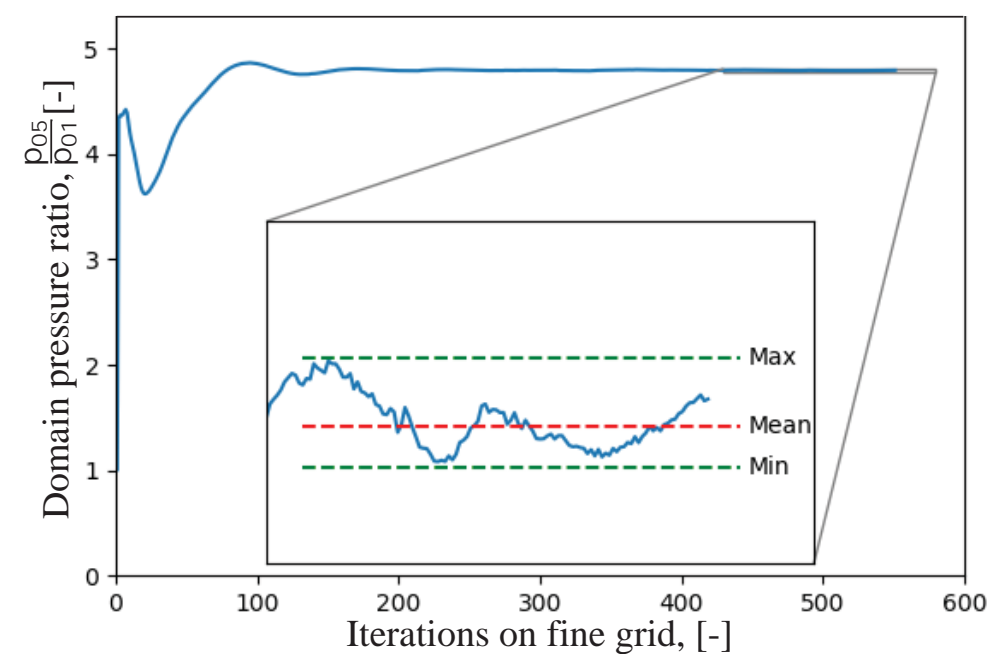

Figure 5.4: Convergence check using total pressure ratio

Design point convergence was determined using inlet mean mass flow rate, $\overline{m_{D P}}$, with convergence deemed satisfactory when

$$
\left|\overline{m_{D P}}-1,089\right|<0,0005
$$


where $1,089 \mathrm{~kg} / \mathrm{s}$ is the desired design point mass flow rate.

A computation was considered as 'crashed' if the density and energy residual requirement of $1 \times 10^{-3}$ was not satisfied. This was implemented to terminate successive operating point computations for the current design since the response values would be discarded from SM training. The stall point computation was thus computed first, as this was the least stable operating point.

\subsubsection{Post-processing}

Post-processing was performed with two methods, where response variables were either obtained from an evaluation plane using the final iteration result, or an average (or fluctuation amplitude) of results was obtained at the domain outlet over the final 100 (or 50) iterations.

\section{Final iteration results}

Responses required to determine compressor performance such as $P R_{(01-4), D P}$ and $\eta_{(01-4), D P}$, were desired near the interface between the compressor stage and the combustion chamber. An evaluation plane was placed at constant axial $z$-coordinate position for each design as shown in Figure 5.5. A study was performed to determine the effect that evaluation plane location had on performance results (see Figure A.3). A linear decrease of $\eta_{(01-4), D P}$ and $P R_{(01-04)}$ were observed with increasing evaluation plane distance from diffuser trailing edge with negligible difference in results obtained between the fine and medium meshes. The decrease of performance was attributed to losses incurred in mixing-out of the flow and viscous losses at passage walls. The evaluation plane was thus placed at $4 \mathrm{~mm}$ from the diffuser trailing edge (42 $\mathrm{mm}$ from the domain outlet) to allow for partial mixing-out of the flow. The evaluation plane was not placed further downstream in order to be located near the estimated interface between the compressor and combustion chamber.

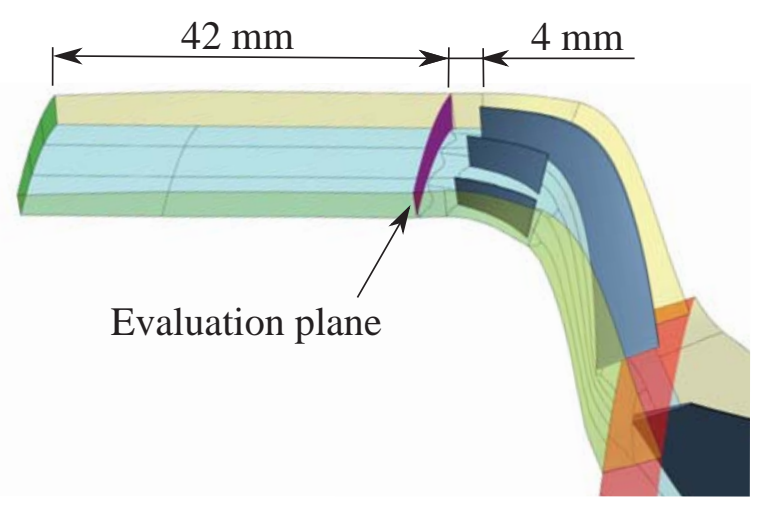

Figure 5.5: Evaluation plane location 
All responses were evaluated as absolute mass-flux weighted averages,

$$
Q_{\text {averaged }}=\frac{\int_{S} Q \rho|\vec{C} \cdot \overrightarrow{d \vec{S}}|}{\int_{S} \rho|\vec{C} \cdot \overrightarrow{d S}|}
$$

with $Q$ and $\rho$ being the response and density scalars, respectively, and $\vec{C}$ and $\overrightarrow{d S}$ being the flow vector and evaluation surface vector, respectively. Mass-flux weighting was implemented due to the variation of mass flow rate across the evaluation plane. Furthermore, absolute values were implemented to avoid backflow at the evaluation plane 'subtracting' from the averaged value (as would be the case for a non-absolute value weighting).

The total temperature and pressure at domain inlet were also obtained using the mass-flux weighting method, with the stage performance subsequently calculated between the domain inlet and the evaluation plane downstream of the diffuser.

\section{Averaged and fluctuating results}

Values for convergence criteria responses, as well as averaged domain pressure ratio, were all obtained from the residual file ( ${ }^{*}$.res). Averaged values could only be obtained for the full domain (not evaluation plane) due to software limitations. The responses were taken over the last 100 iterations for both the stall points, and 50 iterations for the design and choke point simulations using a Python scripted parser. The total pressure ratio for both stall points, as required to calculate $\Delta P R_{(01-05) \text {,stall }}$ (Equation 4.1 ), were obtained as an average due to many designs fluctuating in response values near the stall region.

Impeller shaft input power, $P_{\text {shaft }}$, was also obtained as an averaged value and was determined from the couple moment exerted by the combined rotating blade and endwall surfaces. This was obtained by computing the surface moment integral of surface viscous stress, $\tau$, per differential surface element, $d S$, as follows:

$$
P_{\text {shaft }}=\int_{S} \omega r \tau d S
$$

The aerodynamic analysis setup described in this chapter was implemented in a validation test case as presented in Appendix D. The impeller developed by Diener et al. (2016) was meshed and appropriate boundary conditions were applied. The computed performance curve shows good agreement with the results of Diener et al. (2016), with a $0,3 \%$ difference in $P R_{(01-02)}$ at design point and $0,16 \%$ difference in $m_{\text {choke }}$. The aerodynamic numerical setup was therefore accepted as sufficiently reliable for use in the subsequent optimization process. 


\section{Chapter 6}

\section{Structural Numerical Setup}

\subsection{Computation overview}

A computational solid mechanics (CSM) workflow chain consisting of the Finite element method was included for determining the structural feasibility of designs. Feasibility with respect to the impeller maximum von Mises stress, blade-shroud interference (deflection), and resonance frequencies, was assessed. An impeller geometry was exported during the parametric model generation stage of the workflow, before being imported to a 4-step meshing process with subsequent solving of both a linear static analysis and a modal analysis. Postprocessing was performed with response values exported for predefined locations on the impeller surface.

\subsection{Meshing setup}

CSM meshing was performed as a 4-step process with an initial mixed element mesh built in HEXPRESS ${ }^{\mathrm{TM}} /$ Hybrid. The mesh consisted of hexahedral elements in the blade volume and the remaining solid body (including fillets) comprising of tetrahedral elements. The blade volume was meshed with 3 cells placed in the width of the blade to better solve the suctionto-pressure side stress distribution. This mesh was then converted using HEXPRESS ${ }^{\mathrm{TM}}$ /Hybrid-Datamapper to a fully tetrahedral element mesh by splitting any present hexahedral elements. This was done since the CalculiX (v2.14) solver did not support meshes comprised of varying element types and meshing the blade with 3 cells in the blade width was not possible with only one type of element. The resulting tetrahedral mesh was converted to a ten-node tetrahedral mesh (C3D10), due to the corresponding second order interpolation associated with this element generally producing more accurate results in comparison with the four-node tetrahedral (C3D4) element (Dhondt, 2014). The mesh format was then converted with a Python script from '*.msh' to '*.inp' type for compatibility with the CalculiX solver. 


\subsection{Solver setup}

\subsubsection{Models and assumptions}

Two successive cases were computed by the CSM solver with a linear static computation first performed, followed by a modal computation which included stress and loading computed in the linear static case. The linear static computation inherently assumes that the material behaves isotropically and no plastic deformation occurs. No aerodynamic loading was applied to the CSM case and thus blade flutter was not investigated.

Thermal expansion effects were included into the workflow by applying an approximate temperature distribution to each mesh node, using a Python script developed during the GAMMA research project (Friendship Systems, 2019). Convective heat transfer theory was employed to assume that a Bessel Function of the first-kind and zero-order could be used to model an approximate temperature distribution through the impeller, given three temperatures at the impeller tip and both bore ends (Pletke and Murphy, 1953).

\subsubsection{Boundary conditions}

A body force was applied to each finite element as a centrifugal force computed as follows:

$$
d F=d V \rho \omega^{2} r
$$

at a design speed of 73000 RPM, where $\rho$ is the density of the 7075-T651 aluminium alloy (as required by the CSIR) with properties indicated in Table 6.1.

Table 6.1: 7075-T651 Aluminium material properties with values obtained from ASM Inc. (2019)

\begin{tabular}{llll}
\hline $\begin{array}{l}\text { Density } \\
{\left[\mathrm{kg} / \mathrm{m}^{3}\right]}\end{array}$ & $\begin{array}{l}\text { Elasticity modulus } \\
{[\mathrm{GPa}]}\end{array}$ & $\begin{array}{l}\text { Poissant coef. } \\
{[-]}\end{array}$ & $\begin{array}{l}\text { Thermal expansion coef. } \\
{\left[10^{-6}{ }^{\circ} \mathrm{C}^{-1}\right]}\end{array}$ \\
\hline 2810 & 71.7 & 0.33 & 25.2
\end{tabular}

Cyclic symmetry was applied by meshing and computing only one main and splitter blade section with a periodic connection applied between section faces. Both periodic faces were established by meshing with matching nodes before setting the displacement of each node on one face as equal to its partner node on the other periodic face. 
The impeller was designed to be attached to the shaft by 'bolting' between a nut located at the inlet bulb and a shoulder located at disk backface. To implement this fixation, each node on the disk backface near the bore was constrained from displacement in both tangential and axial directions as shown in Figure 6.1.

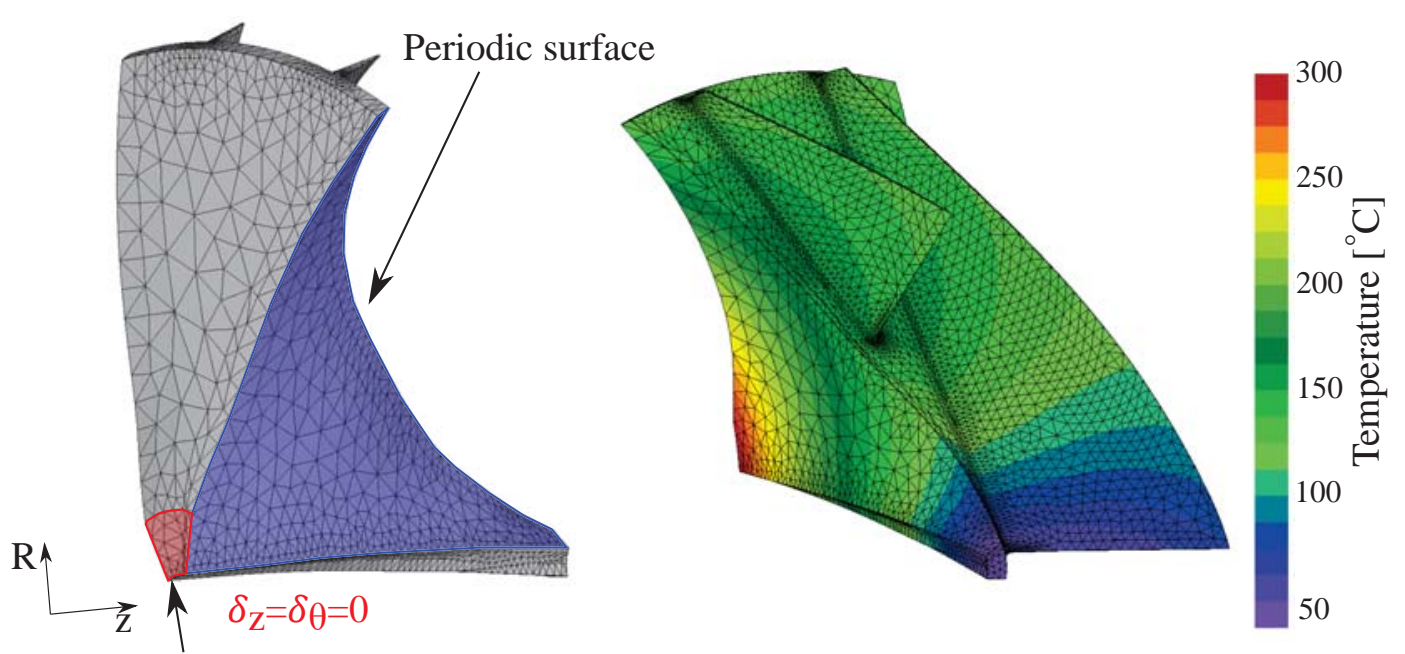

Disk backface (bore side)

Figure 6.1: CSM boundary conditions (left) and applied temperature distribution (right)

For the temperature distribution script, three temperatures for the impeller tip and both bore ends were assumed. The temperature on the face located at the inlet side of the bore was assumed to be atmospheric at $25{ }^{\circ} \mathrm{C}$, while the impeller tip temperature was assumed to be equal to the air temperature at $130{ }^{\circ} \mathrm{C}$ in this region (obtained from the CFD computation). The disk backface near the bore was assumed to be at $300{ }^{\circ} \mathrm{C}$ according to typical observed temperatures in this region due to heat conduction from the combustion chamber (Bonjin et al., 2015).

\subsubsection{Post-processing}

A Python script was implemented to obtain all responses related to the CSM results. The eigenvalues were obtained from the '*.out' summary file created by CalculiX, while all remaining responses were obtained from the '*. frd' nodal results file. 


\section{Stress analysis}

Von Mises stress, $\sigma_{V M}$, is expressed in terms of the three principle stresses ( $x-y-z$ coordinate system) of any finite element as,

$$
\sigma_{V M}=\sqrt{0,5\left(\left(\sigma_{x}-\sigma_{y}\right)^{2}+\left(\sigma_{x}-\sigma_{z}\right)^{2}+\left(\sigma_{y}-\sigma_{z}\right)^{2}\right)}
$$

and is used to determine the possibility of yielding in the material (Ilyushin and Lensky, 1967). The maximum nodal von Mises stress was obtained for the fillet, pressure side, and suction side of both the main and splitter blade as well as the disk backface and bore face. Each face was queried individually rather than a single global maximum response, in order to improve the optimizer's prediction of maximum stress for each stress region independently for a specific design.

\section{Displacement analysis}

It was observed that blade-shroud interference was most likely to occur at the impeller trailing edge due to disk backface deformation. The maximum blade nodal displacement in the $z$-direction was therefore obtained at the blade trailing edge tip (see Figure 6.2). Blade tip radial displacement was also investigated but found to be acceptable (less that $0,05 \mathrm{~mm}$ ) in comparison to the tip gap size for all assessed designs.

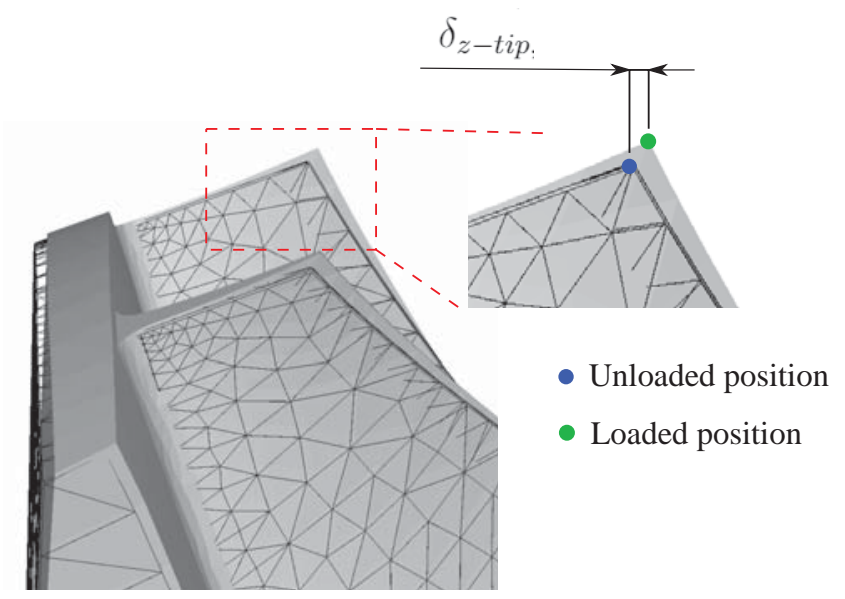

Figure 6.2: Impeller displacement

\section{Resonance analysis}

The first 6 eigenvalues, $\lambda_{i}$, were obtained from the solver output file ('*.dat') and natural frequencies, $\omega_{i}$, were subsequently obtained by

$$
\omega_{i}=\sqrt{-\lambda_{i}}, \mathrm{i}=1,2, . .6
$$

for direct comparison against engine speed. 


\section{Chapter 7}

\section{Results}

\subsection{Optimization strategy assessment}

\subsubsection{Parameter scattering method comparison}

Two databases were generated for training of the SM used in OPTI1 and OPTI2. The first database (DB1) was developed by appending three database computations using the LHS, LCVT, and CVT parameter scattering methods, while the second database (DB2) was computed using only the LCVT method.

\section{DB1}

DB1 was comprised of three smaller databases for the purpose of comparing scattering methods. Figure 7.1 shows the parameter scattering and success rate comparison of the three scattering methods by comparing design space filling of the inlet radius and meridional angle parameters. It can be seen that the CVT method places parameters away from the extremes (with respect to parameter bounds), while the LHS and LCVT methods attempt to cover the entire design space. The overall successful convergence rate of the CVT $(31,4 \%)$ database was much higher than with the LHS $(12,5 \%)$ and LCVT $(15,2 \%)$ databases (Table E.1). This difference was primarily attributed to two reasons:

- Strong parameters shifting the performance curve mass flow so far that either the stall or the design point mass flow imposed boundary condition could not be achieved. This can be seen by the large percentage of failed designs if R_IN $<42,8 \mathrm{~mm}$.

- The large number of free parameters resulting in geometrically unfeasible geometries when multiple parameters were located near their respective bounds, as seen in the LHS and LCVT databases. 

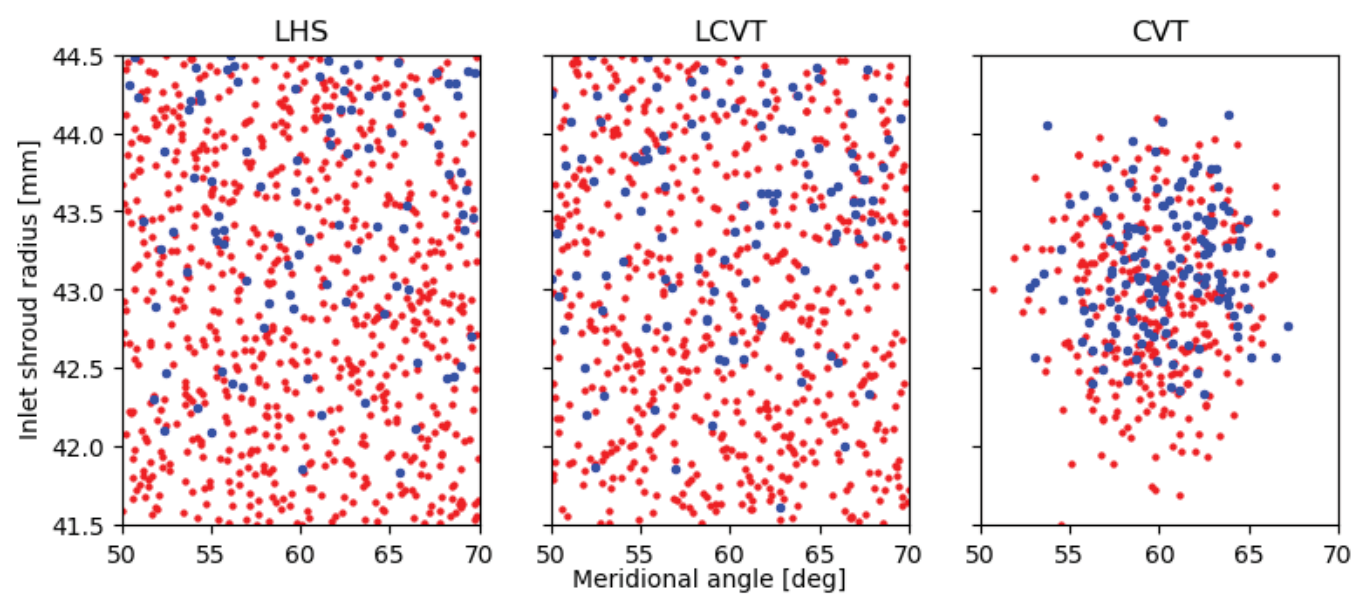

- Failed designs

- Converged designs

Figure 7.1: Parameter scattering comparison of three database populating methods used for DB1

\section{DB2}

DB2 achieved a 100\% success rate due to the considerably narrower explored design space, achieved by freezing most strong free parameters and reducing the remaining parameter bounds. Most meridional parameters such as impeller inlet and outlet shroud radius, impeller and diffuser axial length, and impeller meridional discharge angle were found to have a strong influence and subsequently frozen for DB2.

\subsubsection{Design success filtering}

Once DB1 was populated, the '*.plan' training file was filtered by removing certain design computations, or modifying their success flag for better subsequent training of the SM in OPTI1 as described below.

\section{Removed designs}

All designs that failed due to meshing issues were removed since these would steer the optimizer away from what could be a feasible design space. CFD meshing fails were caused by either a large change in splitter leading edge position and angle, or an aggressive impeller backsweep, which resulted in negative cells being present in the impeller tip region. CSM meshing fails were more likely than CFD meshing failures and were caused by poor triangulation of the splitter leading edge and fillet. 


\section{Modified success flag of designs}

Designs that did not satisfy the convergence criteria, specified in subsection 5.3.3, had their success flag set to ' 0 '. This was done to indicate a failed design with responses that should not be used for SM training, but should only be included in the SM feasibility region prediction. Of the 2006 total designs attempted, $55 \%$ crashed or did not attain a maximum residual of at least $1 \times 10^{-3}$ at one of the operating points. A further $27 \%$ of the designs were filtered out by modifying the success flag to ' 0 '. Finally, $18 \%$ of the initial designs remained as fully converged with reliable response results. This was expected with the operating mass flow rate range shifting dramatically with such major variations in geometry. Previous studies with smaller parameter variations, such as Diener et al. (2016) and Kock (2017), experienced significantly higher convergence rates.

\subsection{Design performance improvement}

A performance comparison of the baseline against the best OPTI1 and OPTI2 designs is shown in Figure 7.2. Major performance differences of each optimized design are stated in this section, while the geometry changes responsible for the performance differences of each optimization step are discussed in section 7.3 .

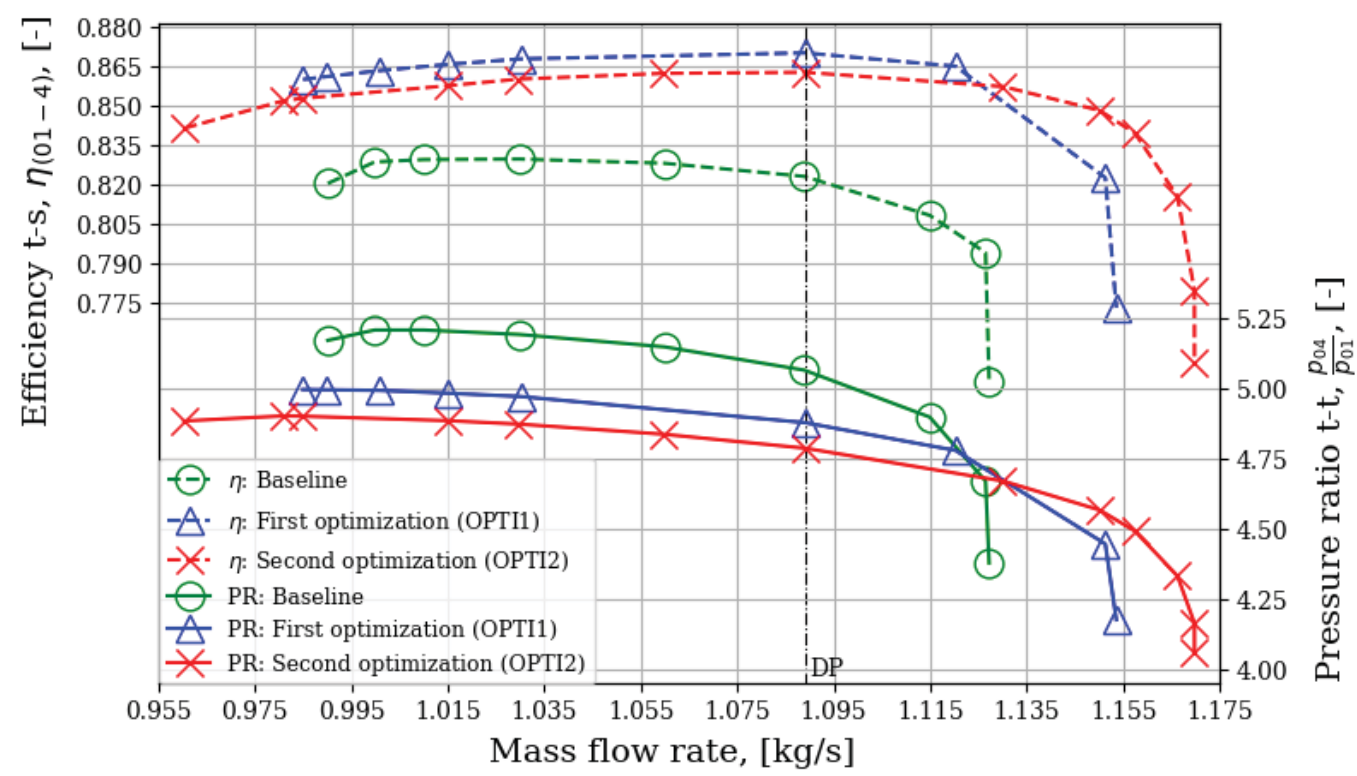

Figure 7.2: Design improvement (performance curves) 
The baseline design was accepted by the CSIR with the aim of obtaining a structurally feasible design of improved stall margin, $\Delta m_{\text {stall }}$, and choke margin, $\Delta m_{\text {choke }}$, as well as improved $\eta_{(01-4), D P}$. The optimizer was stopped when no notable improvement was observed across 50 design iterations (see Figure E.5). Design OPTI1 achieved considerable improvements of $\Delta m_{\text {choke }}$ from $3,5 \%$ to $5,9 \%$ and $\eta_{(01-4), D P}$ from $82 \%$ to $86,6 \%$, while $\Delta m_{\text {stall }}$ only increased by $1,5 \%$. The large increase of $\Delta m_{\text {choke }}$ was achieved through an increase in diffuser throat area while $\eta_{(01-4), D P}$ was mainly improved by reducing diffuser separation losses. The considerable increase in $\eta_{(01-4), D P}$ allowed the optimizer to decrease $P R_{(01-04)}$ through a reduction in impeller total pressure rise while still satisfying the $P R_{(01-4), D P}$ requirement.

OPTI2 was made structurally feasible by an increase in hub blade thicknesses and changes to the impeller undercut. Furthermore, $\Delta m_{\text {choke }}$ and $\Delta m_{\text {stall }}$ were increased to $7,4 \%$ and $11,8 \%$, respectively. This was achieved through a reduction in diffuser main blade number and an increase in splitter number (two per main blade). $\eta_{(01-4), D P}$ was decreased by $0,3 \%$ from that of OPTI1.

\subsection{Aerodynamic geometric feature influence}

This section describes how certain geometric features influence the measured responses by showing a statistical proof of correlation between parameter and response, before giving a physical explanation for the correlation.

\subsubsection{Geometric feature multi-parameter dependencies}

Most geometric features were explicitly controlled by a single parameter; however, some features were controlled by multiple design parameters due to the parametric model setup. This resulted in a 'trickle-down' of influence coefficients to multiple parameters controlling a single geometric feature. Most influential features with multi-parameter dependencies are discussed below.

\section{Trailing edge backsweep}

Blade backsweep was predominantly controlled by the second-to-last Bézier curve parameter, H3_DELTA, but was also affected by any parameter influencing chord length for each respective blade row. This dependency was due to the parametric model method in which camber curve is defined, specifically by the Bézier control point spacing. An increase in axial length increases the physical distance between camber Bézier control points due to the constant geometric ratio spacing applied in the parametric model, as shown in Figure 7.3a. This increase in spacing decreases camber backsweep (and incidence) angle as shown by the corresponding blade angles in Figure 7.3b. 


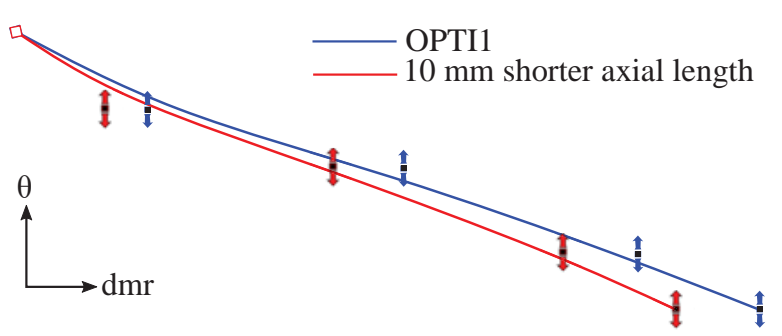

(a) Bézier control points

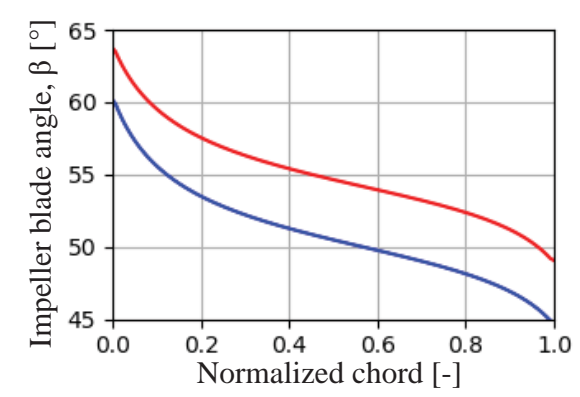

(b) Tip blade angle

Figure 7.3: Impeller length influence on camber angle

\section{Impeller shroud curvature}

The endwall curvature of the hub and shroud of either blade row were dependent on multiple parameters for their respective Bézier definitions. It was found that the impeller shroud controlling parameters significantly influenced stage performance (discussed further in subsection 7.3.2). The most influential parameters associated with impeller shroud curvature were: the third shroud Bézier point parameter (D_S3), impeller meridional discharge angle $(\alpha)$, and impeller axial length (Z_ITE).

\subsubsection{Parameter influence}

The influence of each design parameter, with respect to each important response quantity, was assessed by determining the Pearson correlation coeffcient, $r_{p}$, which quantifies the linear correlation between two variables. A map was constructed from design space information obtained in DB1 to compare the parameters with most significant influence on all responses present in the optimizer objectives or constraints. Parameters with weak influence $\left(\left|r_{p}\right|<0,2\right)$ for all responses were omitted from the correlation map shown in Figure 7.4. The parameters are grouped by their geometric feature control of passage radius and height, leading edge sweep, endwall curvature, passage axial length, and camber curve. It can be seen that the passage radius and height parameters are the strongest in most aspects of compressor performance. Specific geometric features are further discussed below. 


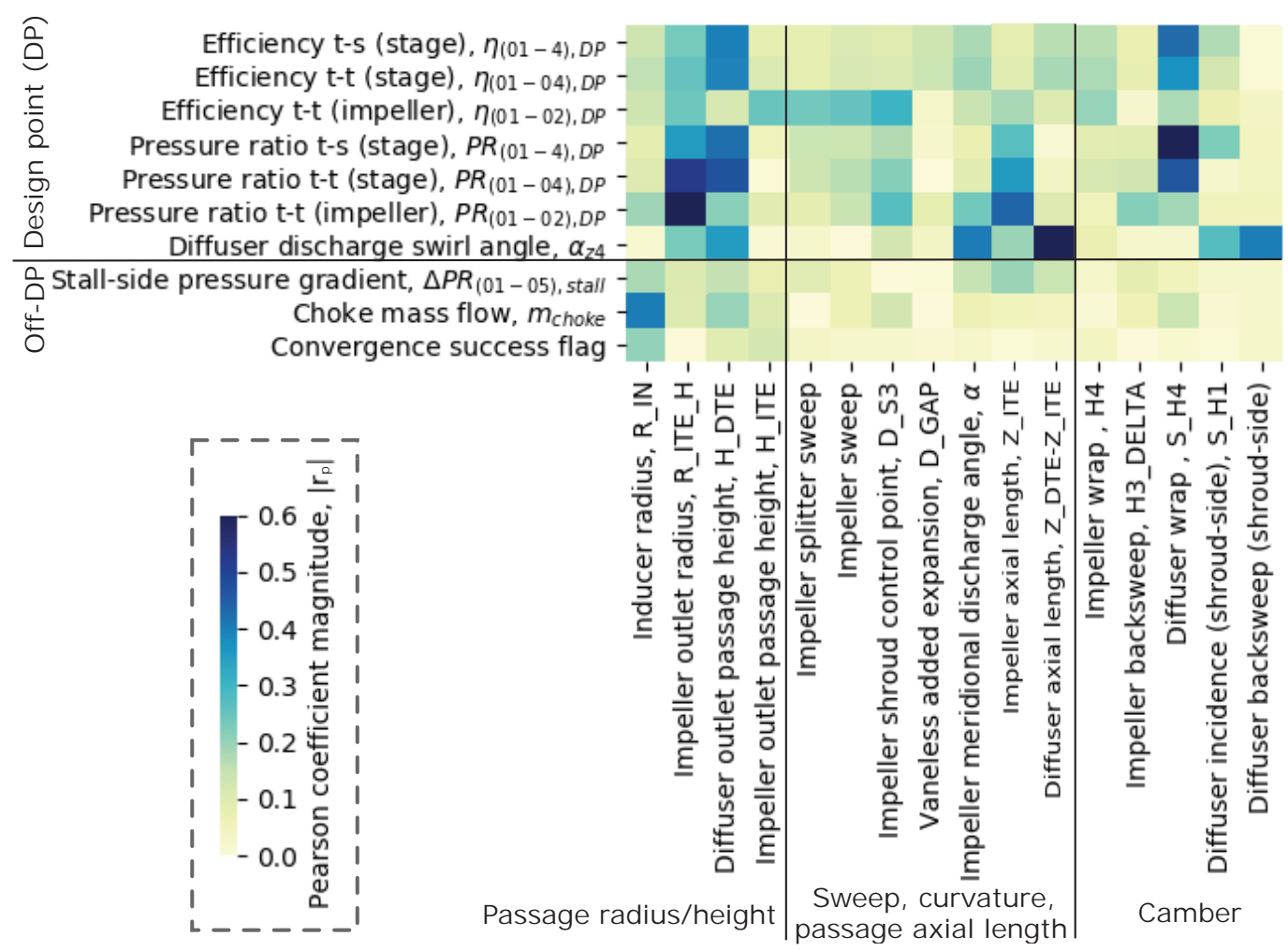

Figure 7.4: Aerodynamic Pearson correlation coefficient map

\section{Inducer radius}

Inducer radius presented a strong influence of all off-DP responses related to operating curve mass flow range, with a $r_{p}=0,18$ and $r_{p}=0,4$ with respect to $\Delta P R_{(01-05), \text { stall }}$ and $m_{\text {choke }}$, respectively. The strong influence on $m_{\text {choke }}$ resulted in many designs reaching choke in the inducer. This resulted in no convergence at design point if $\Delta m_{\text {choke }}$ was within $1 \%$ of $m_{D P}$ or if $m_{\text {choke }}$ $<m_{D P}$. This is illustrated in Figure 7.5, which shows the convergence success rate with respect to inducer radius, which is divided into seven equal intervals between the upper and lower parameter bounds. It can be seen that many designs failed to converge with $\mathrm{R} \_I N<42,8 \mathrm{~mm}$, which indicates an incorrect choice of the lower bound value. Furthermore, the optimized design has a R_IN $=44,45 \mathrm{~mm}$, which indicates the upper parameter bound to also have been incorrectly set too low for OPTI1. Parameter bounds were, however, not subsequently increased due to the decision to freeze all meridional parameters for OPTI2. 


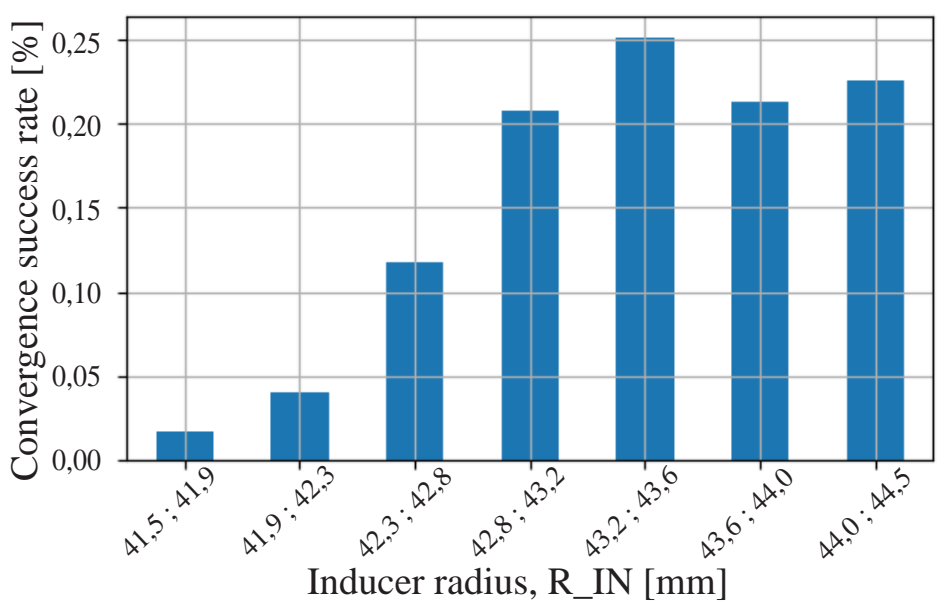

Figure 7.5: Convergence success rate with respect to inducer radius

\section{Impeller main blade sweep}

Impeller main blade forward sweep was increased from $6,6^{\circ}$ to $11^{\circ}$ in OPTI1 in order to increase the blade chord at the shroud. The increase of forward sweep reduced impeller tip shock severity which subsequently reduced separation at the impeller shroud as shown in Figure 7.6. Impeller sweep had a moderate influence on $\eta_{(01-4), D P}$ with $r_{p}=0,26$. Furthermore, the reduction in impeller shroud separation significantly reduced the impeller discharge tangential velocity component near the shroud. This subsequently reduced losses associated with high diffuser incidence at the shroud.

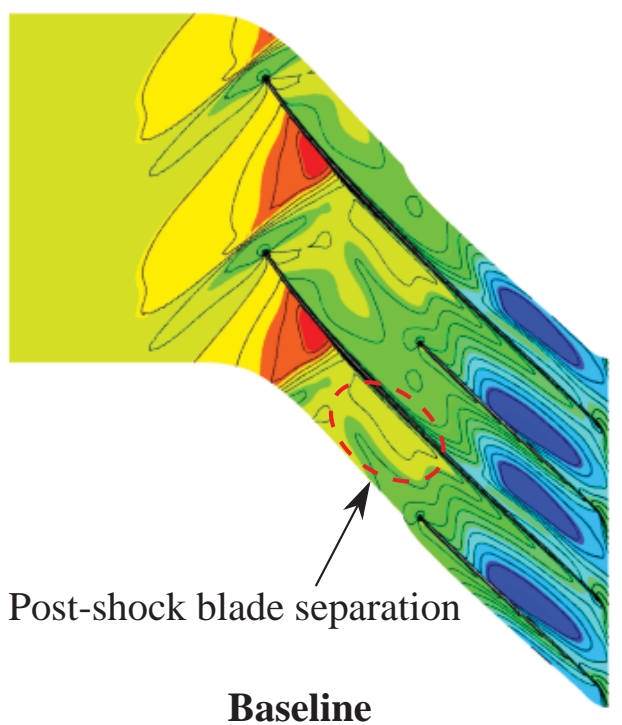

Baseline

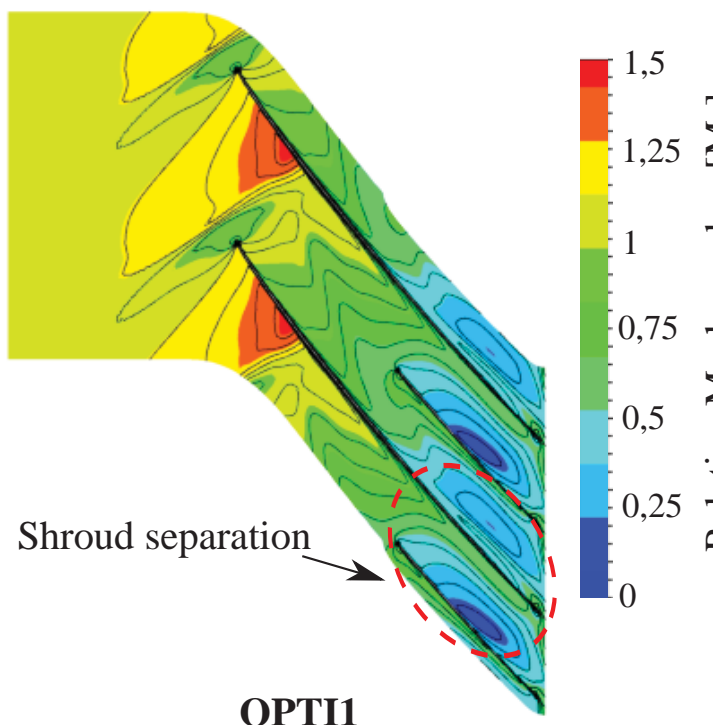

OPTI1

Figure 7.6: Impeller relative Mach number at 95\% span 


\section{Impeller backsweep}

To further decrease shock losses associated with high diffuser incidence, the tangential velocity component entering the diffuser was reduced by an increase in impeller backsweep by a mean value of $6,5^{\circ}$ (Table 7.1 ) from baseline to OPTI2. The increase in backsweep decreased total pressure rise across the impeller; however, the improvement in $\eta_{(01-4), D P}$ allows the design to maintain a satisfactory $P R_{(01-4), D P}$.

It is expected that mixed flow impellers of lower $\alpha_{z 2}$ will require a larger spanwise difference in backsweep angle if the trailing edge does not terminate at constant radius (such as investigated in this thesis). This is due to the spanwise difference in trailing edge tangential velocity resulting from a difference in hub and shroud radii, where $\frac{U_{2 s}}{U_{2 h}}=\frac{r_{2 s}}{r_{2 h}}$.

Table 7.1: Blade leading and trailing edge angles

\begin{tabular}{lllll}
\hline \multirow{2}{*}{ Design } & $\begin{array}{l}\text { Impeller LE } \\
\left.{ }^{\circ}(\text { hub }) /^{\circ} \text { (shroud) }\right]\end{array}$ & Impeller TE & Diffuser LE & Diffuser TE \\
\hline Baseline & $26,5 / 61,3$ & $14,5 / 43,3$ & $71 / 65,9$ & $20 / 10$ \\
OPTI1 & $36,6 / 60,7$ & $23,8 / 44,8$ & $72,1 / 64,8$ & $32 / 23$ \\
OPTI2 & $36,3 / 60,1$ & $25,3 / 45,8$ & $72,8 / 66,3$ & $28 / 10$ \\
\hline
\end{tabular}

\section{Impeller meridional discharge angle}

The impeller meridional exit angle, $\alpha_{z 2}$, was increased from $60^{\circ}$ to $71,6^{\circ}$ as shown in Figure 7.7 (left). $\quad \alpha_{z 2}$ was found to affect many important blade and passage geometric features. Endwall curvature was increased with an increase in $\alpha_{z 2}$, which is subsequently expected to increase impeller shroud separation losses through the impeller; however, the weak correlation of $r_{p}=$ $-0,15$ for $\eta_{(01-02), D P}$ cannot prove this hypothesis. The chord length of both blade rows increases with a decrease in $\alpha_{z 2}$ due to the longer passage length required to reach the diffuser outlet shroud radius. The increase in chord length subsequently increases the Bézier spacing as described in subsection 7.3.1. This decreases $\alpha_{z 4}\left(r_{p}=0,41\right)$ and decreases impeller backsweep which subsequently increases $P R_{(01-02), D P}\left(r_{p}=-0,24\right)$. The diffuser flow passage area increase rate is higher for designs with a higher $\alpha_{z 2}$ due to the more rapid increase in passage radius when compared to a design of lower $\alpha_{z 2}$. 


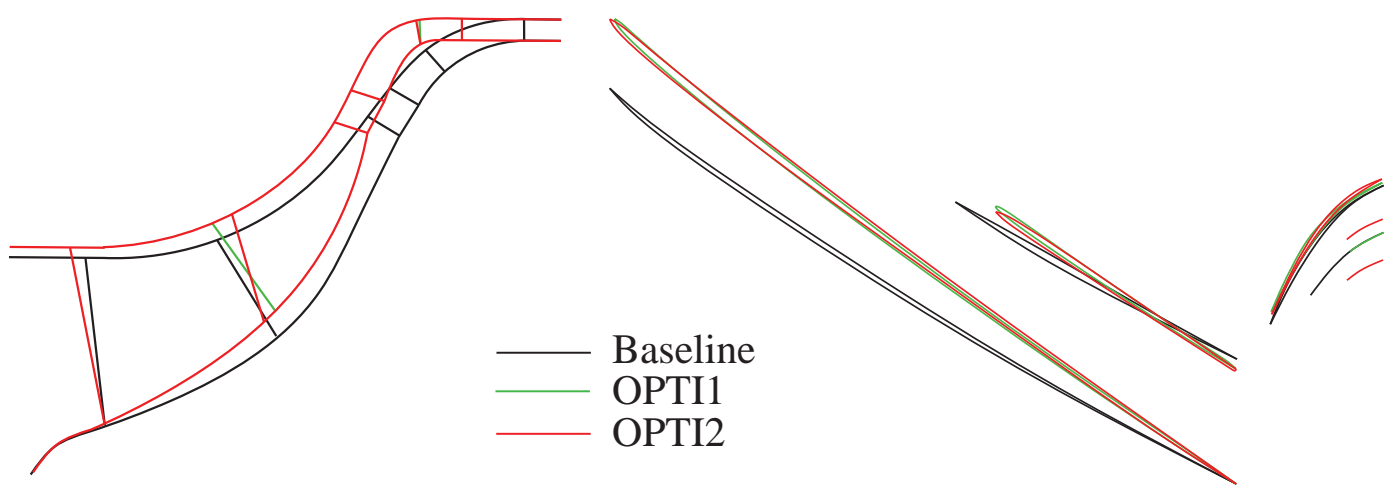

Figure 7.7: Best design meridional (left) and 50\% span B2B (right) comparison

\section{Impeller and diffuser axial length}

Blade row axial length was found to affect similar geometric features to $\alpha_{z 2}$, namely: chord length, endwall surface area, and endwall curvature. Chord length, and thus backsweep of each blade row, was heavily influenced by row axial length as described above ( $\alpha_{z 2}$ effects). This is proven by the strong correlation with $P R_{(01-02), D P}\left(r_{p}=0,44\right)$ and $\alpha_{z 4}\left(r_{p}=-0,65\right)$ for impeller and diffuser length parameters, respectively. Endwall curvature is influenced by the axial length of each blade row due to the endwall length available to produce a smooth Bézier curve. An increase in axial length also increased endwall and blade surface areas resulting in higher viscous losses through the compressor.

\section{Vaneless gap added expansion}

The vaneless gap added expansion (hub side) assisted in flow diffusion and absolute Mach number reduction prior to the diffuser leading edge $\left(M_{a 3}\right)$. The reduction in $M_{a 3}$ subsequently reduced shock losses associated with transonic flow at the vaneless gap endwalls and diffuser leading edge. This was indicated by the slight correlation $\left(r_{p}=0,15\right)$ of $\eta_{(01-04), D P}$ with respect to W_GAP. Figure 7.8 shows a meridionally averaged near sonic flow of $M_{a}=0,97$ entering the diffuser at $75 \%$ spanwise height for the baseline design (left), while the OPTI2 design (right) shows a peak averaged inlet Mach number of $M_{a}=0,9$. The mixing out of spanwise flow differences caused by impeller shroud separation can also be observed in front of the diffuser leading edge. Additionally, the decision to place the added expansion on the hub side (due to separation at the shroud) was confirmed correct by the presence of shroud separation of varying magnitudes in the vaneless diffuser in all assessed designs. 


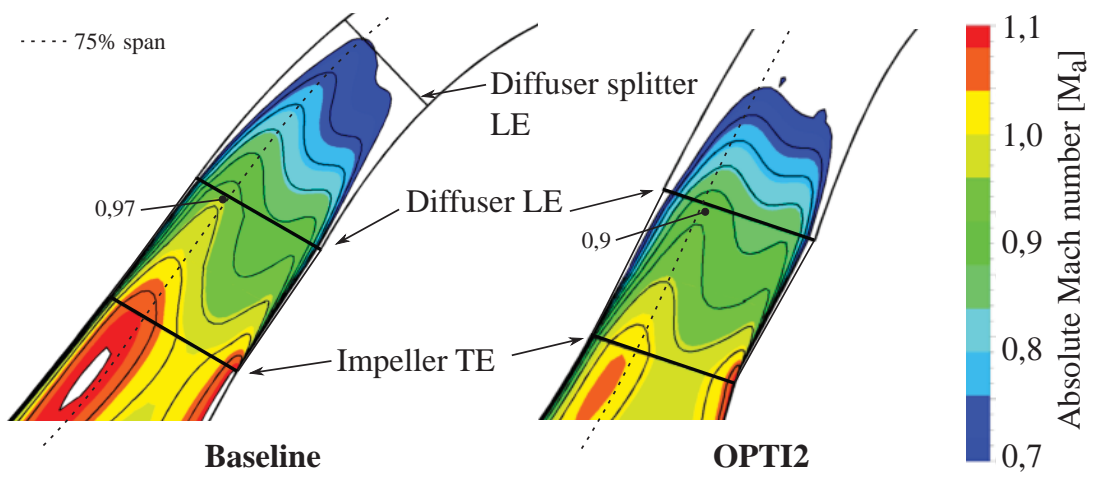

Figure 7.8: Vaneless gap diffusion increase

\section{Diffuser leading edge angle}

Diffuser leading edge blade angle was increased to $72,8^{\circ}$ at the hub and $66,3^{\circ}$ at the shroud in OPTI2. The spanwise difference in diffuser leading edge angle was attributed to the presence of diffuser hub separation (discussed in more detail below). A lower hub side diffuser incidence angle decreases blade loading and subsequently delays the onset of hub separation, while a high shroud side incidence was acceptable due to the low risk of separation at the diffuser shroud. The large tangential velocity component discharged from the impeller, due to the aforementioned impeller separation, did cause leading edge separation in the diffuser between $95 \%$ and $100 \%$ spanwise height.

\section{Diffuser splitter position}

Diffuser splitter leading edge position was moved from $40 \%$ to $70 \%$ main blade chord length in OPTI1, thus placing the splitter fully in the axial portion of the diffuser. The splitter thus functions primarily as a de-swirling vane rather than contributing to diffusion. Diffusion is mostly achieved in the first $50 \%$ of the diffuser, as shown in Figure 7.9, where $88 \%$ of diffuser static pressure rise occurs before the splitter leading edge.

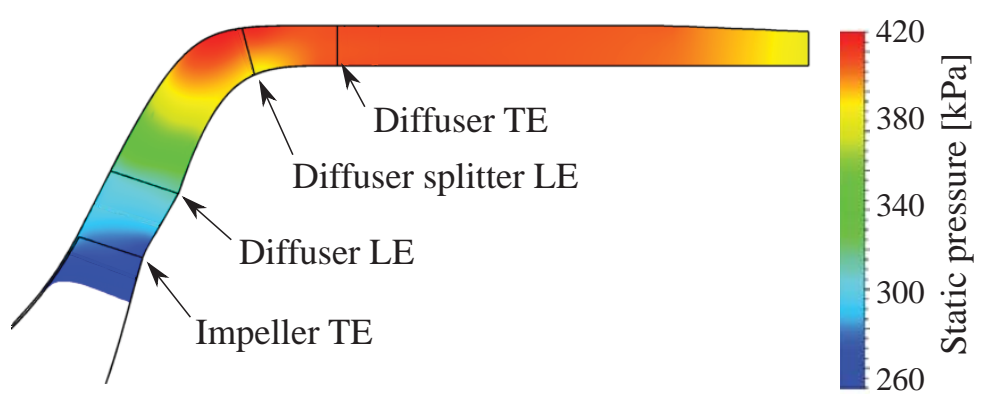

Figure 7.9: Static pressure distribution in the diffuser of OPTI1 


\section{Diffuser throat area}

The diffuser throat for all three designs was located between the diffuser main blade leading edge and the nearest adjacent blade surface. Figure 7.10 shows the absolute Mach number comparison for the three designs under the same outlet static boundary condition. Choke is observed in all designs, but with decreased shock magnitude in OPTI2. Diffuser throat area was found to heavily influence $m_{\text {choke }}$ as shown by the throat area increase of $12 \%$ from Baseline to OPTI1, and further $16 \%$ increase from OPTI1 to OPTI2 increasing $\Delta m_{\text {choke }}$ in each optimization. Parameters controlling diffuser outlet passage height and diffuser wrap angle had $m_{\text {choke }}$ correlation coefficients of $r_{p}=0,20$ and $r_{p}=-0,15$, respectively, as further discussed below.

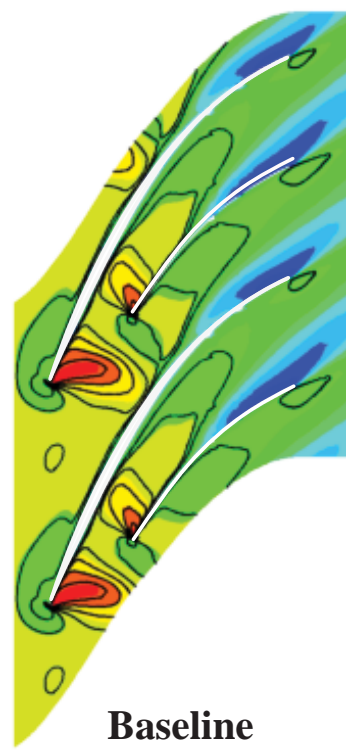

Baseline
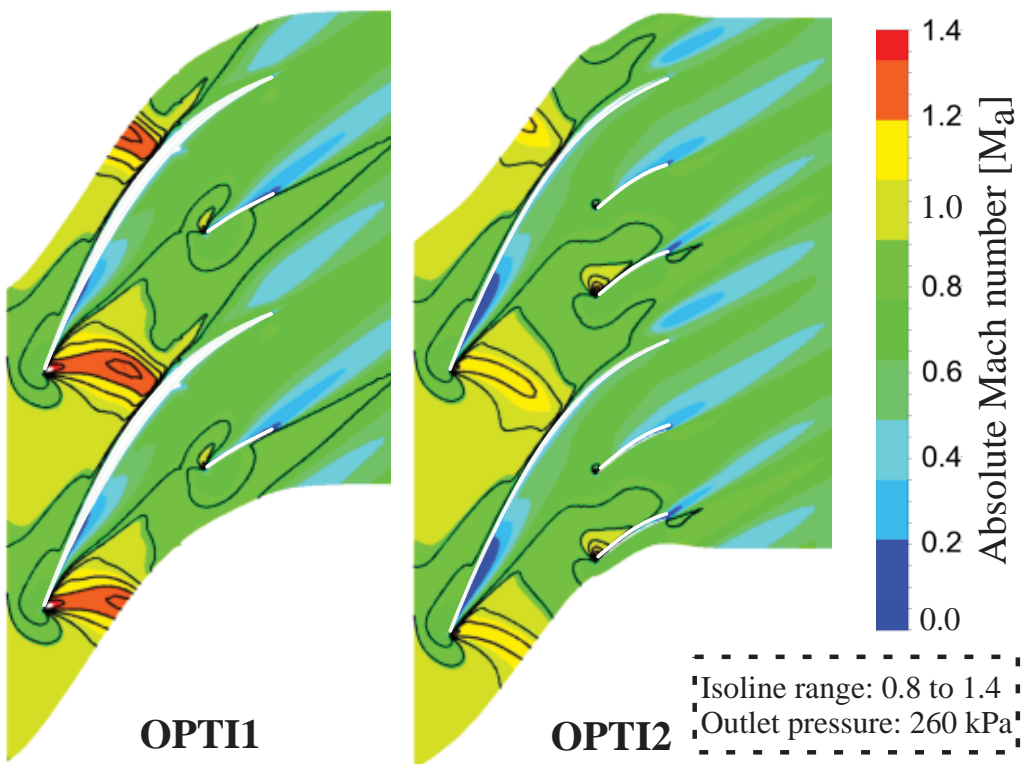

Figure 7.10: Diffuser choke absolute Mach number at 50\% span

\section{Diffuser outlet passage height}

Diffuser outlet passage height, H_DTE, was found to strongly influence stage total-to-total pressure ratio $\left(r_{p}=-0,47\right)$ and subsequently also stage total-tostatic pressure ratio $\left(r_{p}=-0,42\right)$ and accompanying stage efficiencies. Figure 7.11 shows the scatter of fully converged designs with accompanying linear regression curves with respect to $m_{\text {choke }}$ and $P R_{(01-4), D P}$. It should be noted that although the $m_{\text {choke }}$ correlation is not strong, the increase in maximum possible $m_{\text {choke }}$ (upper portion of the scatter) does increase significantly with an increase in H_DTE. This was attributed to an increase in diffuser throat area. A further discussion of the significant design point influence of H_DTE is continued below in conjunction with the diffuser wrap parameter. 


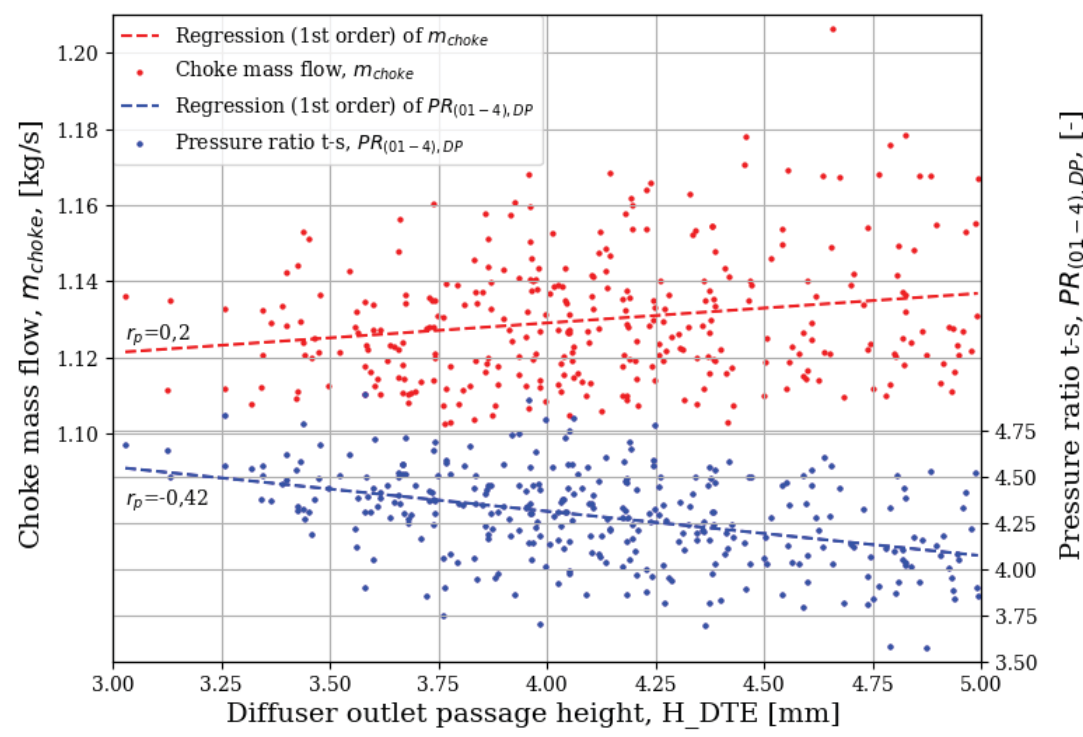

Figure 7.11: Diffuser outlet passage height regression

\section{Diffuser wrap}

The diffuser wrap parameter (trailing edge camber Bézier control point), S_H4, has a very strong influence on stage pressure ratio and efficiency, with the highest influence on $P R_{(01-4), D P}$ of $r_{p}=0,64$. The corresponding $1^{\text {st }}$ and $2^{\text {nd }}$ order regression curves of $\eta_{(01-4), D P}$ are shown in Figure 7.12 , with the general trend of increasing design point performance. The scatter does appear to reach a highest possible efficiency value at $\mathrm{S} \_\mathrm{H} 4=0,46$ with no further improvement to the upper parameter bound as shown by the $2^{\text {nd }}$ order regression curve. It should be noted that the root mean error (RME) of the $2^{\text {nd }}$ order curve is $5 \%$ greater than the $1^{\text {st }}$ order curve so it cannot be explicitly stated as a better scatter trend. Reasoning for the $2^{\text {nd }}$ order trend hypothesis is discussed below.

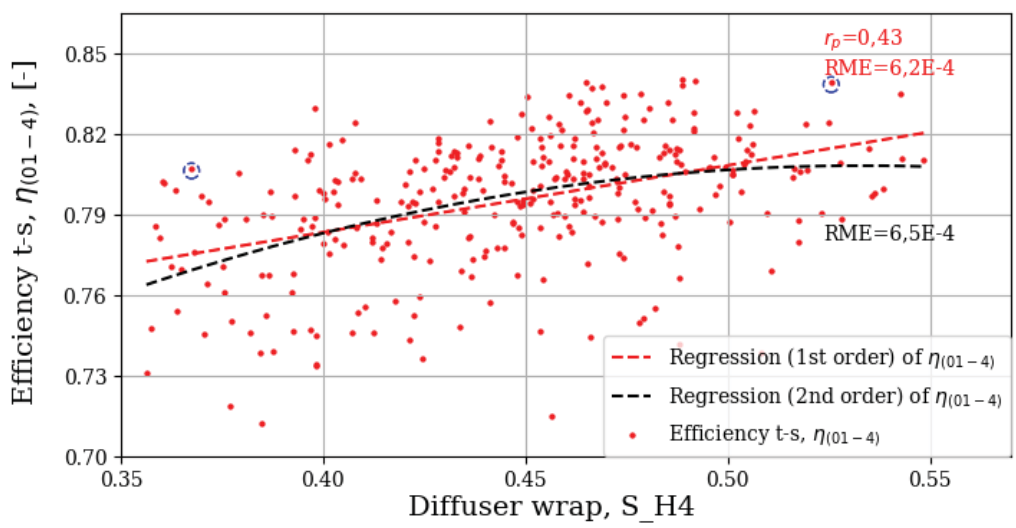

Figure 7.12: Diffuser wrap regression 
As shown above, parameters S_H4 and H_DTE exhibit similar influence trends on response values, which implies that a similar flow phenomenon is being controlled. Both parameters exhibit strong influence on $P R_{(01-04), D P}$, which is strongly affected by losses through the diffuser row. It was identified that diffuser hub separation occurs in all designs to varying magnitudes, such as shown for the final design in Figure 7.13 by the low velocity $\left(M_{a}<0,15\right)$ flow region. The separation initiates at the point of highest hub curvature in the radial-to-axial bend and near the main blade suction surface. Parameters S_H4 and H_DTE are controlling the separation magnitude and thus losses associated with the separated flow. Reasoning for this flow control is given below.

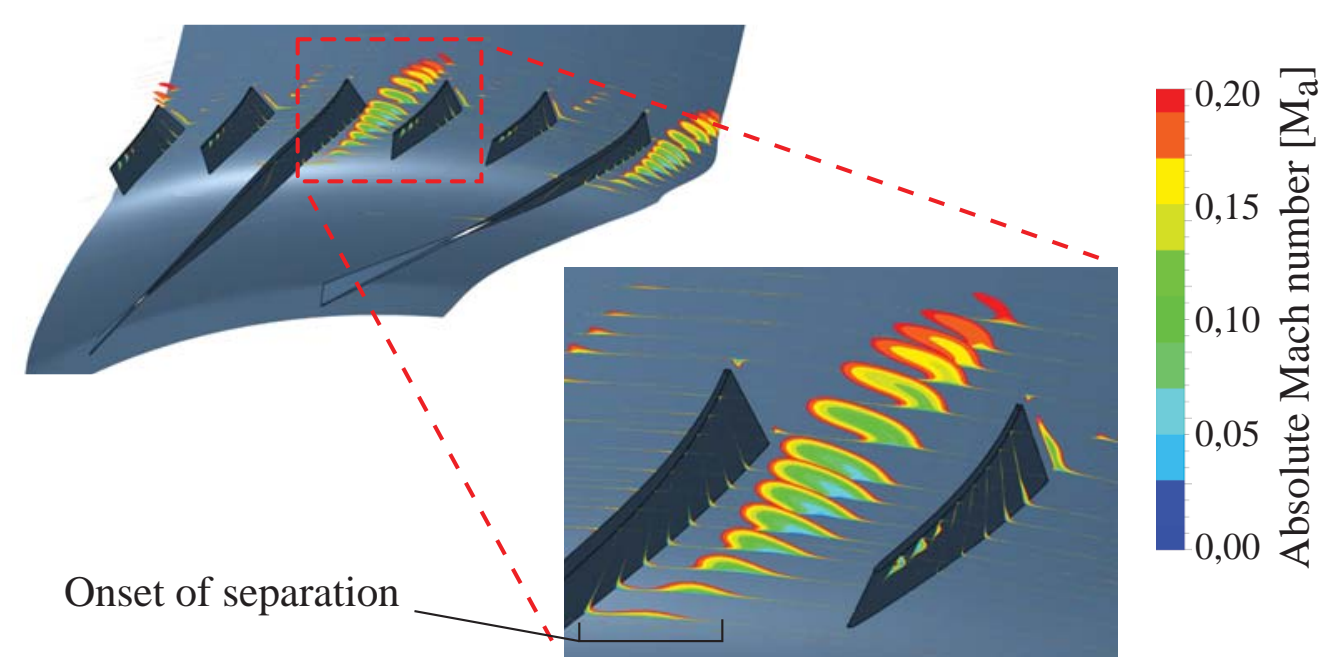

Figure 7.13: Diffuser hub separation of OPTI2

As mentioned in section 2.3, diffusing flow is prone to separation. The magnitude and onset of separation in a diffuser can be controlled by either the rate of increase in flow passage cross sectional area (controlled by passage height and radius), or a change in blade and endwall loading. From this theory, it can be interpreted that a reduction in H_DTE will decrease the rate of flow passage area increase and subsequently decrease separation losses. This theory agrees well with the result trends presented above. Similarly, an increase in S_H4 reduces flow passage area increase rate due to the longer chord length. Additionally, mean blade loading is decreased through the increase in chord length. 
Figure 7.14 compares the diffuser discharge Mach number of both optimized designs against two best $\eta_{(01-4), D P}$ DB1 designs of high and low diffuser wrap and similar H_DTE (circled in blue on Figure 7.12). Both DB1 designs exhibit fully separated flow from the main blade suction side at the trailing edge, but the low wrap design $\left(\mathrm{S} \_\mathrm{H} 4=0,37\right)$ experiences a larger magnitude of separation which contributes to blockage and higher peak Mach number of $M_{a}=0,68$. Both optimized designs have significantly smaller regions of separation, with OPTI1 achieving a $6 \% \eta_{(01-4), D P}$ increase over the 'low wrap' DB1 design. Both optimized designs show only hub separation while flow remains fully attached to the main blade suction side. Furthermore, the larger separated region of OPTI2 contributed to a $0,75 \% \eta_{(01-4), D P}$ decrease from OPTI1.

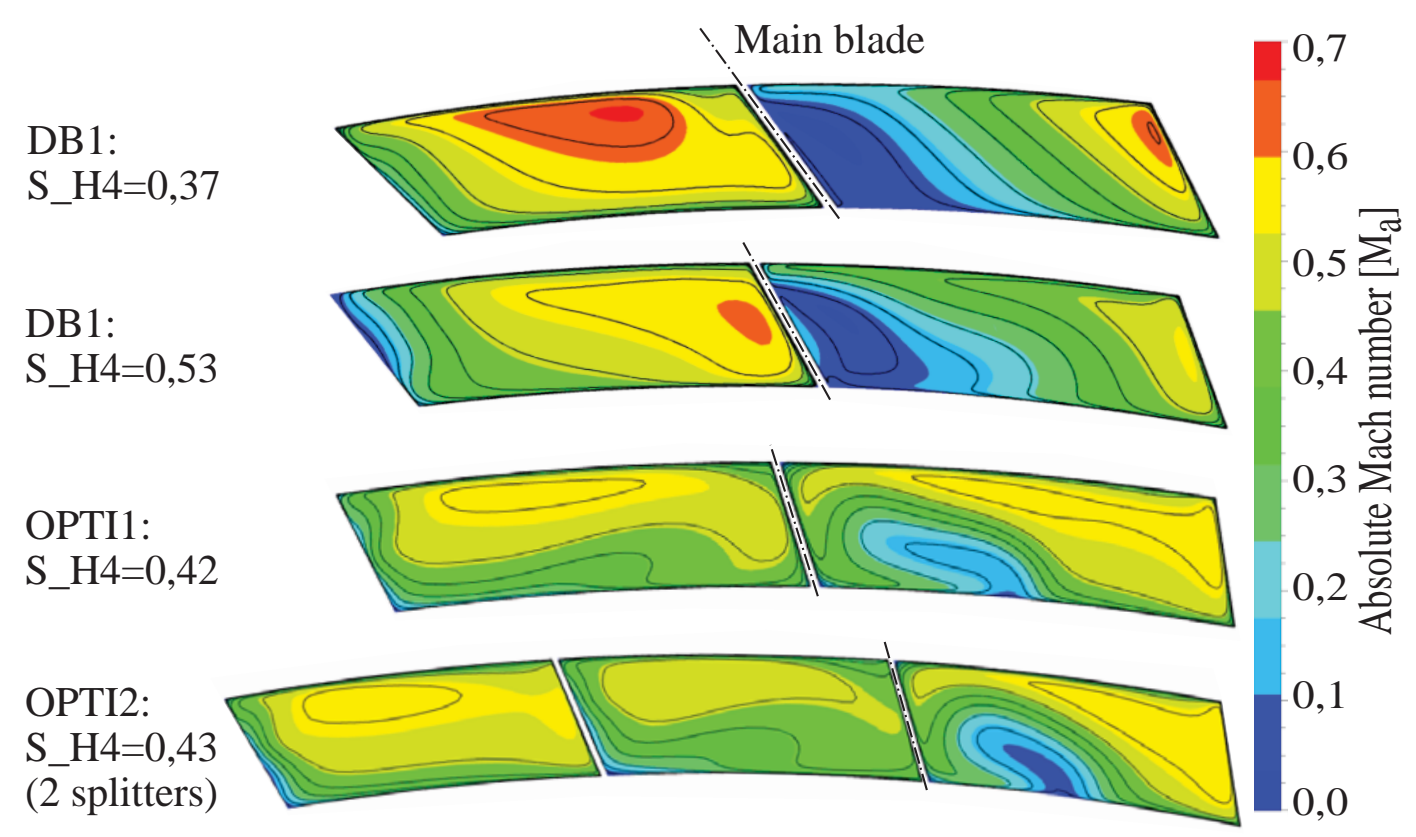

Figure 7.14: Diffuser discharge absolute Mach number comparison

\section{Diffuser main and splitter blade number}

For OPTI2, the number of main blades in the diffuser was reduced from 20 to 17 to increase $m_{\text {choke }}$, through a reduction of blockage contributed by main blade thickness. Furthermore, the diffuser splitter number per passage was doubled, to 2 splitters per main blade, to reduce blade loading and improve $\triangle P R_{(01-05), \text { stall }}$. The onset of compressor stall was suspected to originate at the diffuser hub (at the point of highest curvature) and progress to diffuser main blade suction side. Figure 7.15 shows a more constant splitter and main blade loading for OPTI2, from $80 \%$ main blade chord length at near stall conditions, which subsequently improves the stall side operating range for OPTI2. 


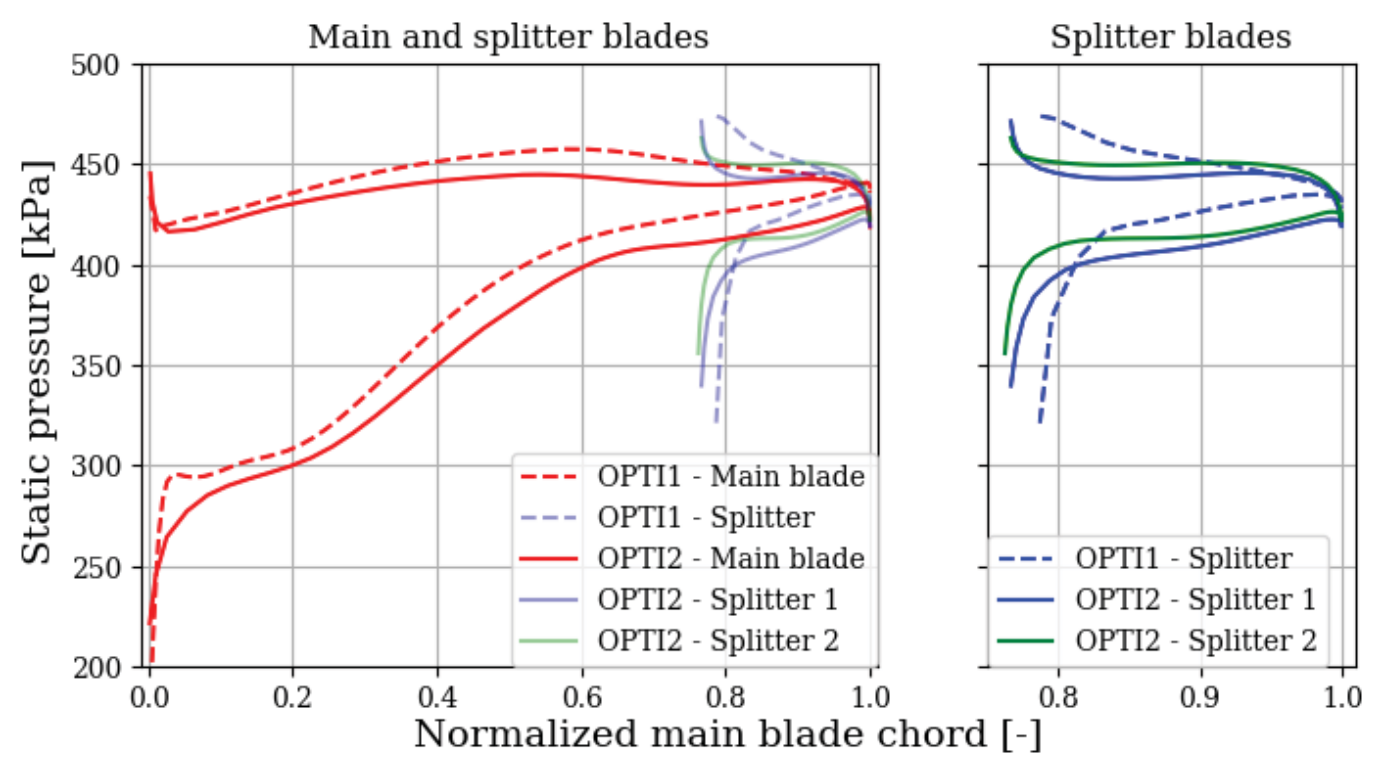

Figure 7.15: Diffuser blade loading at $50 \%$ span; near onset of stall $(m=0,985$ $\mathrm{kg} / \mathrm{s}$ )

\section{Diffuser camber thickness and backsweep}

The aforementioned differences in blade loading were achieved by moving the diffuser main blade mean maximum camber point from $57 \%$ to $72 \%$ chord length, while diffuser backsweep was reduced by $4^{\circ}$ to $28^{\circ}$ at the hub and significantly reduced by $13^{\circ}$ to $10^{\circ}$ at the shroud. Although there was an increase in operating range, the diffuser static pressure recovery coefficient, $C_{p}$, decreased from 0,613 to 0,584 , which contributed to the $0,3 \%$ decrease in $\eta_{(01-4)}$ near stall point. The decrease in $C_{p}$ could be attributed to increased viscous losses associated with the increase of blade surface area contributed by the second splitter.

\subsection{Structural geometric feature influence}

Figure 7.16 shows the parameters with significant influence $\left(r_{p}>0,3\right)$ on CSM responses. Responses are grouped into main and splitter blade $\sigma_{V M, \max }$, as well as bore $\sigma_{V M, \max }$ and $\delta_{z-t i p, \max }$, due to their respective similarities in parameter correlations. Impeller thickness, camber and lean parameters are grouped, as are the two body parameters, W_BORE and W_CUT. It should be noted that dark blue and red blocks indicate strong positive and negative correlations, respectively, while white blocks indicate no notable correlation. Certain geometric features are discussed below. 


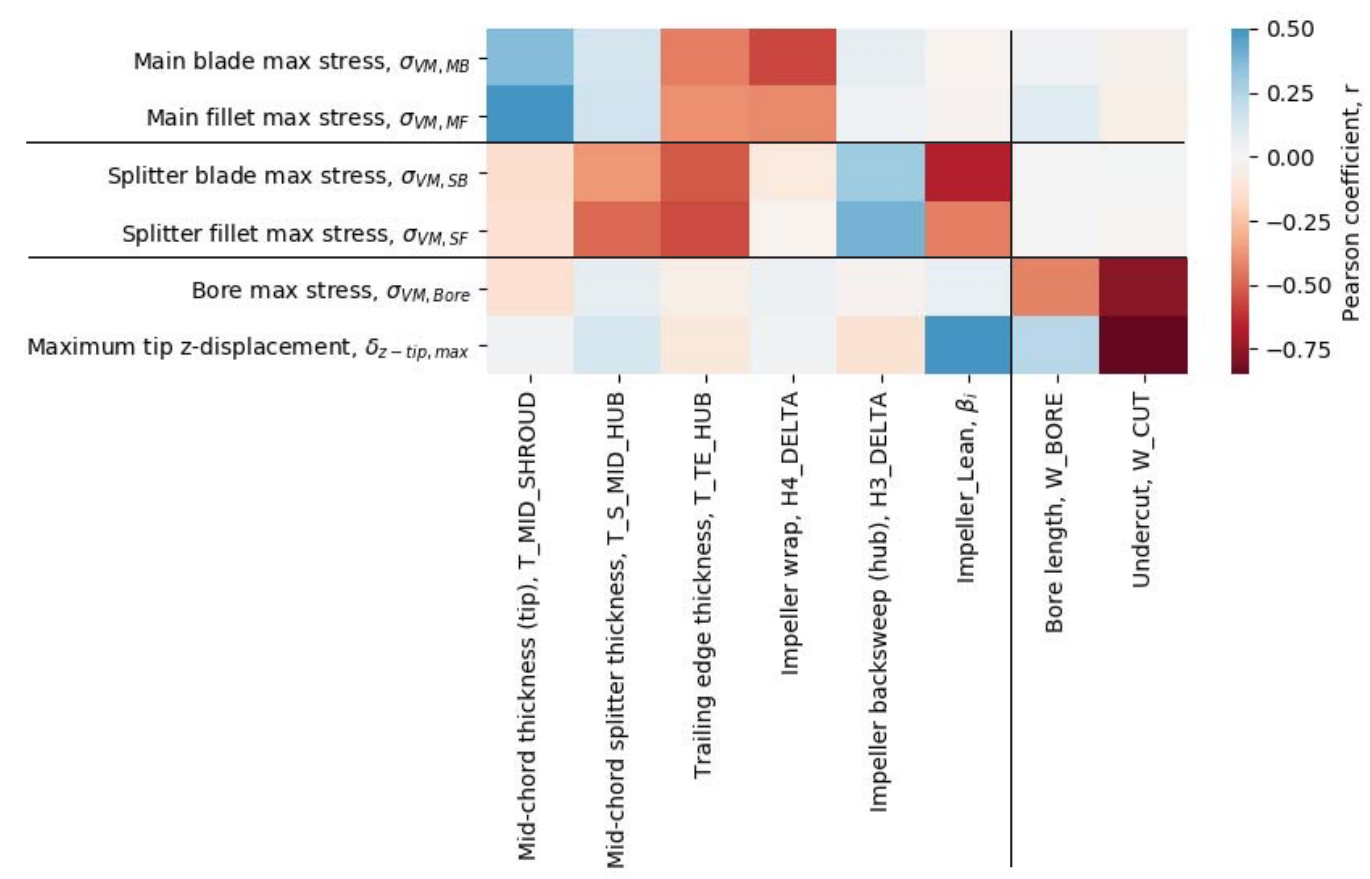

Figure 7.16: Structural Pearson correlation coefficient map

\section{Backface undercut}

The impeller backface undercut, W_CUT, has a very strong influence on both bore $\sigma_{V M, \max }\left(r_{p}=-0,76\right)$ and $\delta_{z-t i p, \max }\left(r_{p}=-0,87\right)$. W_CUT was reduced and inverted (to a positive value) to eliminate overhang of the disk backface as shown in Figure 7.17. An undercut was found to reduce bore stress due to the decreased body mass; however, the undercut also introduced higher trailing edge displacement in the negative $z$-direction, which leads to blade-shroud interference.

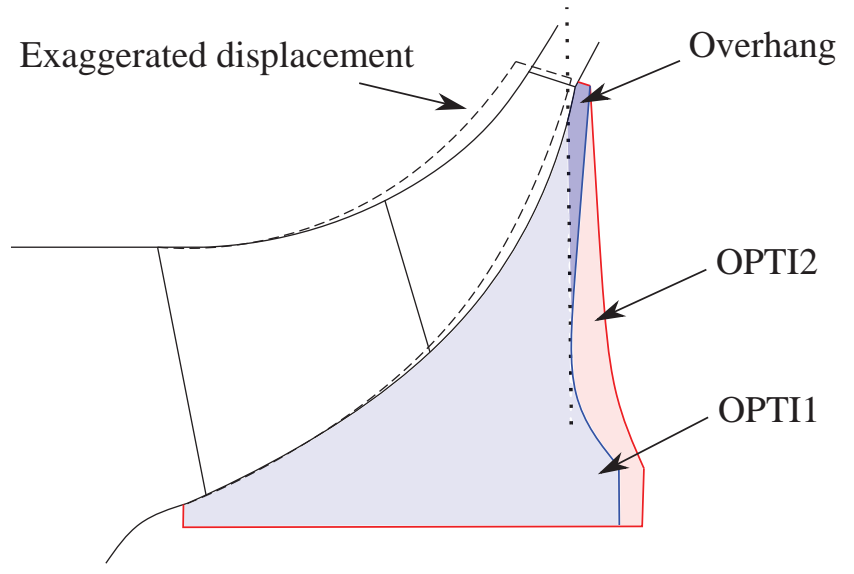

Figure 7.17: Impeller undercut and resulting overhang 


\section{Bore length}

The bore length parameter, W_BORE, was found to have a strong influence on $\sigma_{V M, \max }\left(r_{p}=-0,42\right)$, by controlling the bore surface area. An increase of bore length was thus used to decrease the higher bore stress associated with no undercut.

\section{Camber thickness}

An increase in the section 1 (hub side) camber thickness parameter of either main or splitter blade decreases the $\sigma_{V M, \max }$ in the respective blade and fillet due to the increased blade root cross-sectional area. Contrary to this, an increase in main blade tip camber thickness, T_MID_SHROUD, rapidly increases blade and fillet stress in the main blade due to the increase in blade mass under centrifugal loading.

\section{Blade lean}

Impeller lean, $\beta_{i}$, strongly affected splitter blade and fillet stresses near the trailing edge due to the transverse overhang control introduced by $\beta_{i}$. Impeller lean magnitude was therefore reduced from $-28^{\circ}$ to $-7^{\circ}$ during OPTI2 to reduce splitter blade and fillet stresses. Additionally, $\beta_{i}$ had a strong influence on $\delta_{z-t i p, \max }$ but a reason for this correlation was not determined.

\subsection{Pareto front}

An estimated Pareto surface was constructed using results from OPTI2 by creating a triangulated surface with edges comprising of best performing designs with respect to each of the independent optimization objectives $\left(\triangle P R_{(01-05), \text { stall }}\right.$, $\eta_{(01-4), D P}$, and $\left.m_{\text {choke }}\right)$. Subsequently, any designs that perform best at any weighting between the three objectives were added to the surface to create a Pareto dome as shown in Figure 7.18. 


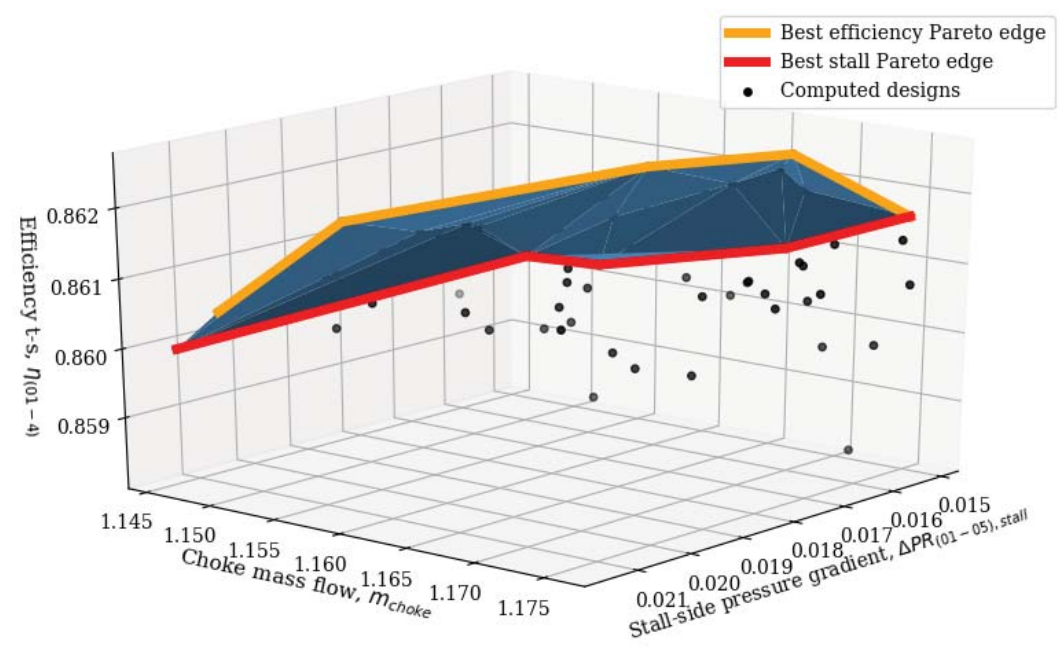

Figure 7.18: Pareto front 3-D dome

The 3-D Pareto dome was projected onto the $m_{\text {choke }}$ vs $\Delta P R_{(01-05), \text { stall }}$ plane, as shown in Figure 7.19 , with $\eta_{(01-4), D P}$ introduced as a filled contour plot. In this figure, the relation between $m_{\text {choke }}$ and $\Delta P R_{(01-05), \text { stall }}$ can be seen by the 'Best stall Pareto edge' curve. This curve represents the operating range shift of a designs' performance curve to either better choke performance at the cost of stall performance or vice versa. It should again be noted that $\triangle P R_{(01-05), \text { stall }}$ is only used to estimate the true stall mass flow rate based on an extrapolation from pressure gradient.

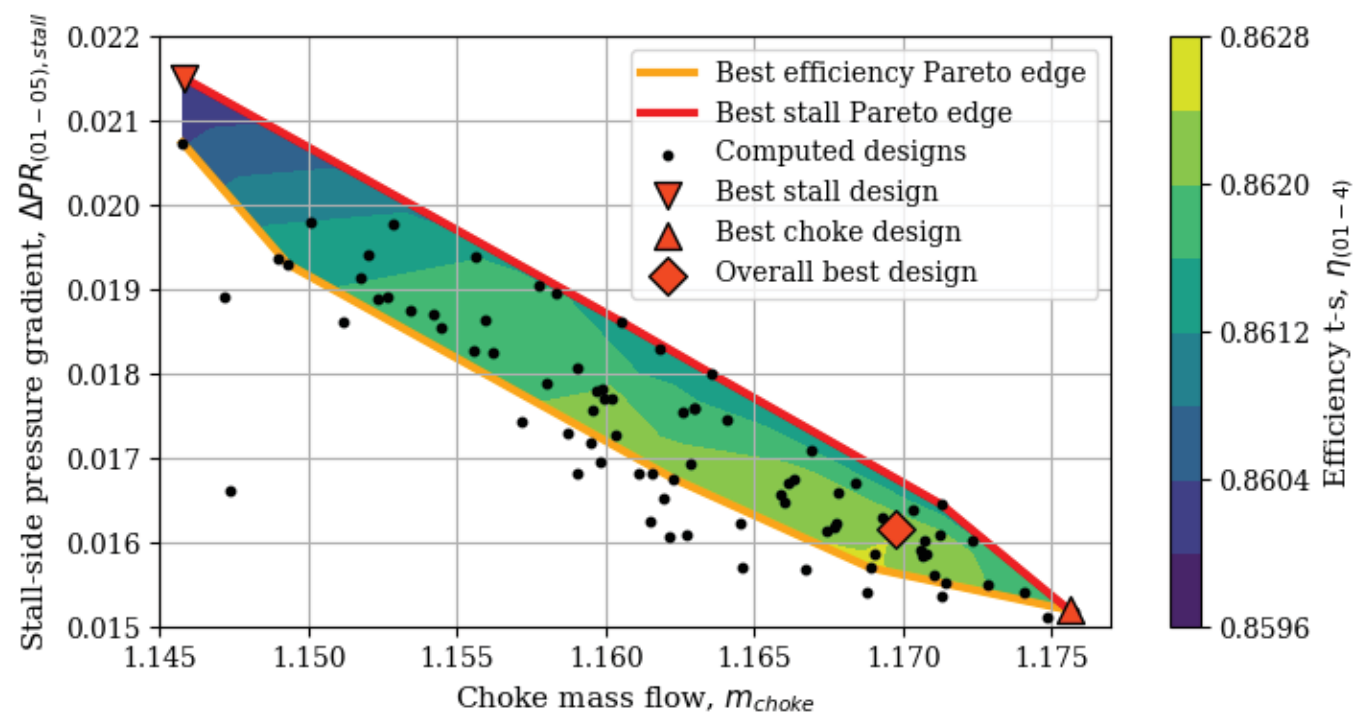

Figure 7.19: Pareto surface projection onto $m_{\text {choke }}$ vs $\Delta P R_{(01-05), \text { stall }}$ plane 
The shift of operating range is shown by the performance curves of the best stall and choke performing designs in Figure 7.20. By comparing these two curves it can be seen that a $0,03 \mathrm{~kg} / \mathrm{s}$ decrease in $m_{\text {choke }}$ corresponds to a $0,025 \mathrm{~kg} / \mathrm{s}$ decrease in $m_{\text {stall }}$ but an increase of $2 \%$ in $P R_{(01-04), \text { stall }}$. This indicates that for a shift in operating curve left or right, the optimizer would also shift the curve up or down to achieve the necessary design point pressure ratio.

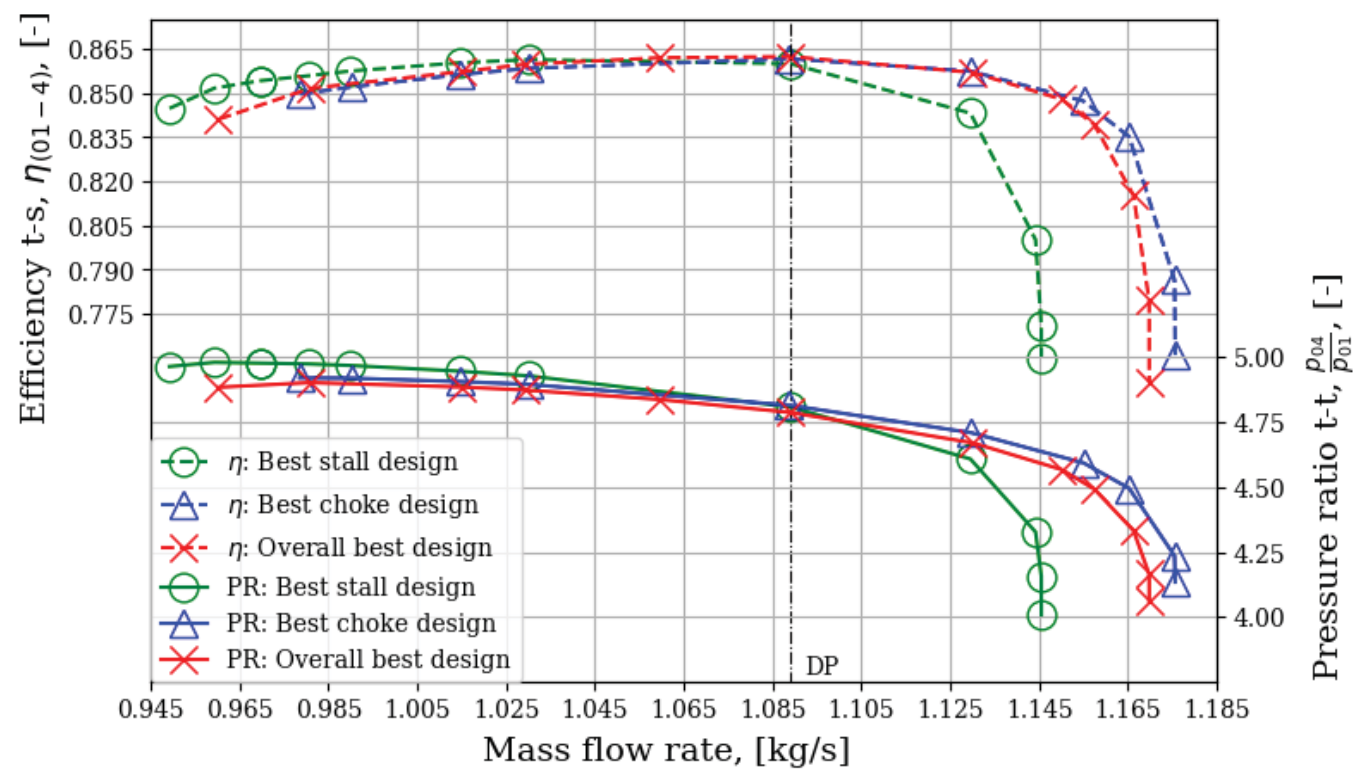

Figure 7.20: Performance curves of selected designs

The effect of operating range shift on design point efficiency is illustrated by the $m_{\text {choke }}$ vs $\eta_{(01-4), D P}$ projection of the Pareto surface in Figure 7.21. When the operating curve is shifted towards the lower mass flow, $\eta_{(01-4), D P}$ decreases due to increasing shock losses associated with $\Delta m_{\text {choke }}$ decreasing. As $\Delta m_{\text {choke }}$ increases, the efficiency performance curve gradient is less severe than towards the choke side. Subsequently, $\eta_{(01-4), D P}$ of the best choke design and best overall design differ by only $0,09 \%$. 


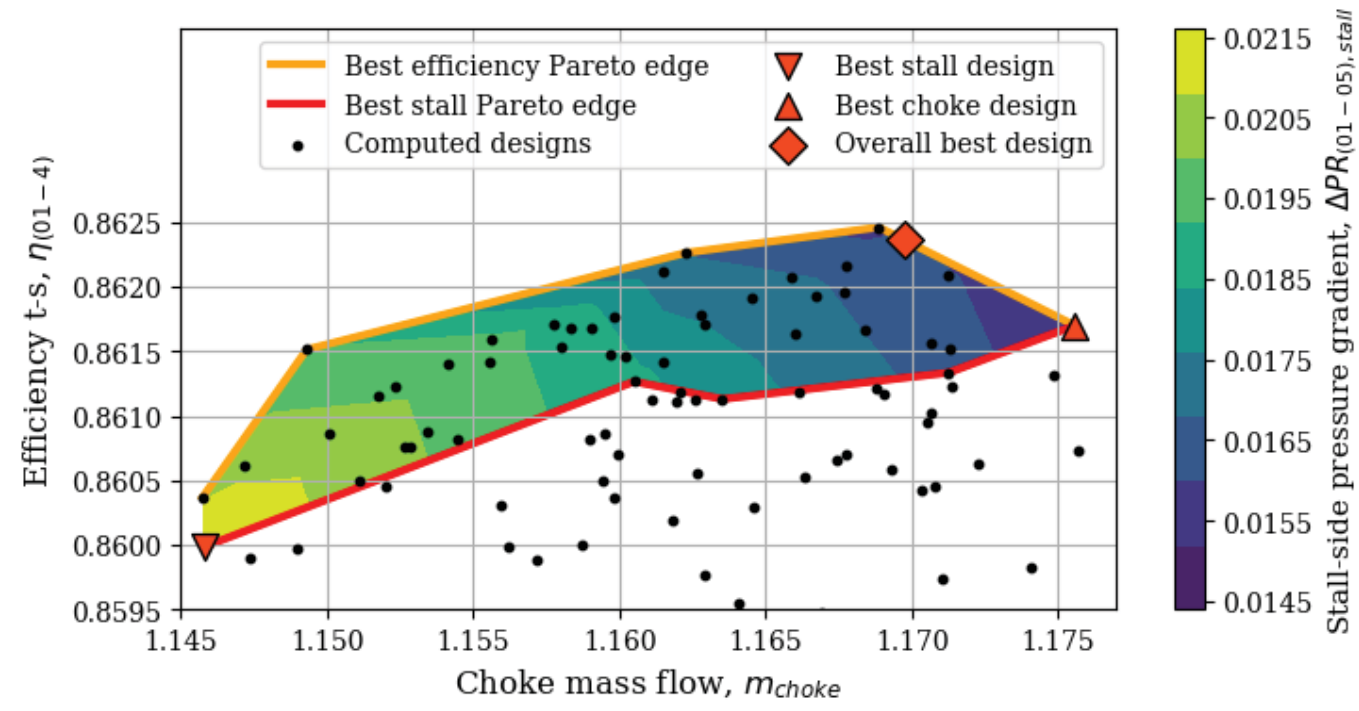

Figure 7.21: Pareto surface projection onto $m_{\text {choke }}$ vs $\eta_{(01-4), D P}$ plane

\subsection{Final selected design}

The best overall design selected after OPTI2 is discussed with respect to aerodynamic performance and structural feasibility when operated under various rotation speeds.

\subsubsection{Aerodynamic performance}

A compressor map for engine speeds ranging from 43000 RPM to 80000 RPM is given in Figure 7.22. The 'Choke line' links points of highest $P R_{(01-04)}$ at the highest mass flow observed for each constant speed curve. The choke line was extrapolated between known points with termination at zero speed $\left(m=0 \mathrm{~kg} / \mathrm{s}\right.$ and $\left.P R_{(01-04)}=1\right)$. The 'Estimated stall line' was obtained in similar fashion to the choke line, but passes through the lowest mass flow points on each respective constant speed curve that converges successfully with oscillations within the acceptable tolerance as defined in subsection 5.3.3. 

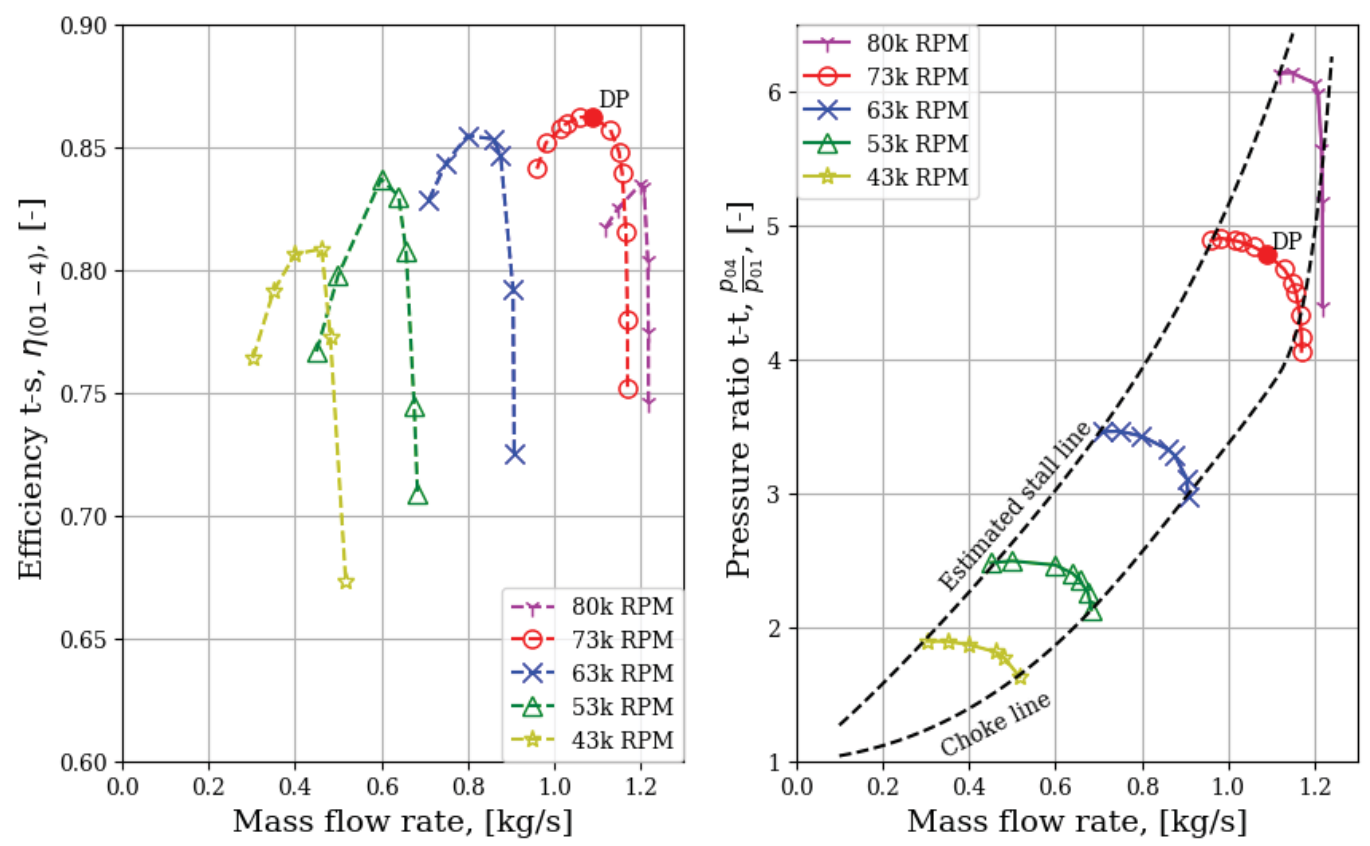

Figure 7.22: Final design compressor map

The efficiency curves of the compressor map show that the design point, 'DP', of the selected design lies at the highest efficiency point of all plotted performance curves. A gradual decline in peak efficiency is observed at decreasing speeds, while a large decrease in peak efficiency $(2,5 \%)$ is seen at the higher speed of 80000 RPM. Furthermore, the operating range at 80000 RPM is only $8,3 \%$, while the operating range at design speed is $19,3 \%$. The significant decrease in operating range and peak efficiency from 73000 RPM to 80000 RPM indicates that the design point is located near the highest efficiency point for this compressor.

The feasibility of the startup-to-design speed operating envelope can only be validated with further numerical and experimental investigation, when paired with an appropriate turbine and startup motor. However, simulation of the full engine assembly falls beyond the scope of this thesis.

A design point shaft power input of $208 \mathrm{~kW}$ was internally calculated using Equation 5.8 for the purpose of turbine matching and specifying test bench requirements for future experimental testing. 


\subsubsection{Structural feasibility}

The final design fulfils the design requirement of a $\sigma_{V M, \max }$ of less than $380 \mathrm{MPa}$ throughout the impeller. A maximum stress of 351,44 MPa was observed in the bore near the impeller backface (see Figure 7.23). It was observed that designs with a lower mixed flow angle would experience larger bore stresses due to the increased body mass under centrifugal loading; as such, the final design has a protruding bore from the backface to increase surface area and distribute the body force across the bore surface. A main blade peak stress of 319,31 MPa was obtained on the suction surface near the trailing edge (at the intersection of the fillet and blade surface). This stress was likely a result of both body displacement inducing stress in the blade root, and blade tangential lean creating a bending moment around the blade root. Blade lean induced stress can also be seen at roughly midspan in the main blade due to blade thickness tapering from thickest at the hub, to thinnest at the shroud. The splitter peak stress of $283,71 \mathrm{MPa}$ was located in the fillet at the leading edge due to the splitter forward sweep introducing a bending moment in the blade root. A maximum $z$-displacement of $0,09 \mathrm{~mm}$ was obtained at the impeller trailing edge tip, which was considered acceptable in order to avoid blade-shroud interference issues with a tip gap size of $0,2 \mathrm{~mm}$.

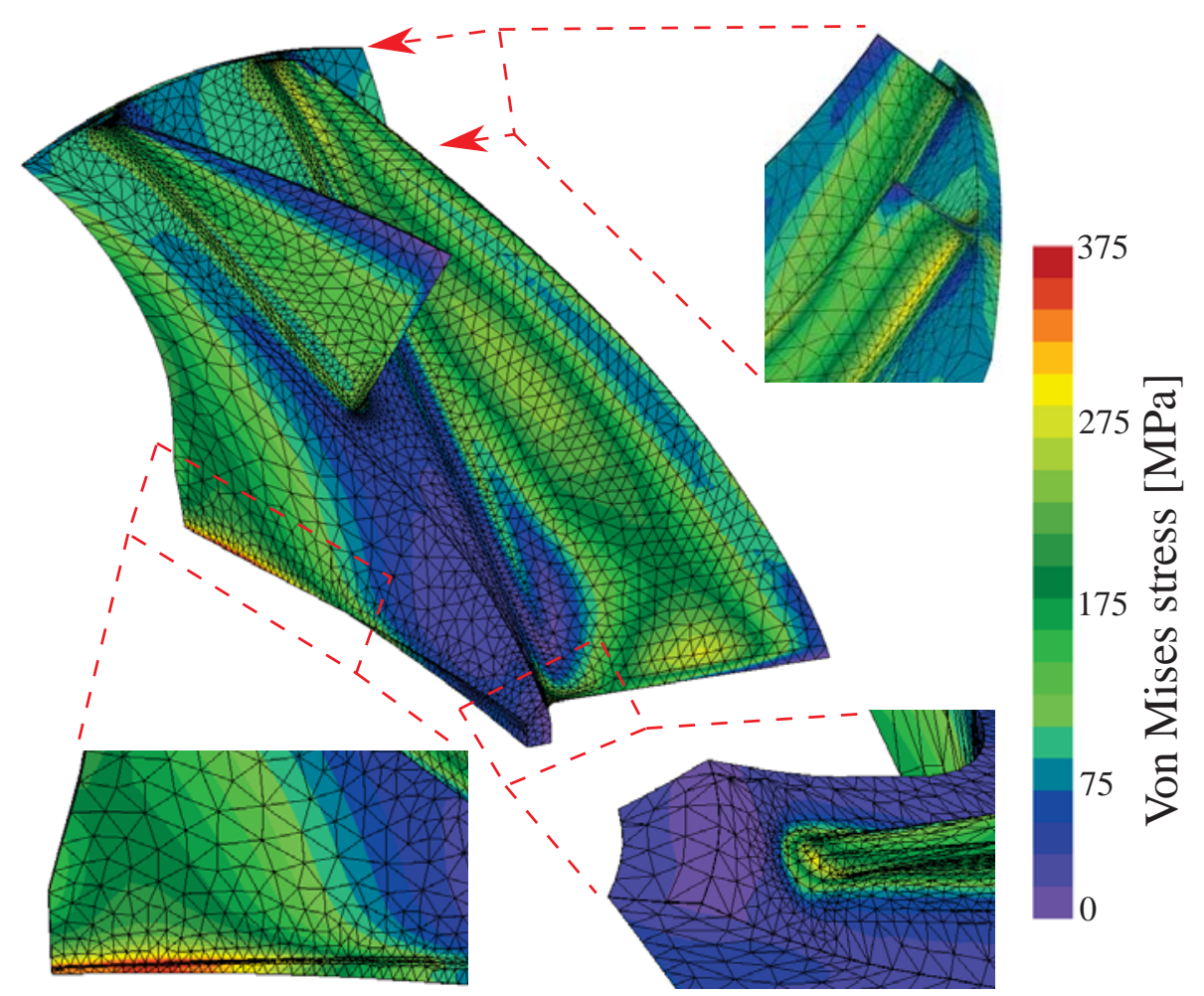

Figure 7.23: Von Mises stress results for the final selected design 
An investigation of possible resonance was conducted under the CSM workflow. A Campbell diagram of the first 6 eigenfrequencies and 4 engine order lines are plotted in Figure 7.24. The first eigenfrequency is encountered at $2831 \mathrm{~Hz}$ and induces a combined oscillation of both main blade and impeller backface. Eigenfrequencies 2 to 6 range from $3258 \mathrm{~Hz}$ to $8047 \mathrm{~Hz}$ and induce only main blade oscillations of increasing mode number (further description given below). Further eigenfrequencies were not assessed since it is generally accepted that the first 3 eigenmodes have the greatest displacement influence on any given design. Higher frequencies result in significantly diminished displacement excitation magnitude and are thus often dampened out entirely by the system Diener et al. (2016).

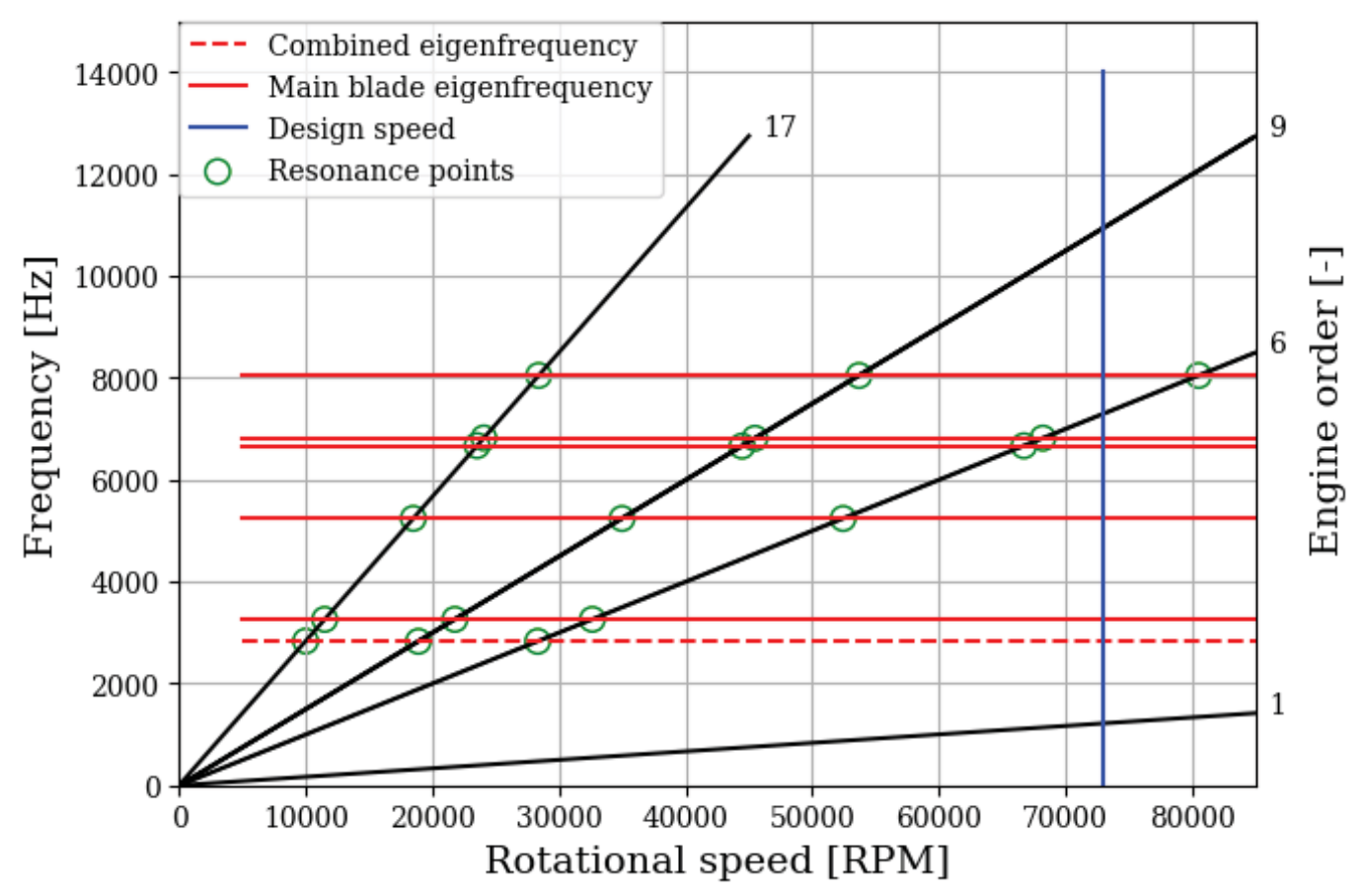

Figure 7.24: Final design Campbell diagram

The engine order lines represent duplicate component numbers; for example, the computed periodic body consists of only one main and splitter blade and is thus of engine order 1 . Resonance points indicate running speeds that could experience excessive displacement excitation, which could lead to structural failure from cyclic stress fatigue or blade-shroud interference. The resonance points are located at intersection points of engine order lines and eigenfrequency lines and should be located away from the design speed line. 
It can be seen that an impeller with a periodicity of 6 would encounter vibration problems near design speed, whereas an impeller periodicity of 9 , such as this design, passes through all problematic frequencies at much lower operating speeds. An engine order of 17 line was included due to possible excitation induced by diffuser shock and flow oscillations originating at the diffuser leading edge with a periodicity of 17 main blades. Overall, the final design passes through the first 3 (most significant) eigenfrequency resonance points between 10000 RPM and 35000 RPM and should be safe to operate near design point.

The main blade first modal shape (second system modal frequency) is similar to a cantilever beam, with fixed support at the blade root and a 'flapping' type oscillation of the full blade in a tangential direction. Modes 2 to 5 of the blade induce further mode shapes along the blade tip. Figure 7.25 shows the $5^{\text {th }}$ mode shape of the impeller.

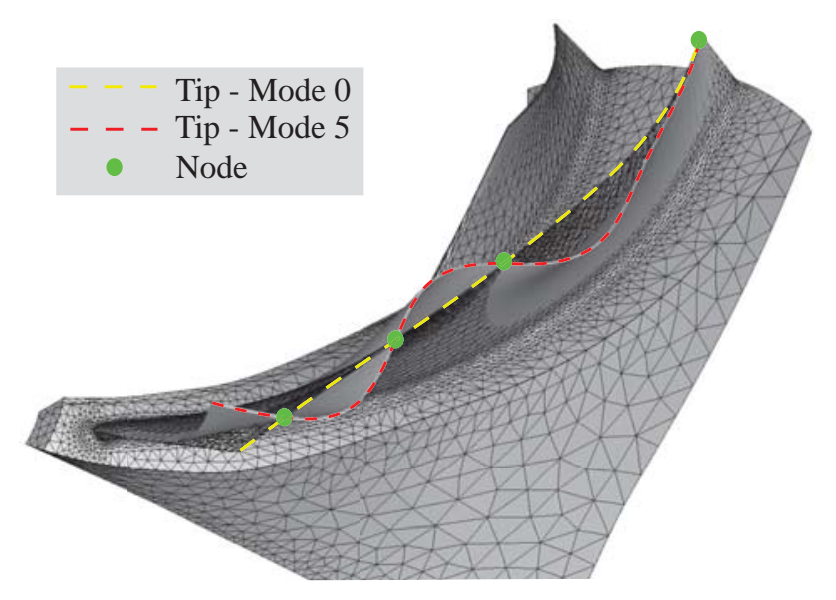

Figure 7.25: Main blade $5^{\text {th }}$ vibration mode shape

\subsubsection{Closing remarks}

Images of the final design are given in Figure F.1, while a list of important meridional and blade geometry parameters are given in Table F.1 and Table F.2, respectively. The design achieves the design requirements specified by the CSIR as indicated by the final design performance indicators in Table F.3. 


\section{Chapter 8}

\section{Conclusions and Recommendations}

\subsection{Research objectives outcomes}

\section{Optimization strategy}

A full workflow was successfully set up for a large design space optimization of a micro gas turbine. A large range of geometric diversity was achieved by coupling many meridional and camber Bézier control points with user-defined parameters to increase feasible design rate and to reduce the number of free parameters required to control all significant geometric features. Two optimizations were performed, with the first (OPTI1) consisting of 48 free parameters that controlled mainly the meridional blade and endwall features. The second optimization (OPTI2) consisted of 25 free parameters that controlled blade camber, blade thickness, and impeller body geometry to ensure structural feasibility. Parameter bound ranges in OPTI2 were greatly reduced compared to OPTI1 due to the low design convergence rate of $17,7 \%$, which subsequently improved to $100 \%$ in OPTI2.

Structural feasibility was ensured by including stress and displacement constraints into the objective function, while resonance feasibility was manually checked for the final design. A non-standard workflow was used to incorporate the CalculiX CrunchiX CSM analysis into the NUMECA FINE ${ }^{\mathrm{TM}} /$ Design3D CFD chain. This was achieved by implementing and adapting a Python script developed by NUMECA Ingenieurbüro as part of the GAMMA research project (Friendship Systems, 2019).

A method of filtering and manipulating response data that is used for surrogate model (SM) training was developed and successfully implemented. A design's responses were not used by the SM if any operating point failed to converge within the predetermined tolerances. A design was considered as unconverged 
if design point computation mass flow (averaged) differed from the imposed outlet boundary mass flow by more than a specified tolerance, or if the stall point pressure ratio fluctuation, $P R_{(01-05) \text {,stall }}^{\prime}$, exceeded a specified tolerance across the final 100 iterations. This method prevented the SM training on non-physical response values, but did allow the SM to train its prediction of the feasible design space.

To further improve SM prediction, the stall side pressure ratio gradient response, $\Delta P R_{(01-05), \text { stall }}$, was defined as a piecewise function of $P R_{(01-05), \text { stall }}^{\prime}$. Designs with intermediate stall fluctuations represented physically unstable designs at the assessed mass flow, but response values averaged across 100 iterations were still deemed valid for SM training; however, $\Delta P R_{(01-05), \text { stall }}$ was manipulated to a negative value (undesirable based on optimization constraints) to give the SM information about the instability.

\section{Design improvement and Pareto front}

A baseline design was obtained that satisfied the aerodynamic performance requirements of the CSIR, which was subsequently optimized in two steps as described above. The first optimized design (OPTI1) achieved a considerable improvement in choke margin from $3,5 \%$ to $5,9 \%$ and design point total-tostatic stage efficiency, $\eta_{(01-4), D P}$, improvement of $4,6 \%$ to $86,6 \%$, from the baseline design. The second optimization further increased the choke margin to $7,4 \%$ and considerably increased the stall margin to $11,8 \%$ but reduced $\eta_{(01-4), D P}$ to $86,24 \%$ from OPTI1.

The final design was selected after the second optimization sequence, since the optimizer obtained no significant design improvements across the final 100 iterations. The selected design achieved a $P R_{(01-4), D P}$ of 4,15 and stall, design, and choke mass flows of $0,96 \mathrm{~kg} / \mathrm{s}, 1,089 \mathrm{~kg} / \mathrm{s}$, and $1,17 \mathrm{~kg} / \mathrm{s}$, respectively, at the design speed of 73000 RPM. A full compressor map was computed to determine the operating envelope of the compressor. A peak von Mises stress, $\sigma_{V M, \max }$, of $352 \mathrm{MPa}$ was obtained at the impeller bore and a maximum blade $z$-displacement of $0,09 \mathrm{~mm}$ (tip gap of $0,2 \mathrm{~mm}$ ) was obtained at the trailing edge tip. The compressor, with 9 main impeller blades and 17 diffuser vanes, passes through the most significant resonance points between 10000 RPM and 35000 RPM with no resonance issues near design speed. The final design therefore satisfied all the requirements of the CSIR.

A Pareto front was computed with respect to the three optimization objective responses to be maximized, namely: $m_{\text {choke }}$ (choke mass flow rate), $\triangle P R_{(01-05), \text { stall }}$, and $\eta_{(01-4), D P}$. A dome structure was created by triangulating a surface comprising of the best performing designs with respect to the three objectives. A pseudo-linear relationship was observed between $m_{\text {choke }}$ 
and $\Delta P R_{(01-05), \text { stall }}$, which corresponds to a translation of performance curve operating range to either higher or lower mass flow. This translation in operating range corresponded to a pseudo-hyperbolic change in $\eta_{(01-4), D P}$ as the peak efficiency point shifts away from the design mass flow.

\section{Geometric feature influence}

Inducer radius was found to heavily influence operating mass flow range which caused many designs to fail when $m_{\text {choke }}<m_{D P}$, as a result of the incorrectly chosen lower bound. Inducer radius was therefore identified as a strong parameter for shifting the performance curve to higher or lower mass flows.

Mixed flow impellers with the trailing edge terminating at a variable radius were found to be optimized with a high spanwise difference in impeller trailing edge backsweep, due to the difference in trailing edge tangential velocity resulting from the varying radius.

An added expansion was incorporated in the vaneless gap to assist in flow diffusion and reduce peak Mach number by $7 \%$ prior to the diffuser leading edge, thus reducing shock losses for the optimized design. The expansion was placed on the hub side due to separation at the shroud downstream of the impeller trailing edge.

Diffuser outlet passage height and wrap angle contributed significant influence on stage $m_{\text {choke }}$ and $\eta_{(01-4), D P}$, as determined by the use of Pearson correlation coefficients. Both parameters heavily influenced rate of increase in diffuser flow passage area, which affected the diffuser throat area and subsequently $m_{\text {choke }}$. However, these two parameters also strongly influenced the onset and magnitude of diffuser separation from the hub in the radial-to-axial bend which subsequently affected $\eta_{(01-4), D P}$.

Diffuser splitter blades were found to improve stall margin by distribution of blade loading in the de-swirling portion of the diffuser, thus delaying major hub separation. Splitter blades also helped achieve a more mixed-out diffuser discharge, due to the relatively low solidity of main blades at the trailing edge. For this design, the addition of a second splitter blade further improved stall margin with a slight reduction in $\eta_{(01-4), D P}$ due to increased viscous losses associated with a larger blade surface area.

The optimization of the impeller meridional discharge angle $\left(\alpha_{z 2}\right)$ was achieved, given a strict (difficult to achieve) compressor stage outer diameter constraint and a requirement that stage discharge should be axial. The meridional angle parameter was allowed to vary from $50^{\circ}$ to $85^{\circ}$ in the database, with the best 
optimizer designs located between $66^{\circ}$ and $74^{\circ}$. The final optimized design had an impeller meridional discharge angle of $71,59^{\circ}$.

\subsection{Recommendations}

It is suggested that a method of determining parameter-response influence using linear regression be implemented early in the database generation process. For example, it is recommended that computing multiple small databases with iterative manipulation of bounds be performed in conjunction with the use of a Pearson correlation coefficient map to assist in determining parameter importance. Furthermore, the use of scatter plots with valid design responses should be used to determine parameter bounds for the final large database.

If a parameter is found to strongly shift the operating range and leads to operating point ill-convergence, it is recommended to either reduce the parameter bound range or to shift the parameter bound into a more feasible region. Such a procedure will improve design convergence rate and improve the correlation coefficient of remaining free parameters.

The parametric model in this thesis was set up with a 4-point Bézier curve defining blade camber, which has the drawback of no explicit control over leading and trailing edge blade angles. Furthermore, changes in blade chord also affect Bézier control point placement which influences blade angle. It is suggested that camber be either defined with explicitly specified blade edge angles, or a macro script be implemented into the post-processing to enquire the blade edge angles. Such information could allow chord controlling parameters to be assessed independently from backsweep and incidence with respect to response influence.

\subsection{Suggestions for future research}

Experimental testing of the compressor stage designed in this thesis should be conducted to verify the claimed CFD and CSM results. Testing could be conducted on a blow-down type test bench such as used by van der Merwe (2012) and Burger (2016), but at the time of writing this thesis there exists no blow-down facility at either Stellenbosch University or the CSIR capable of supplying $208 \mathrm{~kW}$ of shaft power at $73000 \mathrm{RPM}$ to the compressor. Alternatively, the stage could be tested with an accompanying combustor and turbine (still to be designed) on a full MGT test bench.

Successive research to continue the implementation of this compressor stage 
into a functional MGT engine would be to design and manufacture the combustor and turbine stages that could power this compressor. The full operating map given for this compressor should serve as a basis for matching the turbine design requirements. Furthermore, the diffuser discharge flow, specifically the swirl component $\alpha_{z 4}$, should be used to design an appropriate combustor for the MGT engine.

An unsteady CFD analysis should be conducted to ensure that no rotating stall will occur under normal operation. It is suggested that three diffuser passages be stepped past one impeller passage to reduce computational expense associated with a full passage computation. It is expected that the strong impeller wake might result in oscillations of the separation zone identified at the diffuser hub due to fluctuations in absolute Mach number entering the diffuser.

The geometric feature influence on responses and flow observations suggest that for a crossover type diffuser, there exists a design methodology link between impeller meridional discharge angle, $\alpha_{z 2}$, and blade row axial length with respect to diffuser outer radius constraint. The radial passage distance available to diffuse and turn the flow in both blade-to-blade and meridional planes strongly affects separation losses at the diffuser hub. As such, a lower $\alpha_{z 2}$ can allow for a longer diffuser passage and a lower blade loading required to turn flow to discharge the stage axially in the meridional plane. Suggested future research would thus be to develop a mathematical design guideline for $\alpha_{z 2}$ and blade axial length ratio (impeller and diffuser) as a function of stage maximum radius constraint. 


\section{References}

ASM Inc. (2019). Properties of Aluminium 7075. [Online]. Available at: http://asm.matweb.com/search/SpecificMaterial.asp?bassnum= MA7075T6 [Accessed 23/04/2019].

Aungier, R.H. (2000). Centrifugal Compressors - A Strategy for Aerodynamic Design and Analysis. ASME Press.

Bagheri, S., Konen, W. and Bäck, T. (2017). Comparing Kriging and Radial Basis Function Surrogates. In: Workshop Computational Intelligence, Dortmund.

Bennett, I., Tourlidakis, A. and Elder, R.L. (2000). The design and analysis of pipe diffusers for centrifugal compressors. Proceedings of the Institution of Mechanical Engineers, Part A: Journal of Power and Energy, vol. 214, no. 1, pp. 87-96.

Bindeman, M. (2019). Analysing the Performance of a Compressor Impeller for a Micro Gas Turbine. Master's Thesis, Stellenbosch University.

Bonjin, K., Chang-Ho, K., Jong Sung, L., Tae Ho, K. and Kyuho, S. (2015). Analysis and Experimental Test of a $200 \mathrm{~kW}$ Oil-Free Micro Gas Turbine Simulator. In: Pennacchi, P. (ed.), Proceedings of the 9th IFToMM International Conference on Rotor Dynamics. Springer International Publishing.

Burger, C.J. (2016). Design Procedure of a Compact Aerodynamic Crossover Diffuser for Micro Gas Turbine Application. Master's Thesis, Stellenbosch University.

Carter, A.D. and Hughes, H.P. (1946). A Theoretical Investigation Into the Effect of Profile Shape on the Performance of Airfoils in Cascade. techreport 2384, British ARC.

Cevik, M. and Uzol, O. (2011). Design optimization of a mixed-flow compressor impeller for a small turbojet engine. Aircraft Engineering and Aerospace Technology, vol. 83, no. 3, pp. 127-137. 
Dallenbach, F. (1961). The Aerodynamic Design and Performance of Centrifugal and Mixed-flow Compressors. In: SAE International Congress and Exposition of Automotive Engineering.

de Villiers, L.C.B. (2014). Design of a Centrifugal Compressor for Application in Micro Gas Turbines. Master's Thesis, Stellenbosch University.

de Wet, A.L. (2011). Performance Investigation of a Turbocharger Compressor. Master's Thesis, Stellenbosch University.

Deb, K. (1999). An introduction to genetic algorithms. Sadhana, vol. 24, no. 4, pp. 293-315.

Denton, J.D. (1993 October). The 1993 IGTI Scholar Lecture: Loss Mechanisms in Turbomachines. Journal of Turbomachinery, vol. 115, no. 4, pp. $621-656$.

Dhondt, G. (2014 03). CalculiX CrunchiX User Manual, 2nd edn.

Diener, O.H.F., van der Spuy, S.J., von Backström, T.W. and Hildebrandt, T. (2016). Multi-Disciplinary Optimization of a Mixed-Flow Compressor Impeller. In: Turbo Expo: Power for Land, Sea, and Air, vol. 8. ASME.

Dixon, S.L. (1998). Fluid Mechanics, Thermodynamics of Turbomachinery. 4th edn. Butterworth-Heinemann. ISBN 0750670592.

ESTEQ (2016). CFD simulation of complex rotor equipment using FloEFD: Part IV - KJ-66 Micro Gas Turbine. [Online]. Available at: https://esteq.co.za/2016/08/31/cfd-simulation-complexrotor-equipment-using-floefd-part-iv-kj-66-micro-gas-turbine/ [Accessed 12/06/2018].

Friendship Systems (2019). Friendship Systems- GAMMA project. [Online]. Available at: https://www.friendship-systems.com/company/r_ a_d/gamma/ [Accessed 23/04/2019].

Giri, G., Nassar, A., Moroz, L., Sherbina, A. and Klimov, I. (2016). Design and Analysis of a High Pressure Ratio Mixed Flow Compressor Stage. In: AIAA Propulsion and Energy Forum. AIAA, Salt Lake City.

Goldstein, A.W. (1948). Design and Performance of Experimental Axialdischarge Mixed-flow Compressor, Impeller Design Theory. National Advisory Committee for Aeronautics.

Han, G. (2018). High-pressure ratio centrifugal compressor with two different fishtail pipe diffuser configurations. Proceedings of the Institution of Mechanical Engineers - Part A - Power 86 Energy, vol. 232, no. 7, pp. 785-799. 
Han, G., Lu, X., Zhang, Y., Zhao, S., Yang, C. and Zhu, J. (2018). Investigation of two pipe diffuser configurations for a compact centrifugal compressor. Proceedings of the Institution of Mechanical Engineers, Part G: Journal of Aerospace Engineering, vol. 232, no. 4, pp. 716-728.

He, X. and Zheng, X. (2017). Mechanisms of Sweep on the Performance of Transonic Centrifugal Compressor Impellers. Applied Sciences, vol. 7, p. 1081.

Hildebrandt, T., Thiel, P. and Lehmann, I. (2009). Entwicklung eines leistungsgesteigerten Radialverdichters für Ab-gasturbolader: Von der CFD basierten Optimierung mit FINE ${ }^{\mathrm{TM}} /$ Turbo bis zum serienreifen Prototyp im Hause KBB. In: Proceedings of the 14th Aufladetechnische Konferenz. Dresden.

Ilyushin, A. and Lensky, V. (1967). Strength of Materials. 1st edn. Pergamon Press, Pergamon. ISBN 9781483151151.

Japikse, D. (1996). Centrifugal Compressor Design and Performance. Concepts ETI. ISBN 0933283032.

Japikse, D. and Baines, N.C. (1998). Turbomachinery Diffuser Design Technology. Concepts ETI.

Jie, C. and Guoping, H. (2010). Redesign of an $11 \mathrm{~cm}$-diameter Micro Diffuser. Chinese Journal of Aeronautics, vol. 23, no. 3, pp. 298-305.

Kano, F., Fukao, Y. and Shirakami, T. (1984). Development of High Specific Speed Mixed Flow Compressors. In: Proceedings of the 13th Turbomachinery Symposium. Texas A\&M University. Turbomachinery Laboratories.

Kock, M.P. (2017). Design of a Cross-over Diffuser for a Mixed Flow Compressor Impeller. Master's Thesis, Stellenbosch University.

Krige, D.S. (2013). Performance Evaluation of a Micro Gas Turbine Centrifugal Compressor Diffuser. Master's Thesis, Stellenbosch University.

Li, X., Liu, Z. and Lin, Y. (2017 10). Multipoint and Multiobjective Optimization of a Centrifugal Compressor Impeller Based on Genetic Algorithm. Mathematical Problems in Engineering, vol. 2017, pp. 1-18.

Marconcini, M., Rubechini, F., Arnone, A. and Ibaraki, S. (2010 May). Numerical Analysis of the Vaned Diffuser of a Transonic Centrifugal Compressor. Journal of Turbomachinery, vol. 132, no. 4.

NUMECA International (2019a). AutoMesh/AutoGrid5 ${ }^{\text {TM }}$ User Manual. EN201904101125. 
NUMECA International (2019b). FINE/TurboTM User Manual. EN201904101125.

NUMECA International (2019c). FINE/Design3D ${ }^{T M}$ User Manual. EN201904101125.

Oppong, F., van der Spuy, S., von Backström, T. and Diaby, A.L. (2015). AN OVERVIEW OF MICRO GAS TURBINE ENGINE PERFORMANCE INVESTIGATION. RED Journal of the South African Institute of Mechanical Engineers, vol. 31, pp. 35-41.

Pletke, L. and Murphy, G. (1953). Temperature Distribution in a Metal Cylinder Containing a Heat Source. Tech. Rep. ISC-428, United States Atomic Energy Commission.

Qiu, X., Japikse, D., Zhao, J. and Anderson, M.R. (2011). Analysis and validation of a unified slip factor model for impellers at design and off-design conditions. Journal of Turbomachinery, vol. 133, no. 4.

Rajakumar, R., Ramamurthy, S. and Govardhan, M. (2013). Study on the Performance Deterioration of Mixed Flow Impeller due to Change in Tip Clearance. Journal of Thermal Science, vol. 22, pp. 532-538.

Sadagopan, A. and Camci, C. (2019a). A design strategy for a 6:1 supersonic mixed-flow compressor stage. Aerospace Science and Technology, vol. 87, pp. 265-277.

Sadagopan, A. and Camci, C. (2019b). Viscous flow and performance issues in a 6:1 supersonic mixed-flow compressor with a tandem diffuser. Aerospace Science and Technology, vol. 88, p. 9.

Saka, Y., Gunzburger, M. and Burkardt, J. (2007). Latinized, Improved LHS, and CVT point sets in Hypercubes. International Journal of Numerical Analysis and Modelling, vol. 4, no. 3-4, pp. 729-743.

Sarkar, S. (1992 06). Performance prediction of a mixed flow impeller. Proceedings of The Institution of Mechanical Engineers Part A-journal of Power and Energy, vol. 206, pp. 189-196.

Sayers, A.T. (1990). Hydraulic and Compressible Flow Turbomachines. McGraw-Hill. ISBN 0077072197.

Stodola, A. (1927). Steam and Gas Turbines, vol. 1 and 2. McGraw-Hill, New York.

Swanepoel, P.C. (2018). Experimental Validation of a Mixed-Flow Compressor Impeller and Cross-over Diffuser. mathesis, Stellenbosch University. 
Tarnowski, L. and Bulot, N.P. (2018). Patent Issued for Radial Or Mixed-Flow Compressor Diffuser Having Vanes. USPTO 9890792.

Teixeira, M., Romagnosi, L., Mezine, M., Baux, Y., Anker, J., Claramunt, K. and Hirsch, C. (2018). A Methodology for Fully-Coupled CFD Engine Simulations, Applied to a Micro Gas Turbine Engine. In: Turbo Expo: Power for Land, Sea and Air, vol. 2C. ASME.

Tiralap, A., Tan, C., Donahoo, E., Montgomery, M. and Cornelius, C. (2017). Effects of Rotor Tip Blade Loading Variation on Compressor Stage Performance. Journal of Turbomachinery, vol. 139.

van der Merwe, B.B. (2012). Design of a Centrifugal Compressor Impeller for Micro Gas Turbine Application. Master's Thesis, Stellenbosch University.

Verstraete, T., Alsalihi, Z. and Van den Braembussche, R.A. (2010). Multidisciplinary Optimization of a Radial Compressor for Microgas Turbine Applications. Journal of Turbomachinery, vol. 132, no. 3.

Whitfield, A. (1990). Preliminary design and performance prediction techniques for centrifugal compressors. IMechE, vol. 204, no. A03289.

Wilcox, D.C. (1998). Turbulence Modeling for CFD. 2nd edn. DCW Industries Inc. La Canada, United States.

Wilcox, W.W. (1948). Design and Performance of Experimental Axialdischarge Mixed-flow Compressor, Performance of Impeller. National Advisory Committee for Aeronautics.

Wilcox, W.W. and Robbins, W.H. (1951). Design and Performance of Experimental Axial-discharge Mixed-flow Compressor, Over-all Performance of Impeller and Supersonic-diffuser Combination. National Advisory Committee for Aeronautics.

Zhu, M., Qiang, X., Huang, T. and Teng, J. (2013 09). Investigation of Tip Leakage Flow and Stage Matching with Casing Treatment in a Transonic Mixed-Flow Compressor. International Journal of Turbo Jet Engines, vol. 30, pp. 283-292.

Ziegler, K., Gallus, H. and Niehuis, R. (2003 January). A Study of ImpellerDiffuser Interaction- Part 1: Influence and Performance. ASME Journal of Turbomachinery, vol. 125. 


\section{Appendix A}

\section{Mesh and evaluation plane validity study}

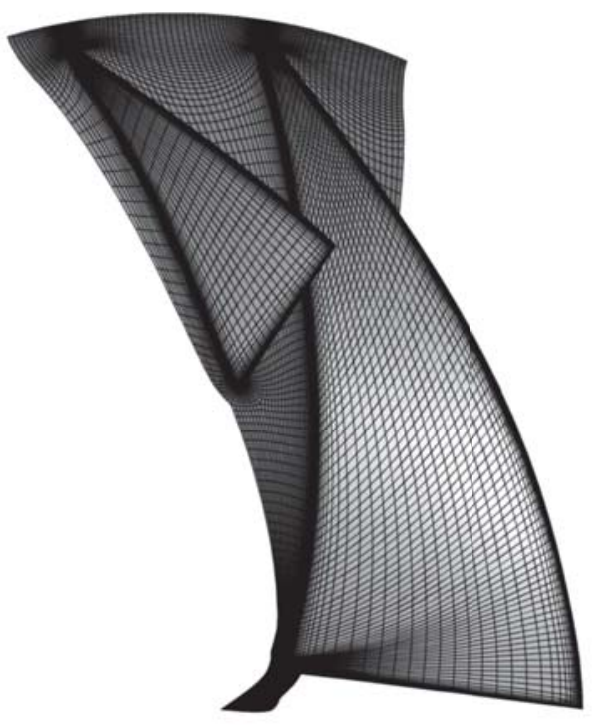

(a) Impeller

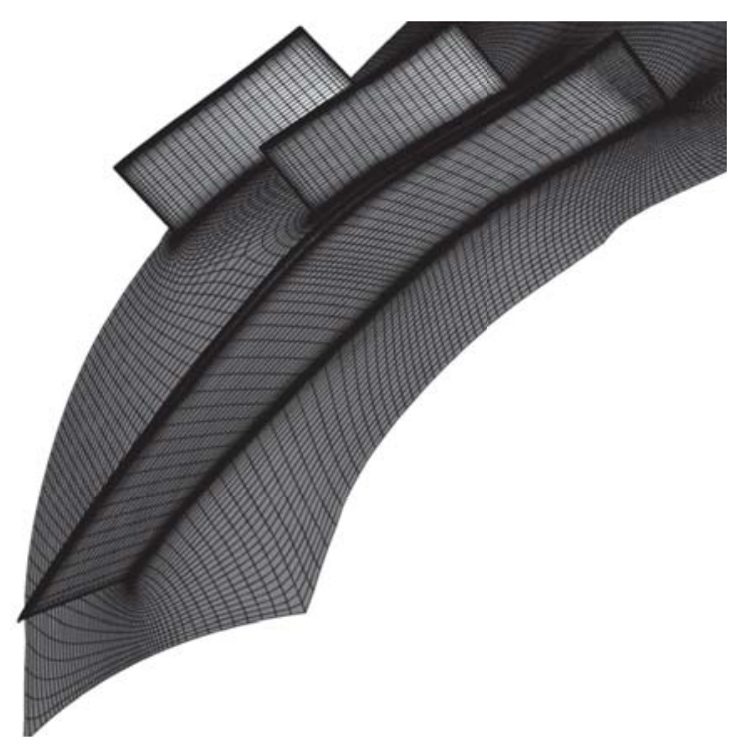

(b) Diffuser

Figure A.1: Mesh surface projection

Table A.1: Mesh quality

\begin{tabular}{lllllll}
\hline Mesh block & Cell count & Min. skewness & $\begin{array}{l}\text { Max. aspect } \\
\text { ratio }\end{array}$ & $\begin{array}{l}\text { Max. expansion } \\
\text { ratio }\end{array}$ & $\begin{array}{l}\text { Spanwise angular } \\
\text { deviation }\end{array}$ & $\begin{array}{l}\text { Spanwise expansion } \\
\text { ratio }\end{array}$ \\
\hline Inlet bulb & 96579 & $47^{\circ}$ & 337,8 & 1,71 & $17,5^{\circ}$ & 1,71 \\
Impeller & 1044930 & $27^{\circ}$ & 570,3 & 2,97 & $20,8^{\circ}$ & 1,39 \\
Diffuser & 1076483 & $28^{\circ}$ & 386,9 & 3,28 & $94,96^{\circ}$ & 2,20 \\
\hline
\end{tabular}




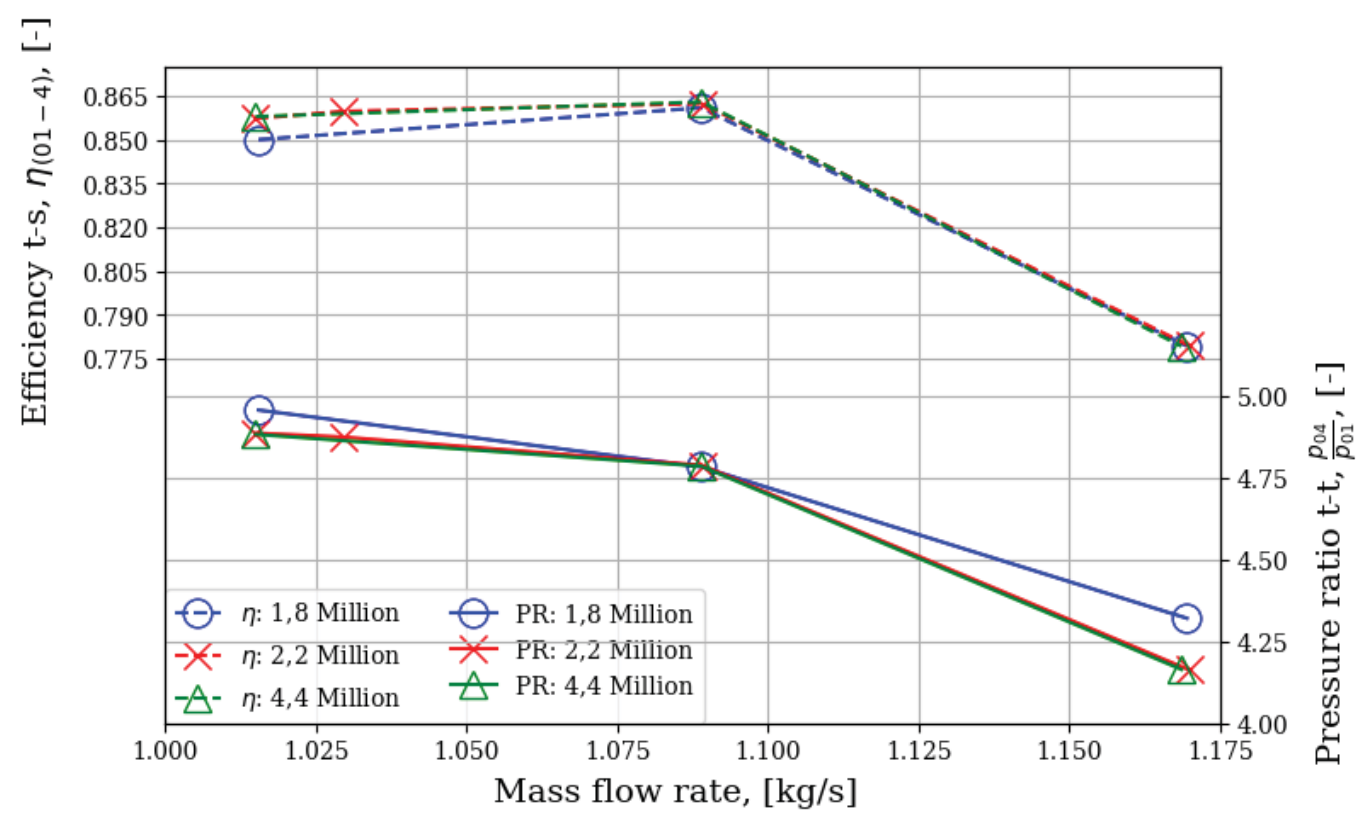

Figure A.2: Mesh independence study

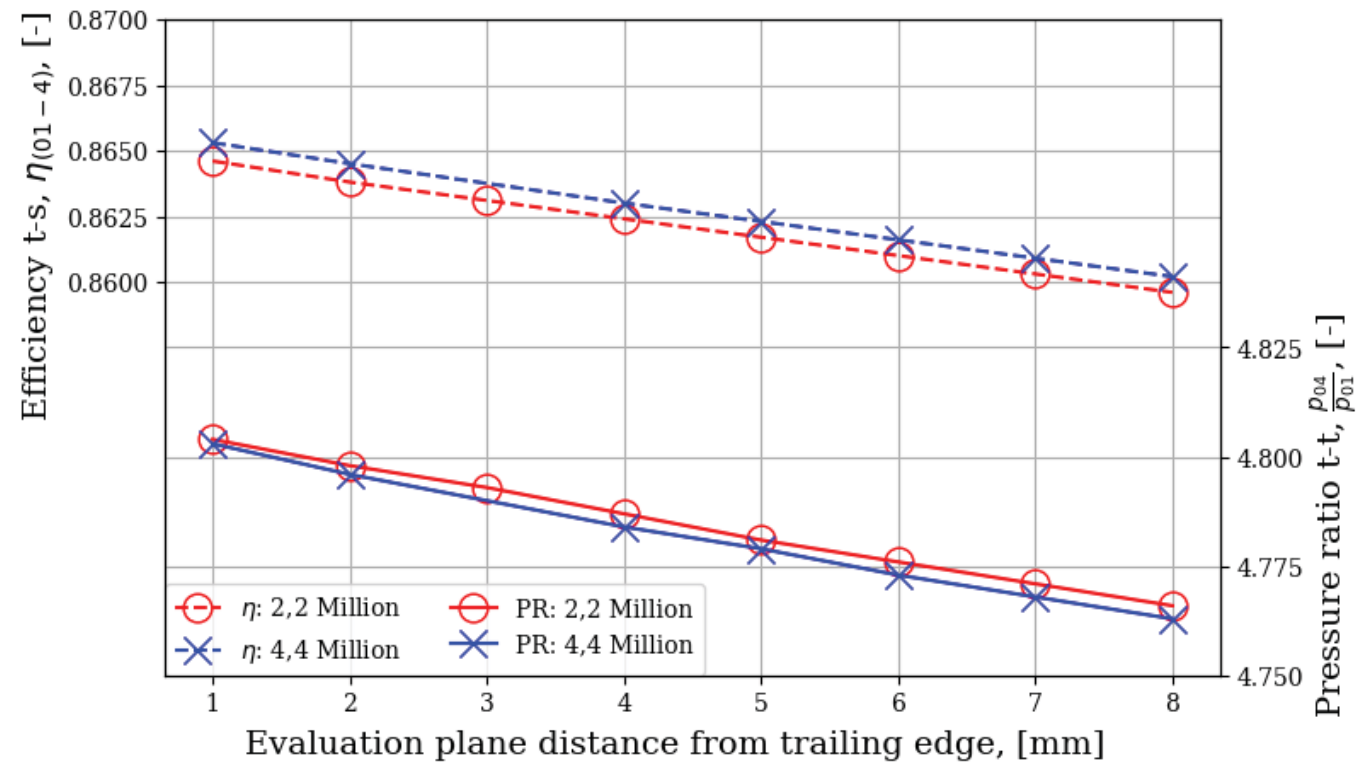

Figure A.3: Evaluation plane location study 


\section{Appendix B}

\section{$\mathrm{y}^{+}$plots}

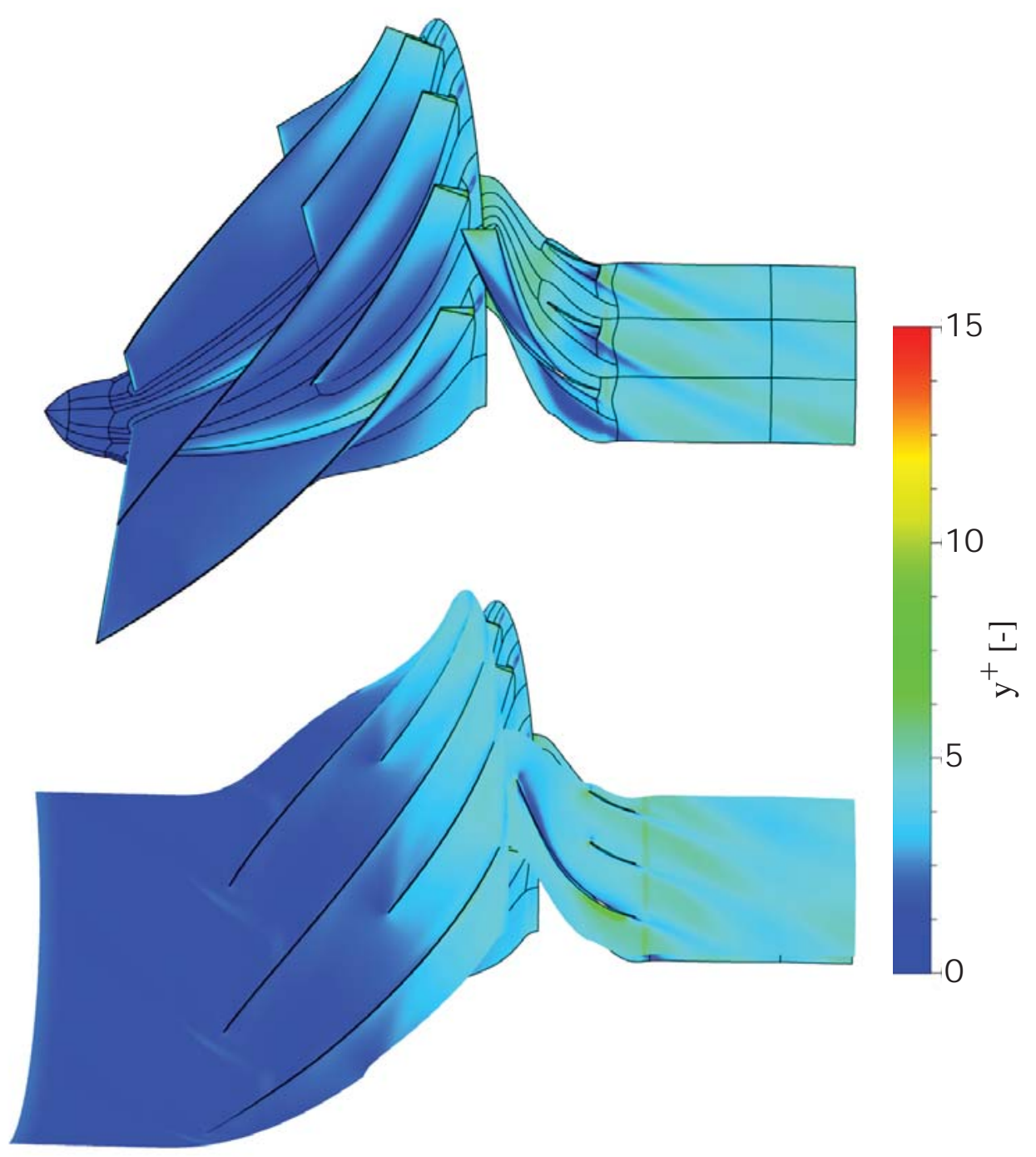

Figure B.1: $\mathrm{y}^{+}$of hub and blades (top), and shroud (bottom) 


\section{Appendix C}

\section{Software specific settings}

Table C.1: Parametric modeller software settings

\begin{tabular}{|c|c|c|c|}
\hline Grouping & Software setting & Impeller value (or selection) & Diffuser value (or selection) \\
\hline \multirow[t]{2}{*}{ Endwalls } & $\begin{array}{l}\text { Hub curve construction sequence } \\
\text { (type[point count]) }\end{array}$ & $\begin{array}{l}\text { B_spline[4]-Bézier[5]-Line- } \\
\text {-Bézier[5]-Line }\end{array}$ & -Same as impeller- \\
\hline & $\begin{array}{l}\text { Shroud curve construction sequence } \\
\text { (type[point count]) }\end{array}$ & $\begin{array}{l}\text { Line-Bézier[5]-Line-Bézier[5]- } \\
\text {-Line-Line }\end{array}$ & -Same as impeller- \\
\hline \multirow[t]{2}{*}{ Stream surfaces } & Surface type & Hub-to-shroud interpolation & -Same as impeller- \\
\hline & Section spanwise location & {$[-0,021,02] *$ passage height } & {$[-0,051,05] *$ passage height } \\
\hline \multirow[t]{3}{*}{ Stacking laws } & Stacking point and type & Trailing edge, line & Leading edge, line \\
\hline & $\begin{array}{l}\text { Leading edge definition } \\
\text { (intersect coordinate, interpolation) }\end{array}$ & Hub/shroud: Z, linear & Hub/shroud: $R$, linear \\
\hline & $\begin{array}{l}\text { Trailing edge definition } \\
\text { (intersect coordinate, interpolation) }\end{array}$ & Hub/shroud: $R$, linear & Hub/shroud: Z, linear \\
\hline \multirow[t]{5}{*}{ Main blade } & Construction plane & dmr, theta & -Same as impeller- \\
\hline & Camber curve type and spacing & $\begin{array}{l}\text { Bézier with } 4 \text { points and } \\
\text { twice geometric }[2,51,5] \text { spacing }\end{array}$ & $\begin{array}{l}\text { Bézier with } 4 \text { points and } \\
\text { geometric }[1,4] \text { spacing }\end{array}$ \\
\hline & Thickness model & $\begin{array}{l}\text { Symmetric addition } \\
\text { (from camber curve) }\end{array}$ & $\begin{array}{l}\text { Suction addition } \\
\text { (from camber curve) }\end{array}$ \\
\hline & Thickness curve type & $\begin{array}{l}\text { B_spline with } 5 \text { points and } \\
\text { [2] geometric spacing }\end{array}$ & $\begin{array}{l}\text { Bézier with } 6 \text { points and }\left[\begin{array}{ll}0,6 & 1\end{array}\right] \\
\text { twice geometric spacing }\end{array}$ \\
\hline & Edge control (leading, trailing edge) & Rounded, blunt at (constant dmr) & -Same as impeller- \\
\hline \multirow[t]{3}{*}{ Splitter blades } & Number per passage & 1 & 2 \\
\hline & Camber curve & From main blade & -Same as impeller- \\
\hline & Thickness curve type & $\begin{array}{l}\text { B_spline with } 5 \text { points and } \\
\text { double spacing }\end{array}$ & $\begin{array}{l}\text { B_spline with } 3 \text { points and } \\
{[2] \text { geometric spacing }}\end{array}$ \\
\hline Tip gap & Size & $0,2 \mathrm{~mm}$ & none \\
\hline \multirow[t]{6}{*}{ Solid body } & $\begin{array}{l}\text { Body curve construction sequence } \\
\text { (type[point count]) }\end{array}$ & Line-Bézier[4]-Line-Line-Line & - \\
\hline & Fillet type & Constant radius & - \\
\hline & Sector curve range & {$\left[\begin{array}{lll}0,06 & 0,7\end{array}\right]$} & - \\
\hline & Sector positioning (main/splitter) & {$\left[\begin{array}{ll}0,6 & 0,4\end{array}\right]$} & - \\
\hline & Transition factor & 0,3 & - \\
\hline & Loft profile and extensions & Along reference curve & - \\
\hline
\end{tabular}


Table C.2: Meshing software settings

\begin{tabular}{|c|c|c|c|}
\hline Blade row & Setting grouping & Software setting & Value (or selection) \\
\hline \multirow[t]{16}{*}{ Impeller } & 3-D control & Inlet bulb smoothing steps & 2 \\
\hline & Meridional control & Tip gap & $0.2 \mathrm{~mm}$ \\
\hline & \multirow[t]{3}{*}{ Optimization } & Fine grid steps & 350 \\
\hline & & Gap steps & 100 \\
\hline & & Multigrid steps & 0 \\
\hline & \multirow[t]{5}{*}{ Flow paths control } & Number of flow paths & 73 \\
\hline & & First cell height & $5 \times 10^{-06} \mathrm{~m}$ \\
\hline & & Control points & 100 \\
\hline & & Intermediate points & 10 \\
\hline & & General/endwall smoothing steps & $0 / 10$ \\
\hline & \multirow[t]{6}{*}{ Blade to blade control } & Inlet topology & 'I' at high angle \\
\hline & & Expansion ratio & 1.18 \\
\hline & & Clustering relaxation & 3 \\
\hline & & Trailing edge cell width & $1,5 \times 10^{-05} \mathrm{~m}$ \\
\hline & & Relax inlet clustering & Enabled \\
\hline & & Points in clearance O-mesh & 5 \\
\hline \multirow[t]{12}{*}{ Diffuser } & \multirow[t]{2}{*}{ Optimization } & Fine grid steps & 200 \\
\hline & & Multigrid steps & 0 \\
\hline & \multirow[t]{5}{*}{ Flow paths control } & Number of flow paths & 53 \\
\hline & & First cell height & $5 \times 10^{-06} \mathrm{~m}$ \\
\hline & & Control points & 350 \\
\hline & & Intermediate points & 10 \\
\hline & & General/endwall smoothing steps & $20 / 200$ \\
\hline & \multirow{5}{*}{ Blade to blade control } & Inlet topology & 'I' low angle \\
\hline & & Expansion ratio & 1.18 \\
\hline & & Clustering relaxation & 1 \\
\hline & & Trailing edge cell width & $1,5 \times 10^{-05} \mathrm{~m}$ \\
\hline & & Points in clearance O-mesh & 17 \\
\hline \multirow[t]{5}{*}{ Both rows } & \multirow[t]{3}{*}{ Blade to blade control } & Outlet topology & 'H' normal angle \\
\hline & & High stagger & Enabled \\
\hline & & Free inlet/outlet angle & Enabled/enabled \\
\hline & \multirow[t]{2}{*}{ 3-D control } & Span interpolation & $5 \%$ \\
\hline & & Untwist inlet/outlet & Disabled/disabled \\
\hline
\end{tabular}




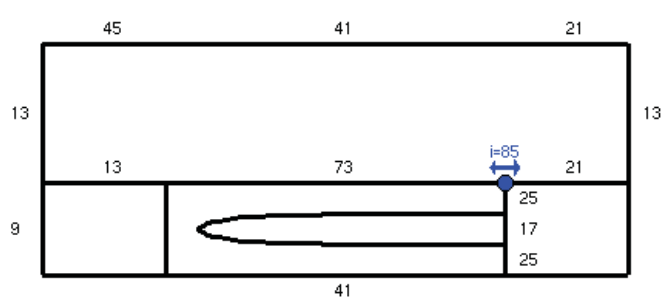

(a) Impeller main blade

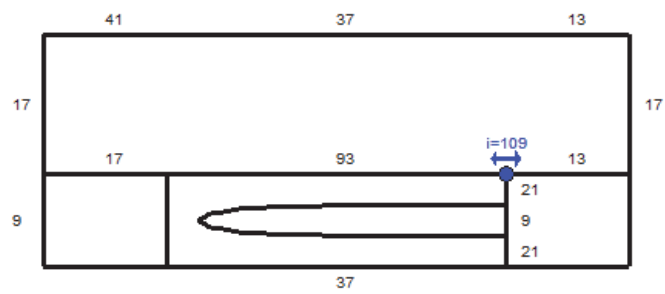

(c) Diffuser main blade

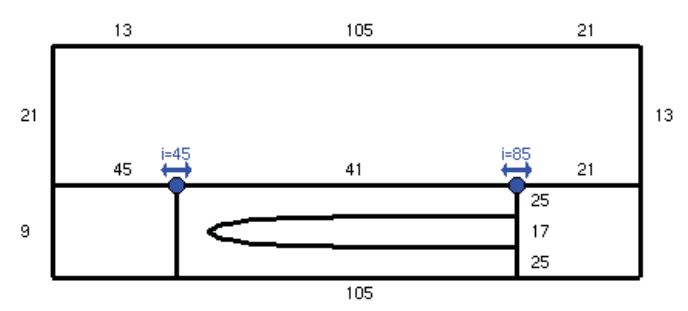

(b) Impeller splitter blade

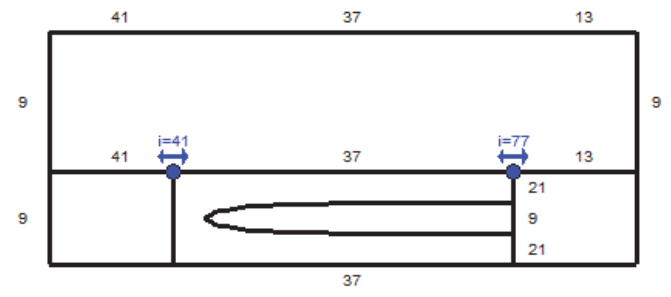

(d) Diffuser splitter blade

Figure C.1: Grid point topology of each blade type

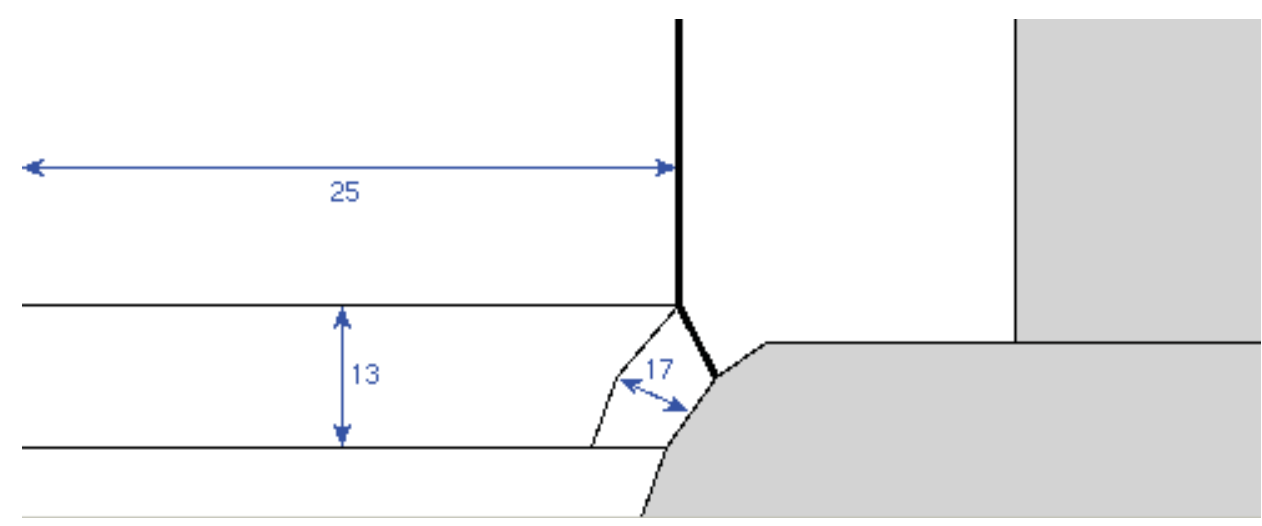

Figure C.2: Hub bulb grid point topology 
Table C.3: Solver software settings

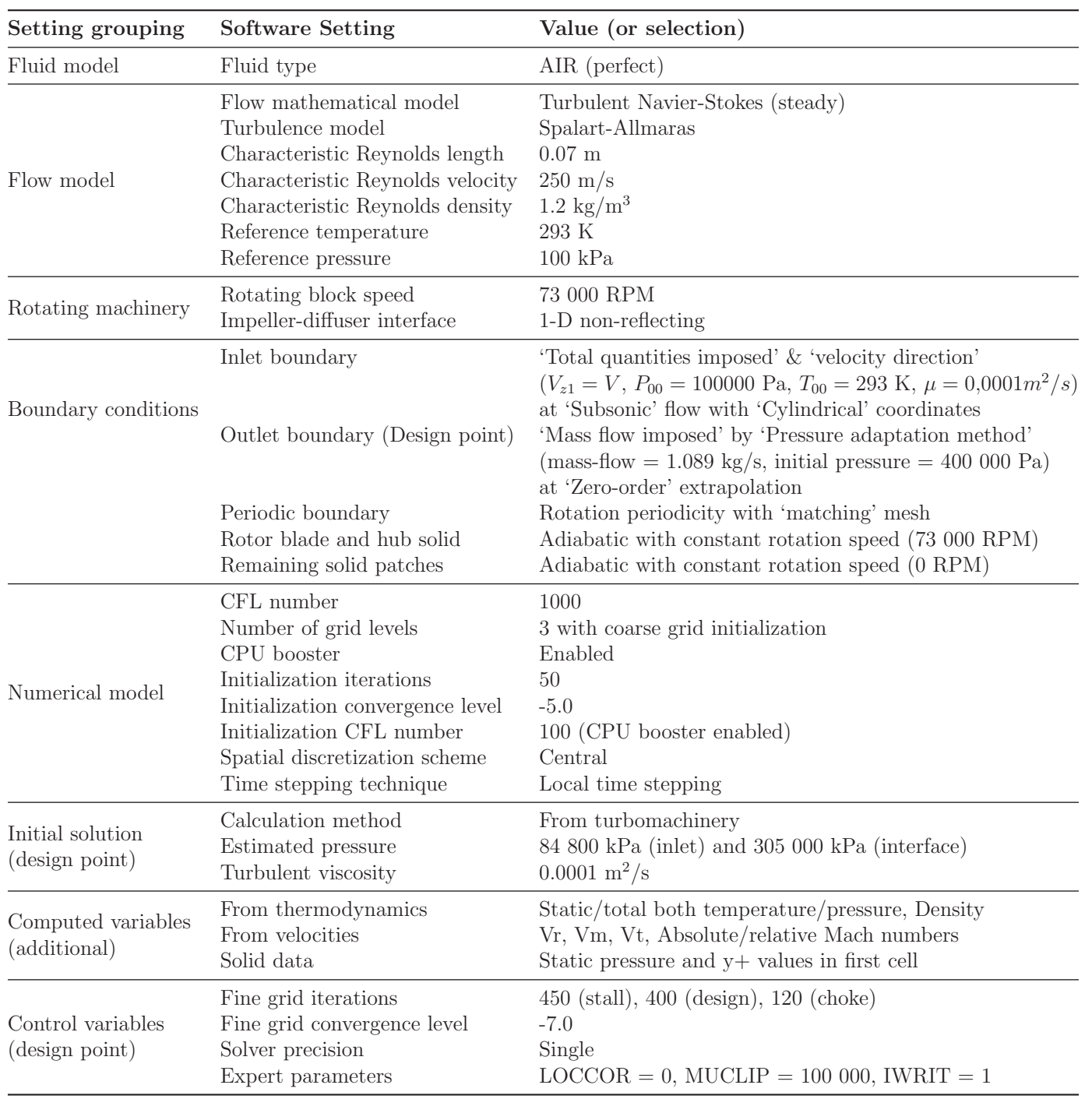




\section{Appendix D}

\section{Validation case}

A mixed flow impeller $\left(\alpha_{z 2}=74,5^{\circ}\right)$ developed by Diener et al. (2016) was chosen as a validation case for the aerodynamic numerical setup described above. The ${ }^{*}$.geomturbo geometry for blade and meridional profile was meshed and the solver configured with the setup as described in section 5.3, with exception of the diffuser specific settings. Inlet and outlet properties were set as required to obtain the performance curve comparison seen in Figure D.1. A maximum near design point difference of $0,3 \%$ in $P R_{(01-02)}$ and $0,4 \%$ in $\eta_{(01-02)}$ was obtained at a mass flow rate of $0,825 \mathrm{~kg} / \mathrm{s}$. A choke mass flow difference of $0,16 \%$ was obtained between the results quoted by Diener et al. (2016) and the computed numerical results. The efficiency and pressure ratio near the stall point $(m=0,76 \mathrm{~kg} / \mathrm{s})$ was still oscillating after 500 iterations and thus differed by a greater amount from the Diener results than the remainder of the curve. The remaining differences in results were attributed to errors in mass flow weighting and cell property interpolation across the evaluation plane due to the strong wake present near the evaluation plane. The evaluation plane was placed in relatively close proximity $(2,5 \mathrm{~mm})$ of the rotor trailing edge. The difference in results was deemed acceptable to prove validity of the aerodynamic numerical setup. 


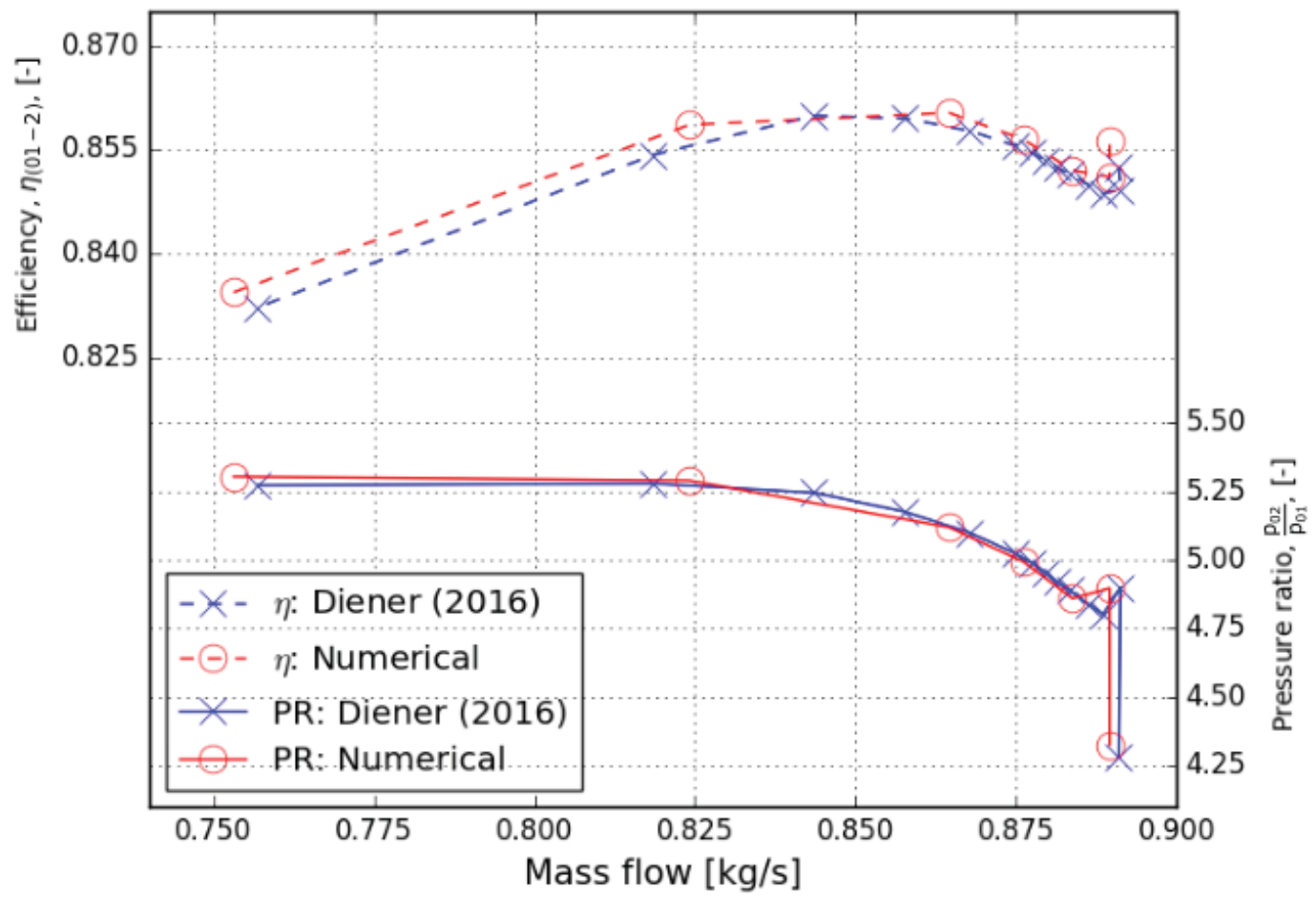

Figure D.1: Validation performance curves 


\section{Appendix E}

\section{Database generation and design samples}

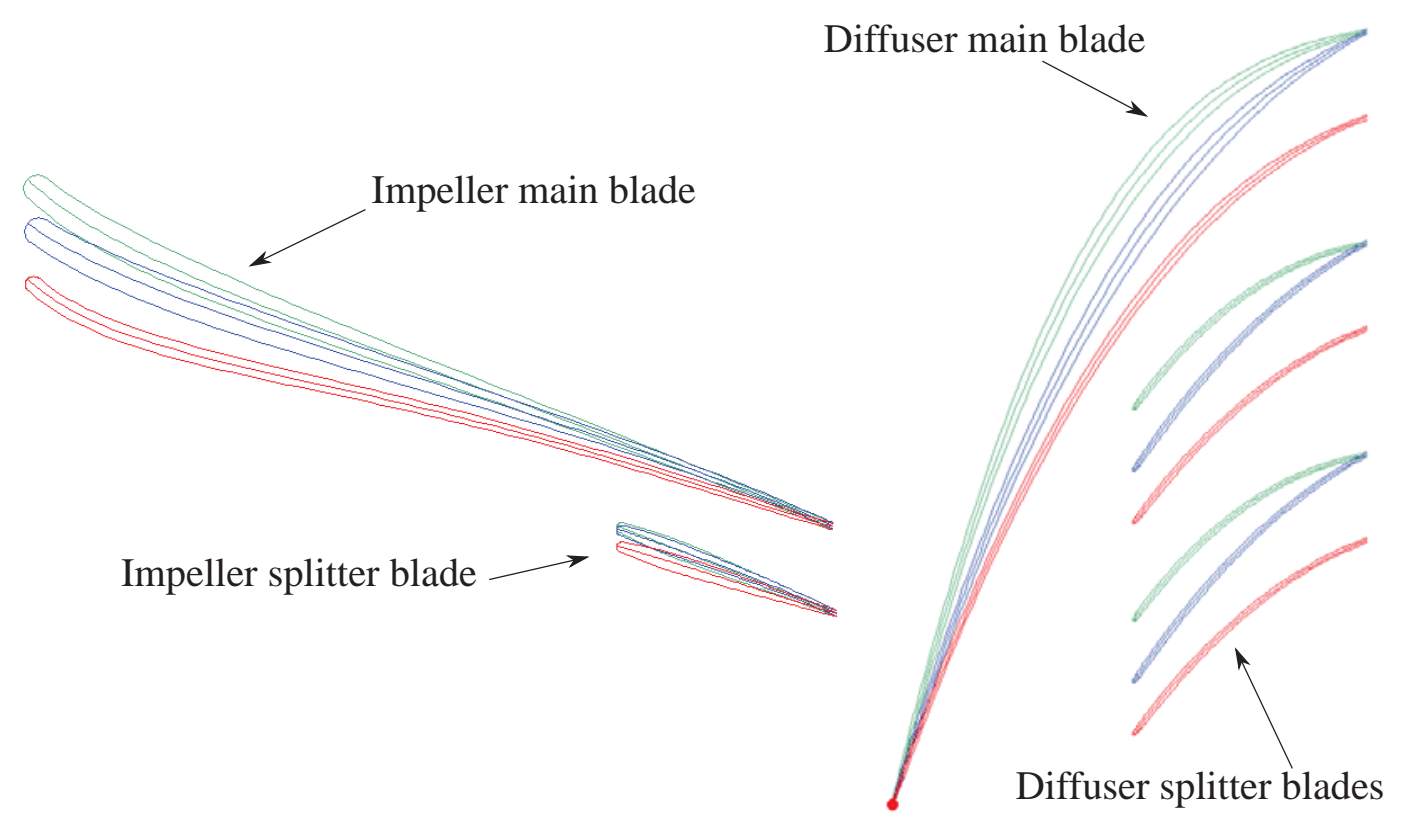

Figure E.1: Blade profiles (section 1) of random database designs 

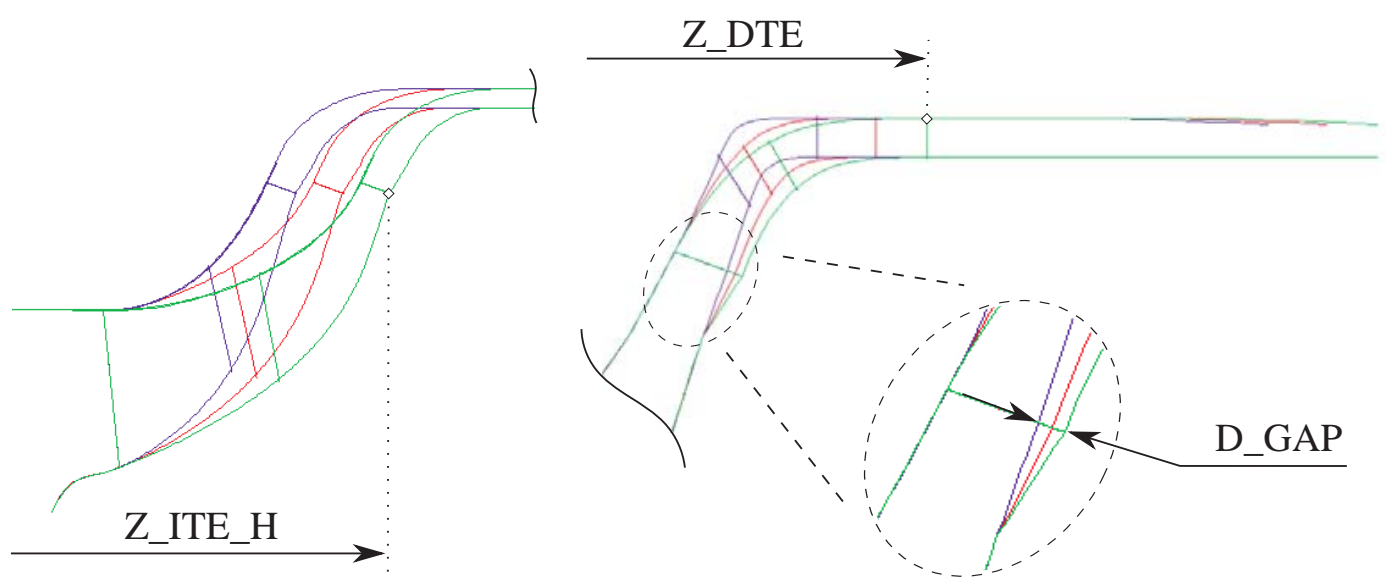

Figure E.2: Sample designs with varying only axial length parameters
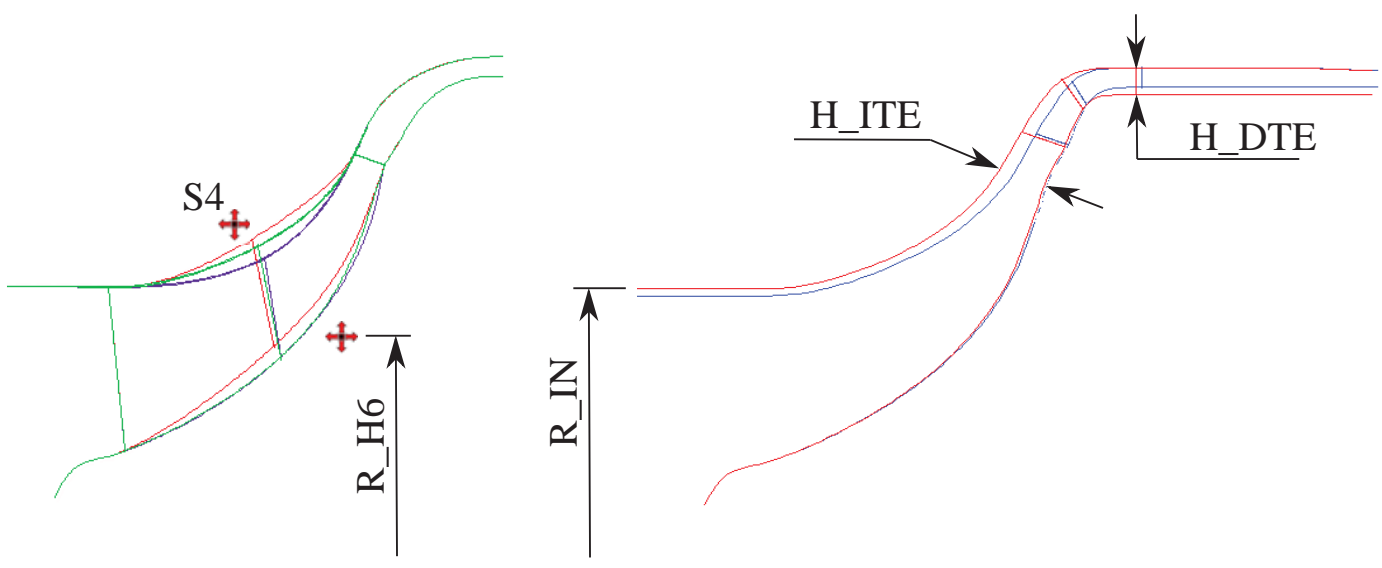

Figure E.3: Sample designs with varying only impeller endwall curvature parameters (left) and varying only passage height parameters (right)

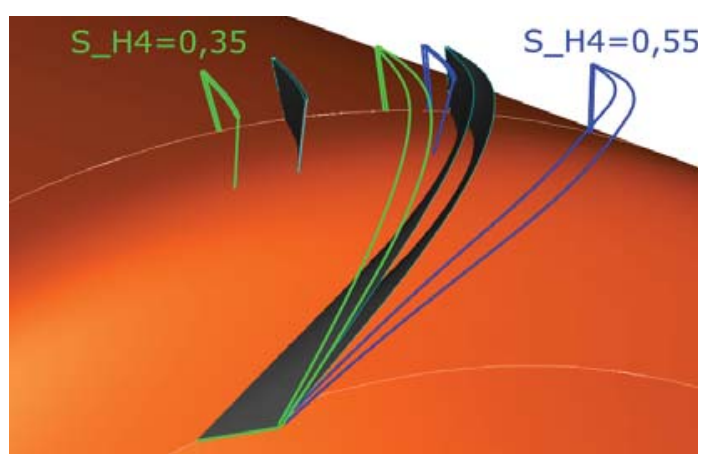

Figure E.4: Diffuser wrap possible range 
Table E.1: Database design validity count

\begin{tabular}{|c|c|c|c|c|c|}
\hline & \multicolumn{3}{|c|}{ DB1 (48 parameters) } & \multirow[b]{2}{*}{ Total } & \multirow{2}{*}{$\frac{\text { DB2 (25 parameters) }}{\text { LCVT }}$} \\
\hline & LHS & LCVT & CVT & & \\
\hline Attempted designs & 818 & 739 & 449 & $\overline{2006}$ & 60 \\
\hline Valid designs & 101 & 112 & 141 & 354 & 60 \\
\hline $\begin{array}{l}\text { Valid design percentage } \\
\text { (of total DB samples) }\end{array}$ & $12,3 \%$ & $15,2 \%$ & $31,4 \%$ & $17,7 \%$ & $100 \%$ \\
\hline
\end{tabular}

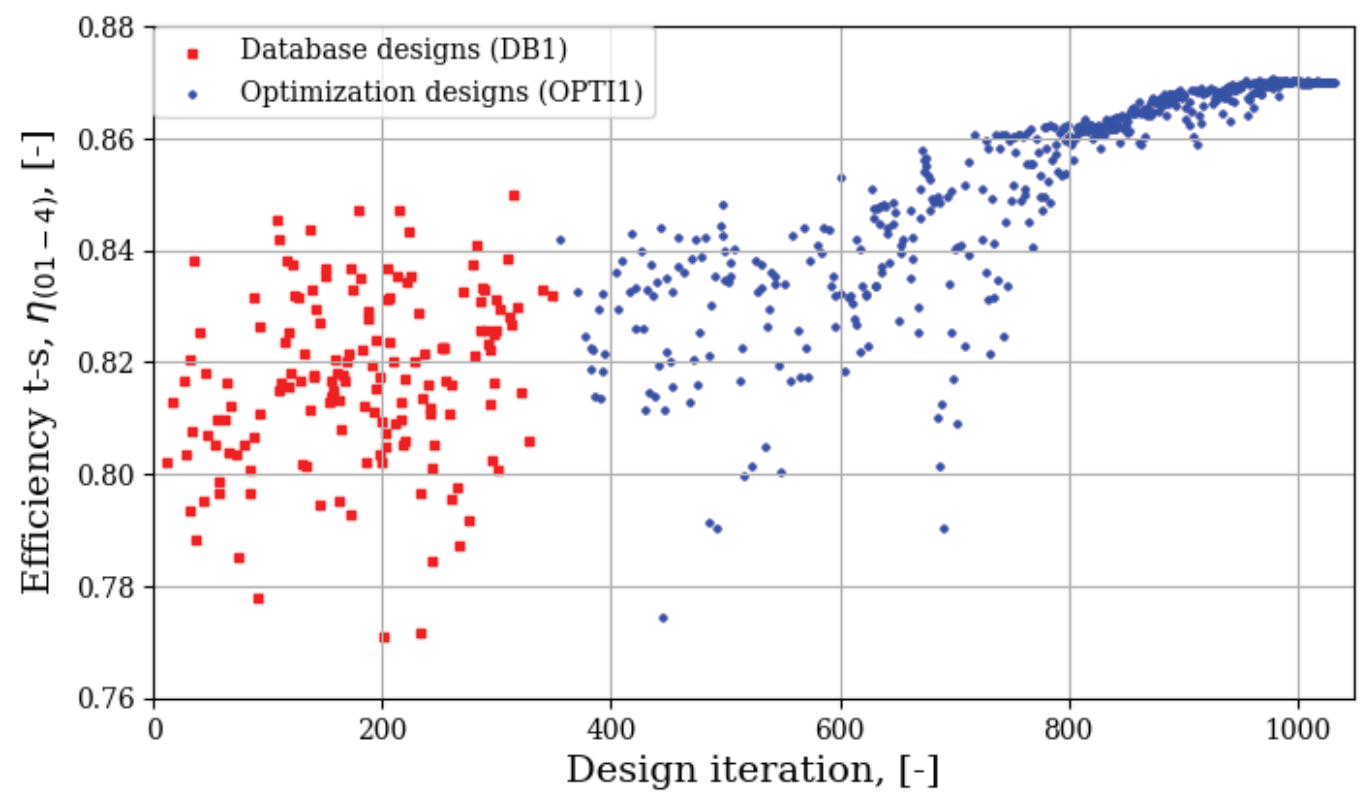

Figure E.5: Optimized design convergence 


\section{Appendix F}

\section{Final design}

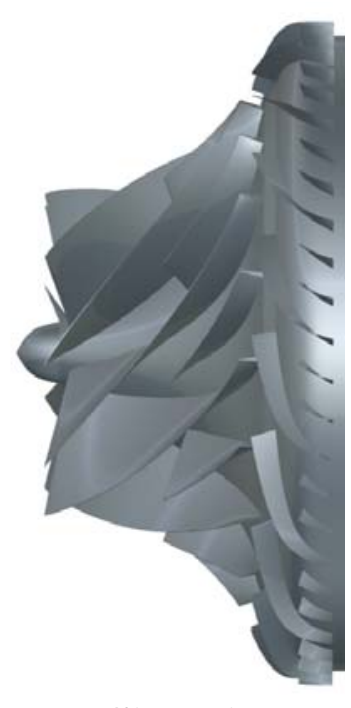

Side view
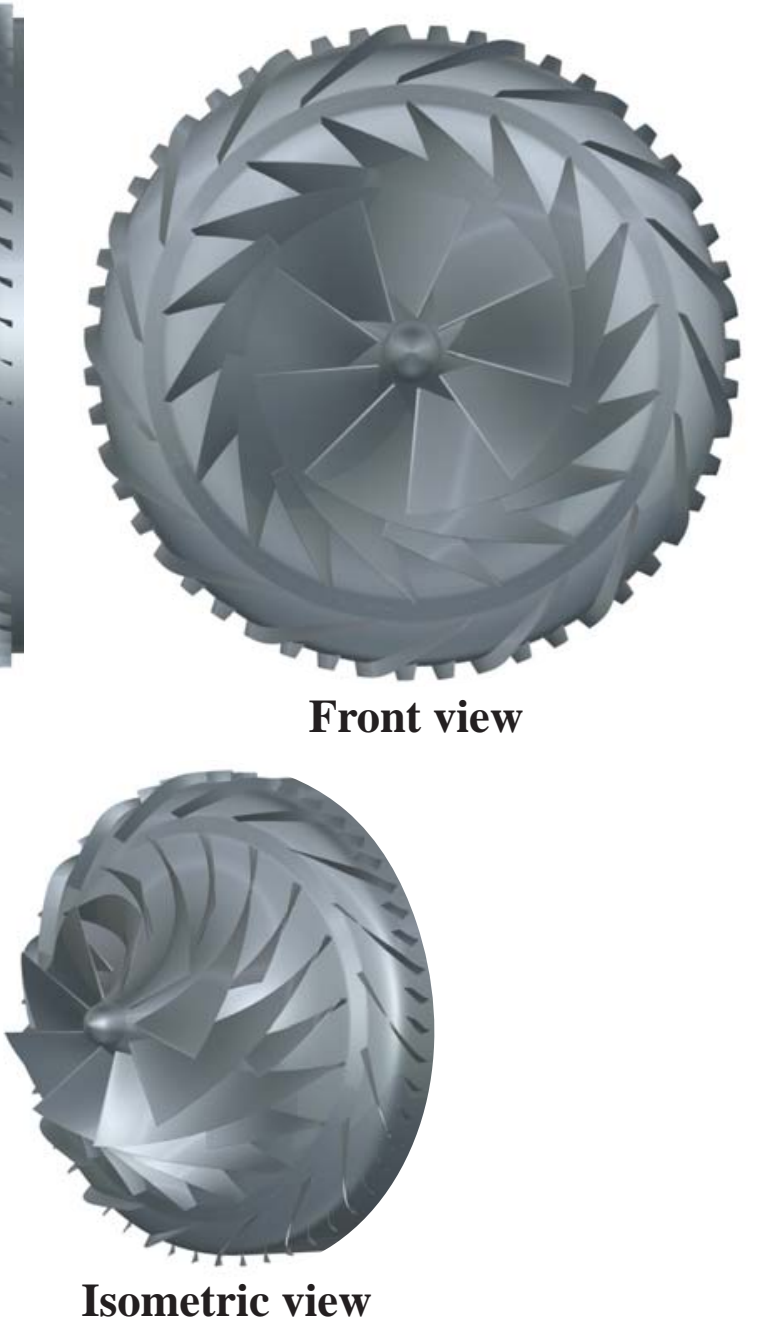

Figure F.1: Final design geometry 
Table F.1: Final design important meridional geometry parameters

\begin{tabular}{ll}
\hline Parameter & Value \\
\hline Inducer shroud radius, $r_{1 s}$ & $44,45 \mathrm{~mm}$ \\
Inducer hub radius, $r_{1 h}$ & $8,27 \mathrm{~mm}$ \\
Impeller forward sweep & $11,18^{\circ}$ \\
Impeller mean outlet radius, $r_{2 m}$ & $68,90 \mathrm{~mm}$ \\
Impeller outlet meridional angle, $\alpha_{z 2}$ & $71,59^{\circ}$ \\
Impeller outlet passage height, $b_{2}$ & $6,65 \mathrm{~mm}$ \\
Vaneless gap radius ratio, $k$ & 1,09 \\
Diffuser maximum radius, $r_{4 s}$ & $90,00 \mathrm{~mm}$ \\
Diffuser outlet passage height, $b_{4}$ & $3,92 \mathrm{~mm}$ \\
\hline
\end{tabular}

Table F.2: Final design important blade geometry parameters

\begin{tabular}{ll}
\hline Parameter & Value \\
\hline Impeller blades (main/splitter) & $9 / 9$ \\
Diffuser blades (main/splitter) & $17 / 34$ \\
Impeller LE angle (shroud), $\beta_{1 s}$ & $60,67^{\circ}$ \\
Impeller LE angle (hub), $\beta_{1 h}$ & $36,25^{\circ}$ \\
Impeller TE angle (shroud), $\beta_{2 s}$ & $45,82^{\circ}$ \\
Impeller TE angle (hub), $\beta_{2 h}$ & $25,33^{\circ}$ \\
Diffuser LE angle (shroud), $\beta_{3 s}$ & $66,31^{\circ}$ \\
Diffuser LE angle (hub), $\beta_{3 h}$ & $72,77^{\circ}$ \\
Diffuser TE angle (shroud), $\beta_{4 s}$ & $10,32^{\circ}$ \\
Diffuser TE angle (hub), $\beta_{4 h}$ & $27,87^{\circ}$ \\
\hline
\end{tabular}

Table F.3: Final design aerodynamic performance parameters

\begin{tabular}{ll}
\hline Performance parameter & Value \\
\hline Design point total-to-static stage pressure ratio, $P R_{(01-4), D P}$ & 4,15 \\
Design point total-to-total stage pressure ratio, $P R_{(01-04)}$ & 4,79 \\
Design point total-to-total impeller pressure ratio, $P R_{(01-02), D P}$ & 5,18 \\
Design point total-to-static stage efficiency, $\eta_{(01-4), D P}$ & $86,24 \%$ \\
Design point total-to-total stage efficiency, $\eta_{(01-4), D P}$ & $87,23 \%$ \\
Design point total-to-total impeller efficiency, $\eta_{(01-4), D P}$ & $89,59 \%$ \\
Design point stage B2B discharge angle, $\alpha_{z 4}$ & $26^{\circ}$ \\
Design point shaft power input, $P_{\text {shaft }}$ & $208 \mathrm{~kW}$ \\
Design point mass flow, $m_{D P}$ & $1,089 \mathrm{~kg} / \mathrm{s}$ \\
Choke mass flow (and choke margin), $m_{\text {choke }}$ & $1,170 \mathrm{~kg} / \mathrm{s}(7,4 \%)$ \\
Stall mass flow (and stall margin), $m_{\text {stall }}$ & $0,960 \mathrm{~kg} / \mathrm{s}(11,8 \%)$ \\
Operating speed, $N$ & $73000 \mathrm{RPM}$ \\
\hline
\end{tabular}

